Ana Carolina de Albuquerque Cavalcanti Ferreira Novo

\title{
Evolução dos níveis séricos de cistatina C em recém-nascidos de termo no primeiro mês de vida
}

Dissertação apresentada à Faculdade de Medicina da Universidade de São Paulo para obtenção do título de Mestre em Ciências

São Paulo 
Ana Carolina de Albuquerque Cavalcanti Ferreira Novo

\section{Evolução dos níveis séricos de cistatina $C$ em recém-nascidos de termo no primeiro mês de vida}

Dissertação apresentada à Faculdade de Medicina da Universidade de São Paulo para obtenção do título de Mestre em Ciências

Área de concentração: Pediatria

Orientadora: Profa. Dra. Cléa Rodrigues Leone

São Paulo

2009 
Dados Internacionais de Catalogação na Publicação (CIP)

Preparada pela Biblioteca da

Faculdade de Medicina da Universidade de São Paulo

Creprodução autorizada pelo autor

Novo, Ana Carolina de Albuquerque Cavalcanti Ferreira

Evolução dos níveis séricos de cistatina $\mathrm{C}$ em recém-nascidos de termo no primeiro mês de vida / Ana Carolina de Albuquerque Cavalcanti Ferreira Novo. -- São Paulo, 2009.

Dissertação(mestrado)--Faculdade de Medicina da Universidade de São Paulo. Departamento de Pediatria.

Área de concentração: Pediatria.

Orientadora: Cléa Rodrigues Leone.

Descritores: 1.Cistatinas 2.Recém-nascido 3.Taxa de filtração glomerular 4.Creatinina 5.Rim/fisiologia

USP/FM/SBD-034/09 
Dedicatória

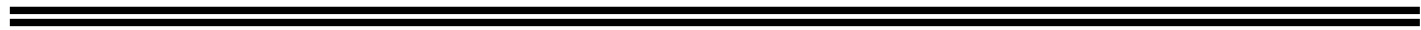


A Fernando, Joaquim, Guilherme e Henrique, que todos os dias iluminam minha vida.

A meus pais Alicita e Marcos e a minha irmã Paula, pelo apoio incondicional. 
Agradecimentos

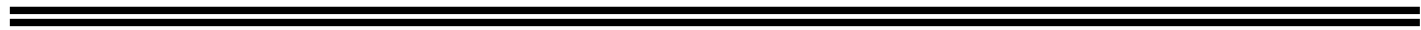




\begin{abstract}
À Prof. Dra. Cléa Rodrigues Leone, por compartilhar comigo seus conhecimentos, por seu contínuo apoio e disponibilidade e por sua confiança em meu trabalho.
\end{abstract}

A todas as mães que aceitaram participar deste estudo, por confiarem em mim e na possibilidade de auxiliarem, no futuro, crianças não tão saudáveis quanto as suas.

A todos os recém-nascidos que, mesmo sem saber, contribuíram para este estudo.

A todos os que me apoiaram na execução deste trabalho, com seus ensinamentos, dedicação, apoio e amizade, em especial a

Dr. Fernando da Costa Ferreira Novo

Dra. Lilian Rodrigues Sadeck

Profa. Dra. Thelma Suely Okay

Prof. Dr. Claudio Leone

Dr. Ulysses Doria Filho

Dra. Naila de Oliveira Elias Barbosa 
Dr. Renato Yamada

Enfermeira Edi Toma

Enfermagem do Berçário Anexo à Maternidade do HCFMUSP

Bióloga Karina Hatamoto Kawasato

Bibliotecária Mariza Kazue Umetsu

Profa. Dra. Cristina Moerbeck Casadei Pietraróia

Profa. Dra. Ruth Guinsburg

Profa. Dra. Sônia Regina Testa da Silva Ramos

Profa. Dra. Vera Hermina Kalika Koch

Dra. Clery Bernardi Gallacci.

A todos aqueles que, mesmo não citados, deixaram sua marca e seu esforço neste trabalho e em minha vida. Sem eles, a tarefa teria sido ainda mais árdua e o resultado final mais distante.

A todos, o meu muito obrigado. 
Epígrafe

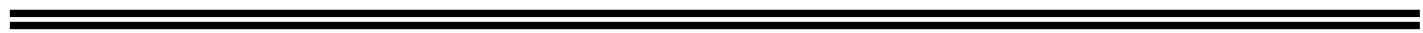




\section{Brinquedo}

Foi um sonho que eu tive:

Era uma grande estrela de papel,

Um cordel

E um menino de bibe.

O menino tinha lançado a estrela

Com ar de quem semeia uma ilusão;

E a estrela ia subindo, azul e amarela, Presa pelo cordel à sua mão.

Mas tão alto subiu

Que deixou de ser estrela de papel.

E o menino, ao vê-la assim, sorriu

E cortou-lhe o cordel.

(Miguel Torga, 1941) 
Normatização ב 
Esta dissertação está de acordo com as seguintes normas, em vigor no momento desta publicação:

Referências: adaptado de International Committee of Medical Journals Editors (Vancouver).

Universidade de São Paulo. Faculdade de Medicina. Serviço de Biblioteca e Documentação. Guia de apresentação de dissertações, teses e monografias. Elaborado por Annelise Carneiro da Cunha, Maria Julia de A. L. Freddi, Maria F. Crestana, Marinalva de Souza Aragão, Suely Campos Cardoso, Valéria Vilhena. $2^{\underline{a}}$ ed. São Paulo: Serviço de Biblioteca e Documentação; 2005.

Abreviaturas dos títulos dos periódicos de acordo com List of Journals Indexed in Index Medicus da National Library of Medicine. 
Sumário

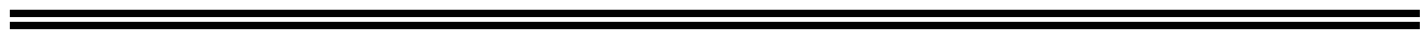


Lista de abreviaturas

Resumo

Summary

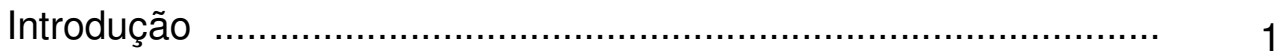

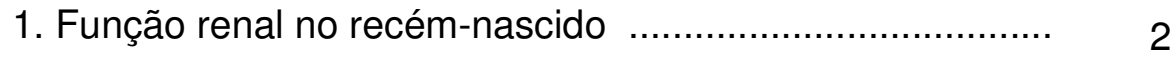

2. Ritmo de filtração glomerular .................................... 4

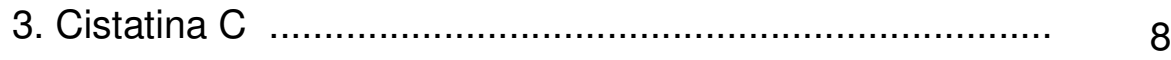

4. Cistatina C como marcador do RFG .......................... 15

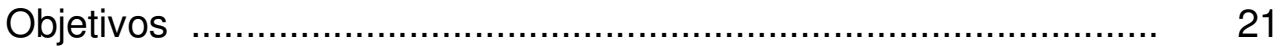

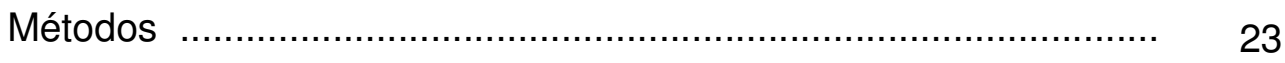

1. Ética ................................................................ 24

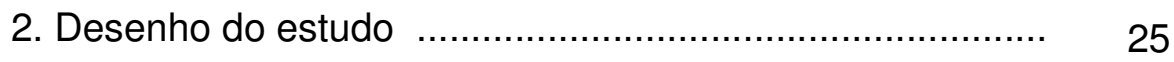

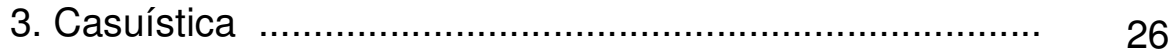

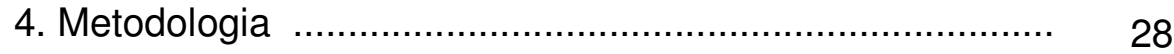

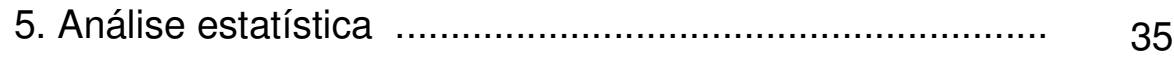

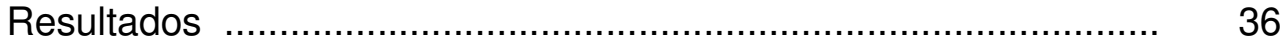

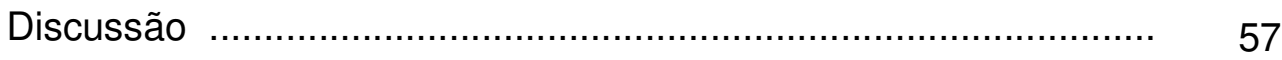

1. Análise do método ................................................ 59

2. Análise dos resultados .......................................... 73

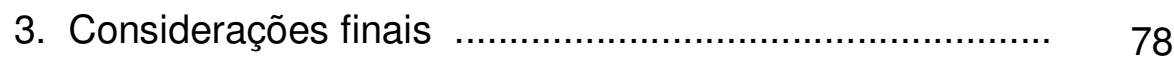

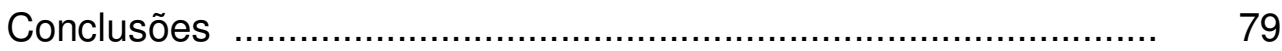

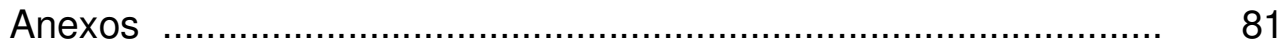

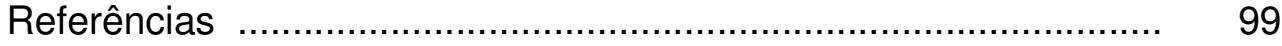


Lista de abreviaturas

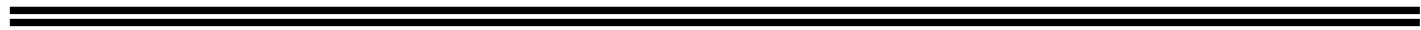




$\begin{array}{ll}\text { CIUR } & \text { Crescimento intra-uterino restrito } \\ \text { Cis } & \text { Cistatina C } \\ \text { CICr } & \text { Clearance de creatinina } \\ \text { Cr } & \text { Creatinina } \\ \text { FSR } & \text { Fluxo sanguíneo renal } \\ \text { HCFMUSP } & \text { Hospital das Clínicas da Faculdade de Medicina } \\ & \text { da Universidade de São Paulo } \\ \text { IG } & \text { Idade gestacional } \\ \text { PA } & \text { Pressão arterial } \\ \text { RFG } & \text { Ritmo de filtração glomerular } \\ \text { RN } & \text { Recém-nascido } \\ \text { T4 } & \text { Tiroxina } \\ \text { TSH } & \text { Hormônio estimulante da tireóide } \\ & \end{array}$


Resumo

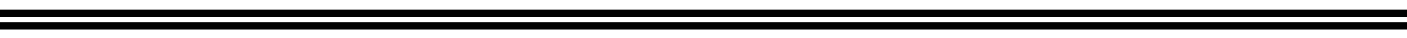


Novo ACACF. Evolução dos níveis séricos de cistatina $C$ em recémnascidos de termo no primeiro mês de vida [dissertação]. São Paulo: Faculdade de Medicina, Universidade de São Paulo; 2008. 111p.

INTRODUÇÃO: A cistatina C sérica apresenta boa correlação com o ritmo de filtração glomerular (RFG) e não é influenciada pela função renal materna, podendo ser um bom marcador da função renal, especialmente na 1ª semana de vida. Porém, não há valores normais definidos para o período neonatal. OBJETIVO: Determinar a evolução dos níveis séricos da cistatina C (Cis) em recém-nascidos ( $\mathrm{RN})$ de termo saudáveis ao longo do $1^{\circ}$ mês de vida. MÉTODOS: Estudo prospectivo. Inclusão: idade gestacional (IG) entre 37 e 41 6/7 semanas; peso de nascimento adequado para a IG; Apgar $1^{0}$ min > 7; mães sem insuficiência renal, hipertensão arterial ou uso de drogas que interferissem com a função renal do feto. Exclusão: má-formação major ou renal; ausência de diurese nas primeiras 12 horas de vida ou diurese no $2^{\circ}$ ou $3^{\circ}$ dia $<1 \mathrm{~mL} / \mathrm{kg} / \mathrm{h}$; perda de peso $>10 \%$ até o $3^{\circ}$ dia; pressão arterial elevada; insuficiência cardíaca ou renal, fototerapia, infecção, alteração da função tireoidiana ou uso de drogas vasoativas ou diuréticos. Dosagens laboratoriais: Cis $(\mathrm{mg} / \mathrm{L})$ por imunonefelometria e creatinina sérica $(\mathrm{Cr})(\mathrm{mg} / \mathrm{dL})$ pelo método de Jaffé, da mãe e do $\mathrm{RN}$, no cordão umbilical (d0) e com 3 (d3), 7 (d7) e 28 (d28) dias. O clearance de creatinina foi estimado pela fórmula de Schwartz $\left(\mathrm{mL} / \mathrm{min} / 1,73 \mathrm{~m}^{2}\right)$. Comparação de médias pelo teste ANOVA one way para medidas repetidas e teste de Tukey. Análise de correlação pelo coeficiente de correlação de Pearson. Nível de significância=0,05. RESULTADOS: Preencheram os 
critérios de inclusão $35 \mathrm{RN}$ e, destes, 14 foram excluídos. Foram analisados 21 RN. Mães: idade (média): 29,1 anos. Os RN apresentaram IG (mediana) de 39,4 sem e peso (média) de $3224 \mathrm{~g} ; 57,1 \%$ eram do sexo masculino. A diurese (média) no $2^{\circ}$ e no $3^{\circ}$ dias foi 2,1 e $2,4 \mathrm{~mL} / \mathrm{kg} / \mathrm{h}$, respectivamente, e a perda de peso máxima (média) foi 7,1\% e ocorreu com 2 dias (mediana). Dos $21 \mathrm{RN}, 17$ (81\%) receberam aleitamento materno exclusivo e 13 $(61,9 \%)$ tiveram icterícia. Cis (média $\pm d p):$ mãe: $1,00 \pm 0,20 ; \quad R N$ : $d 0=1,70 \pm 0,26 ; d 3=1,51 \pm 0,19 ; d 7=1,54 \pm 0,15 ; d 28=1,51 \pm 0,15$. Cr (média $\pm d p):$ mãe: $\quad 0,63 \pm 0,15 ; \quad R N: \quad d 0=0,63 \pm 0,15 ; \quad d 3=0,48 \pm 0,16 ; \quad d 7=0,37 \pm 0,10$; d28 $=0,26 \pm 0,05$. Os valores de $\mathrm{Cr}$ não foram diferentes dos encontrados na literatura para $\mathrm{RN}$ de termo saudáveis. $\mathrm{A} \mathrm{Cr}$ da mãe não foi diferente de d0, enquanto a Cis materna foi menor do que em d0 $(p<0,001)$. A $\mathrm{Cr}$ no $\mathrm{RN}$ diminuiu com o tempo ( $d 0 x d 3, p=0,007 ; d 3 x d 7, p=0,002 ; d 7 x d 28, p<0,001$ ). A Cis diminuiu de d0 para d3 $(p=0,004)$ e manteve-se estável após d3. A Cis e a $\mathrm{Cr}$ da mãe apresentaram correlação positiva. Houve correlação positiva entre $\mathrm{Cis}$ e $\mathrm{Cr}$ em d3 e d28. CONCLUSÕES: A Cis do RN, que ao nascimento foi maior do que a da mãe, reduziu-se até d3 e permaneceu estável até d28. A Cis e a Cr da mãe correlacionaram-se entre si. Em d3 e d28 houve correlação entre Cis e $\mathrm{Cr}$ do $\mathrm{RN}$.

Descritores: 1.Cistatinas 2.Recém-nascido 3.Taxa de filtração glomerular 4.Creatinina 5. Rim/fisiologia 
Summary

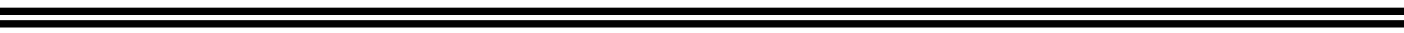




\section{Novo ACACF. Cystatin C serum levels in term newborns along the neonatal period [dissertação]. São Paulo: Faculdade de Medicina, Universidade de São Paulo; 2008. 111p.}

INTRODUCTION: Cystatin C (Cys) is a good marker of glomerular filtration rate (GFR), and is not affected by maternal renal function. OBJECTIVE: To determine the levels of Cys in healthy term newborns (NB), along the $1^{\text {st }}$ month of life. METHODS: Cohort study. Inclusion: term NB with appropriate weight; $1^{\text {st }}$ min Apgar $>7$; mother without renal failure or drugs that could affect fetal GFR. Exclusion: malformations; hypertension; no diuresis in the first 12 hours of life or oliguria in the first three days; excessive weight loss until the third day; heart or kidney failure; thyroid dysfunction; use of diuretics, vasoactive drugs or any drug that could affect renal function. Cys (mg/L) and creatinine $(\mathrm{Cr})(\mathrm{mg} / \mathrm{dL})$ were determined in the mother (Mo) and in the NB at birth $(\mathrm{d} 0), 3^{\text {rd }}(\mathrm{d} 3), 7^{\text {th }}(\mathrm{d} 7)$ and $28^{\text {th }}(\mathrm{d} 28)$ days. Creatinine clearance was estimated in the NB using the Schwartz formula. Statistics: one way ANOVA and Pearson's correlation tests. Significance level=0.05. RESULTS: Data from 21 NB were obtained. Mothers: age (mean): 29.1 years. NB: gestational age (median): 39.4 weeks; birth weight (mean): $3224 \mathrm{~g} ; 57.1 \%$ were male. Diuresis (mean) in the $2^{\text {nd }}$ and $3^{\text {rd }}$ days of life: $2.1 \pm 0.6$ and $2.4 \pm 0.7 \mathrm{~mL} / \mathrm{kg} / \mathrm{h}$, respectively. Maximum weight loss (mean): $7.1 \%$; it occurred in the $2^{\text {nd }}$ day (median). $81 \%$ of the NB were breastfed and $61.9 \%$ had jaundice. Cys (mean $\pm s d$ ): Mo: $1.00 \pm 0.20 ;$ NB: $d 0=1.70 \pm 0.26$; $d 3=1.51 \pm 0.19 ; d 7=1.54 \pm 0.15 ; d 28=1.51 \pm 0.15$. Cr (mean $\pm s d)$ : Mo: $0.63 \pm 0.15$; 
NB: $d 0=0.63 \pm 0.15 ; d 3=0.48 \pm 0.16 ; d 7=0.37 \pm 0.10 ; d 28=0.26 \pm 0.05$. These $\mathrm{Cr}$ values are similar to those found in the literature for healthy term NB. Mo $\mathrm{Cr}$ was not different from d0 $\mathrm{Cr}$, while Mo Cys was lower than d0 Cys $(p<0.001)$. NB Cr decreased ( $d 0 x d 3, p=0.007 ; d 3 x d 7, p=0.002 ; d 7 x d 28, p<0.001$ ) along the time, while Cys decreased from d0 to $d 3(p=0.004)$. Correlations were obtained between Mo Cr and Mo Cys, as well as d3 Cr and d3 Cys, d28 Cr and d28 Cys. CONCLUSIONS: At birth, NB Cys values were higher than Mo Cys values. NB Cys decreased from $\mathrm{d} 0$ to $\mathrm{d} 3$ and remained stable from $\mathrm{d} 3 \mathrm{3}$ to d28. Mo Cys correlated with Mo Cr and NB Cys correlated with NB Cr at d3 and $\mathrm{d} 28$.

Descriptors: 1.Cystatins 2.Infant, newborn 3.Glomerular filtration rate 4.Creatinine 5.Kidney/physiology 
Introdução

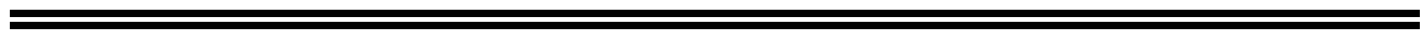


O recém-nascido apresenta função renal peculiar e seu ritmo de filtração glomerular (RFG) pode variar conforme o grau de desenvolvimento renal ao nascimento.

Durante o período fetal, com 5 semanas de gestação surge o rim primitivo, enquanto os primeiros glomérulos, ainda indiferenciados, aparecem apenas com 9 semanas. Seu número vai aumentando gradualmente até a $36^{a}$ semana. Nessa fase, embora a formação do rim esteja completa quanto ao número de glomérulos, a função renal, medida pelo RFG, corresponde a apenas $5 \%$ do valor normal do adulto. Isso é decorrente em grande parte dos níveis mais baixos de pressão arterial sistêmica, característicos do feto, associados à resistência vascular renal elevada, determinada por vasoconstricção de sua microvasculatura ${ }^{1}$.

\section{Função renal no recém-nascido}

Com o nascimento, a regulação da homeostase de fluidos e eletrólitos do organismo, até então realizada pela placenta, passa a ser desempenhada pelos rins. Estes são os responsáveis por remover da circulação a água em excesso e os metabólitos potencialmente deletérios, mantendo os solutos essenciais como sódio, cloro, bicarbonato, açúcares e aminoácidos. Este processo inicia-se no glomérulo, onde o plasma é ultrafiltrado sob pressão, sendo dependente diretamente do fluxo sanguíneo renal (FSR) ${ }^{2}$.

No adulto, o FSR corresponde de 20 a $30 \%$ do débito cardíaco e depende da pressão de perfusão renal, que é muito próxima da pressão 
arterial sistêmica, e da resistência vascular renal, a qual é determinada pelas arteríolas aferente e eferente. Ao nascimento, o FSR é baixo e, nas primeiras 2 semanas de vida, aumenta progressivamente, chegando a dobrar o seu valor. Isso ocorre em consequência da elevação do débito cardíaco e da intensa redução da resistência vascular renal, que faz com que uma maior fração do débito cardíaco seja direcionada aos rins².

Ao nascimento, o RFG é diretamente proporcional à idade gestacional. No recém-nascido de termo, alcança valores inferiores a $10 \%$ do valor de um adulto, mesmo quando considerado em relação à superfície corpórea ou ao peso renal. Contudo, o RFG aumenta progressivamente até atingir valores iguais aos do adulto, com 2 anos de idade ${ }^{2}$.

Os recém-nascidos também apresentam imaturidade relativa dos mecanismos de transporte tubular. A fração de excreção de sódio é elevada ao nascimento, podendo chegar a até $5 \%$. Diminui progressivamente a seguir e, com 2 a 3 semanas, o recém-nascido passa a apresentar balanço positivo de sódio. Já a reabsorção de bicarbonato está diminuída, levando a concentrações plasmáticas de bicarbonato mais baixas. No entanto, o maior limitante à adaptação pós-natal é a baixa filtração glomerular. Embora seja suficiente para o crescimento e desenvolvimento do recém-nascido em condições normais, o RFG baixo passa a ser um limitante à adaptação pósnatal na presença de intercorrências, como asfixia, instabilidade hemodinâmica ou uso de drogas nefrotóxicas ${ }^{3}$.

Para poder detectar adequadamente a presença de anormalidade da função renal, é fundamental o conhecimento do valor normal do RFG 
esperado para cada idade gestacional e idade pós-natal, por meio de métodos confiáveis para sua avaliação.

\section{Ritmo de filtração glomerular}

O RFG é o volume de fluido plasmático filtrado para dentro da cápsula de Bowman por unidade de tempo. Pode ser estimado por meio da taxa de depuração plasmática (clearance) de determinadas substâncias. O clearance de um soluto corresponde ao volume virtual de sangue que seria totalmente depurado deste soluto por unidade de tempo. Para que o clearance de uma substância possa refletir o RFG, esta substância deve obedecer a alguns critérios:

- ser livremente filtrada nos glomérulos;

- não ser reabsorvida nem secretada pelos túbulos renais;

- não ser metabolizada nem sintetizada pelos rins;

- ser fisiologicamente inerte e não tóxica;

- não se ligar a proteínas plasmásticas ${ }^{4,5}$.

Os métodos disponíveis para a determinação do RFG nem sempre preenchem todos estes requisitos, conforme será exposto a seguir. 


\subsection{Clearance de inulina}

A inulina, um polímero de frutose de peso molecular de $5200 \mathrm{Da}$, extraído da raiz da dália, preenche todos os critérios do marcador ideal do RFG, sendo o seu clearance considerado padrão para a avaliação da função renal.

Estudos realizados em néfrons isolados de mamíferos mostraram que a concentração de inulina no fluido glomerular é igual à concentração plasmática, ou seja, ela é livremente filtrada. Por sua vez, perfundindo túbulos isolados com soluções com quantidades conhecidas de inulina marcada, foi possível demonstrar que a inulina não é nem secretada nem reabsorvida pelo túbulo. Além disso, considerando-se um RFG constante, a quantidade de inulina excretada é diretamente proporcional à sua concentração plasmática. O clearance de inulina não varia, nem com a sua concentração plasmática, nem com o débito urinário ${ }^{4}$.

No entanto, para medir o clearance de inulina é necessário fazer a infusão intravenosa contínua de inulina, de forma a atingir níveis plasmáticos adequados. O clearance deve ser realizado em jejum e pela manhã, com sobrecarga hídrica, para estimular a diurese. São necessárias múltiplas coletas de sangue e urina, com sondagem vesical. A dosagem de inulina é ainda muito trabalhosa, não sendo realizada rotineiramente nos laboratórios de análises clínicas. Desta forma, não é possivel o seu uso na prática médica, sendo necessário encontrar outros marcadores para o $\mathrm{RFG}^{4,5}$. 


\subsection{Clearance de creatinina}

A creatinina apresenta propriedades semelhantes à inulina, de forma que seu clearance pode ser usado para a estimativa do RFG. Sendo endógena, não há necessidade de infusão intravenosa. Sua dosagem é realizada rotineiramente nos laboratórios de análises clínicas. Contudo, como a creatinina é produzida a partir da metabolização da creatina e da fosfocreatina, sua produção depende da massa muscular do indivíduo, a qual varia com a idade e com o sexo. Além disso, ela é influenciada pela ingestão de creatina (presente na carne), que também não é constante ${ }^{4,5}$.

A creatinina é totalmente filtrada pelos glomérulos, mas é secretada ativamente por transportadores de cátions nos túbulos proximais. Quando o RFG é normal, 5 a 10\% da creatinina urinária provém da secreção tubular, o que por si só poderia superestimar o RFG em 10 a $20 \mathrm{~mL} / \mathrm{min} / 1,73 \mathrm{~m}^{2}$. No entanto, como os métodos laboratoriais de dosagem da creatinina no plasma usualmente superestimam suas concentrações séricas, o clearance de creatinina calculado acaba por ser muito próximo do clearance de inulina, quando a função renal é normal. Contudo, quando o RFG diminui, a proporção de creatinina que é secretada em relação à fitrada aumenta e, portanto, o RFG é ainda mais superestimado. Por outro lado, alguns fármacos, como cimetidina e trimetoprin, são capazes de inibir a secreção tubular de creatinina ${ }^{4,5,6}$.

A creatinina também pode ser eliminada do organismo pelo trato gastrointestinal, pois sofre degradação bacteriana quando presente nas 
secreções intestinais. Em condições normais, a eliminação extrarrenal não é significativa. Porém, quando o RFG está muito diminuído, há um aumento na quantidade de creatinina nas secreções intestinais e a quantidade degradada no trato gastrointestinal pode corresponder a até $68 \%$ da produção diária ${ }^{6}$.

Estudos realizados em crianças mostraram que, quando o clearance de inulina está entre 3 a $192 \mathrm{~mL} / \mathrm{min} / 1,73 \mathrm{~m}^{2}$, a correlação entre o clearance de creatinina e o clearance de inulina é de 0,94. Contudo, na presença de disfunção renal, o clearance de creatinina tende a superestimar o RFG, uma vez que ocorre maior secreção tubular da mesma. Quando o RFG é menor do que $21 \mathrm{~mL} / \mathrm{min} / 1,73 \mathrm{~m}^{2}$, o clearance de creatinina é quase $20 \%$ maior do que o clearance de inulina ${ }^{7,8}$.

\subsection{Creatinina no período neonatal}

No período neonatal, devido à dificuldade técnica para a realização de coleta de urina por período de algumas horas de forma não invasiva, utilizase a dosagem sérica da creatinina para a avaliação da função renal, seja por meio de dosagens seriadas, seja pela estimativa do RFG, com base na fórmula de Schwartz, onde o clearance depende do valor sérico de creatinina e da estatura ${ }^{7}$.

No entanto, ao nascimento, o valor sérico de creatinina depende não somente da sua produção e excreção, mas também é um reflexo da creatinina materna. No recém-nascido de termo, a creatinina sérica cai 
progressivamente, atingindo na segunda semana valores estáveis em torno de $0,4 \mathrm{mg} / \mathrm{dL}$. Contudo, em recém-nascidos muito prematuros, a creatinina sérica aumenta após o nascimento, com pico no quarto dia de vida, após o que diminui progressivamente, normalizando-se com 3 a 4 semanas. Esse aumento deve-se provavelmente à reabsorção tubular de creatinina por difusão passiva, que ocorre nos túbulos imaturos ${ }^{3,9}$.

Apesar de a dosagem seriada da creatinina sérica ser, na prática clínica, a principal forma de estimar o RFG no período neonatal, seu valor deve ser interpretado conforme o contexto de cada recém-nascido. Por isso, com o intuito de se encontrar um marcador endógeno do RFG que seja mais preciso, tem sido estudada a cistatina $\mathrm{C}$.

\section{Cistatina C}

A cistatina C é uma proteína identificada pela primeira vez em 1961 por Jorgen Clausen no líquido cefalorraquidiano humano. Como apresentava um padrão de migração em eletroforese na região $\gamma$ (gama), foi denominada líquido cefalorraquidiano- $\gamma$ ( $\gamma$-cerebrospinal fluid $)^{10}$. No mesmo ano, Butler e Flynn descreveram uma nova proteína presente na urina humana, também com migração para a região $\gamma$, denominada proteína pós- $\gamma$ (post- $\gamma$-protein $)^{10}$. Em 1962, Hochwald e Thornbecke isolaram em eletroforese uma proteína com a mesma característica de migração para a região $\gamma$ no plasma, no líquido cefalorraquidiano, na urina e nos líquidos ascítico e pleural, chamando-a traço- $\gamma(\gamma \text {-trace })^{10}$. Nas duas décadas seguintes, esta proteína 
foi isolada em diversos outros fluidos. Em 1981, Grubb e Löefberg isolaram a traço- $\gamma$ na hipófise humana e conseguiram determinar sua sequência de aminoácidos ${ }^{11}$. Contudo, ela somente passou a ser denominada cistatina $\mathrm{C}$ por Barrett, em 1984, após a determinação da sua função como inibidora da cisteína proteinase ${ }^{12}$.

\subsection{Classificação}

Cistatinas são proteínas capazes de se ligar de forma reversível às cisteína proteinases, de modo a formar um complexo enzimaticamente inativo. Formam, portanto, um grupo de inibidores competitivos potentes das cisteína proteinases lisossômicas, presentes em animais, plantas e protozoários. Todas as cistatinas apresentam três porções que se conservam ao longo de toda a evolução, formando um sítio de ligação com a enzima. É esta característica que permite classificá-las todas em uma única superfamília, subdividida em quatro grandes grupos:

- tipo 1 - cistatinas A e B, predominantemente intracelulares;

- tipo 2 - cistatinas $C, S, S N, S A, D, E / M$ e $F$, proteínas não glicosiladas extracelulares;

- tipo 3 - cininogênios, proteínas glicosiladas intravasculares;

- tipo 4 - fetuínas (fetuins), importantes na osteogênese e reabsorção óssea e na recuperação de processos inflamatórios ${ }^{10,13}$. 


\subsection{Estrutura}

A cistatina C humana, na sua forma ativa, é uma proteína não glicosilada, de cadeia única, formada por 120 aminoácidos, que tem baixo peso molecular (13.343 Da na forma não hidroxilada). Espacialmente, constitui-se de 5 folhas $\beta$ paralelas, envolvendo uma longa $\alpha$-hélice ( $\alpha 1$ ). Apresenta ainda uma $\alpha$-hélice curta ( $\alpha 2)$. As alças L1 (entre as folhas $\beta 2$ e $\beta 3$ ) e L2 (entre as folhas $\beta 4$ e $\beta 5$ ) e a extremidade $N$-terminal da folha $\beta 1$ ficam alinhadas na forma de uma cunha. Esta cunha, ao ligar-se ao sítio catalítico da enzima, inibe sua ação (figura 1$)^{14}$.

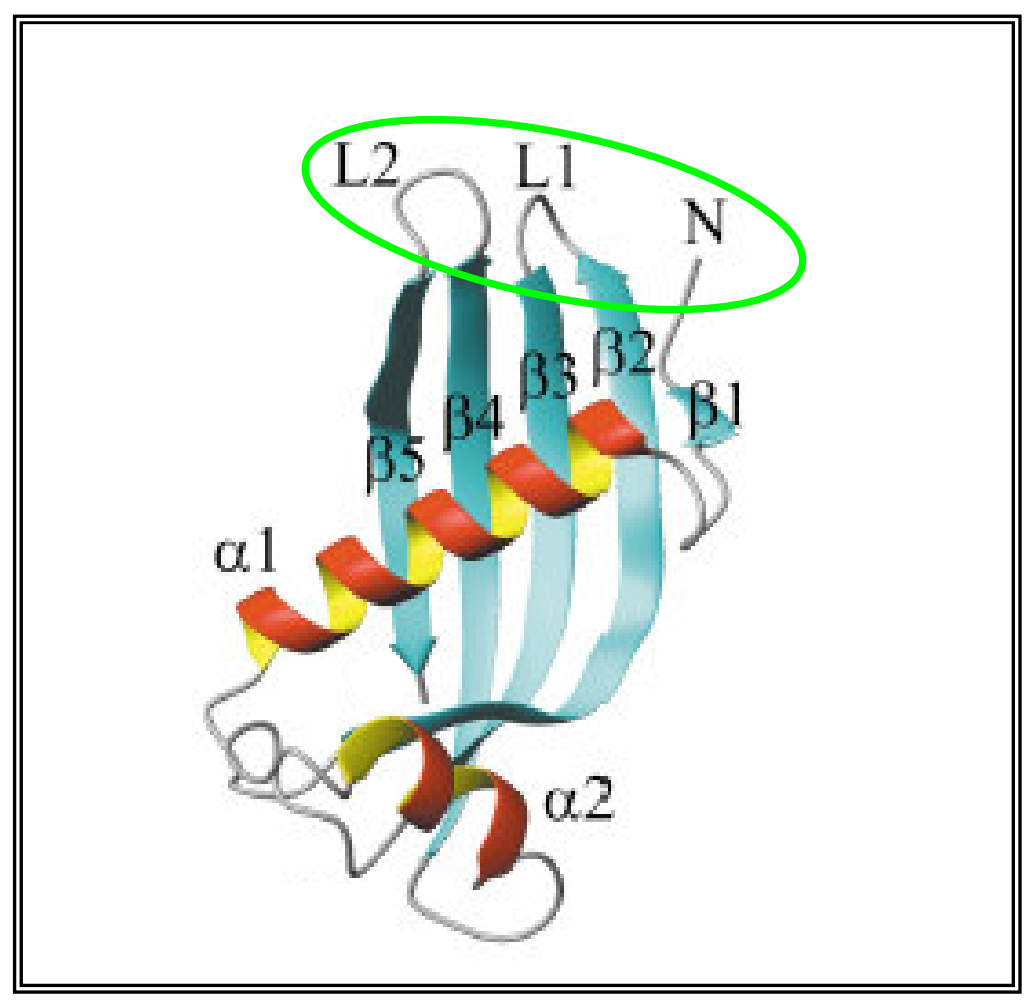

Figura 1 - Estrutura terciária da cistatina C humana. Em verde, está evidenciado o sítio de ligação. Modificado de Janowski R, $2001^{14}$. 


\subsection{Síntese, secreção e metabolização}

A cistatina $\mathrm{C}$ é sintetizada e secretada de forma constante por todas as células nucleadas. Mesmo na vigência de processos infecciosos, a sua concentração sérica depende fundamentalmente do RFG, não variando nem com o sexo, nem com a massa muscular ${ }^{13,15}$. No entanto, ela é influenciada pela função tireoidiana. De fato, o nível sérico da cistatina $\mathrm{C}$ é mais baixo no hipotireoidismo e mais elevado no hipertireoidismo, possivelmente por influência direta do hormônio tireoidiano na taxa de produção desta proteína $^{16,17}$.

No intracelular, a cistatina C fica predominantemente no retículo endoplasmático e nos corpúsculos de Golgi, na forma de dímeros, que são inativos. Os dímeros são formados a partir da troca de três subdomínios (a $\alpha$-hélice $\alpha 1$ e as folhas $\beta 1$ e $\beta 2$ ) entre dois monômeros de cistatina $C$ (figura 2). Como consequência, a alça L1 desaparece, o que explica porque o dímero não é capaz de inibir a ação de proteases. Nas vesículas secretoras, ocorre a dissociação dos dímeros, de forma que só são secretados monômeros ativos. No extracelular, a cistatina C apresenta-se na forma de monômeros. Apenas em condições patológicas ocorrem quantidades significantes de dímeros. A cistatina C está amplamente distribuída nos fluidos orgânicos, sendo sua concentração no líquido cefalorraquidiano cinco a seis vezes maior do que no plasma ${ }^{10}$.

A metabolização da cistatina $C$ ocorre no rim. Seu peso molecular baixo 
e sua carga positiva em $\mathrm{pH}$ fisiológico permitem que ela seja livremente filtrada pelos glomérulos, sendo quase completamente removida da circulação. Ocorre, então, a reabsorção pelas células tubulares de virtualmente toda a cistatina $\mathrm{C}$ filtrada, com posterior degradação enzimática dentro dos lisossomos. Assim, em condições fisiológicas, o conteúdo urinário de cistatina C é mínimo ${ }^{10,13}$.

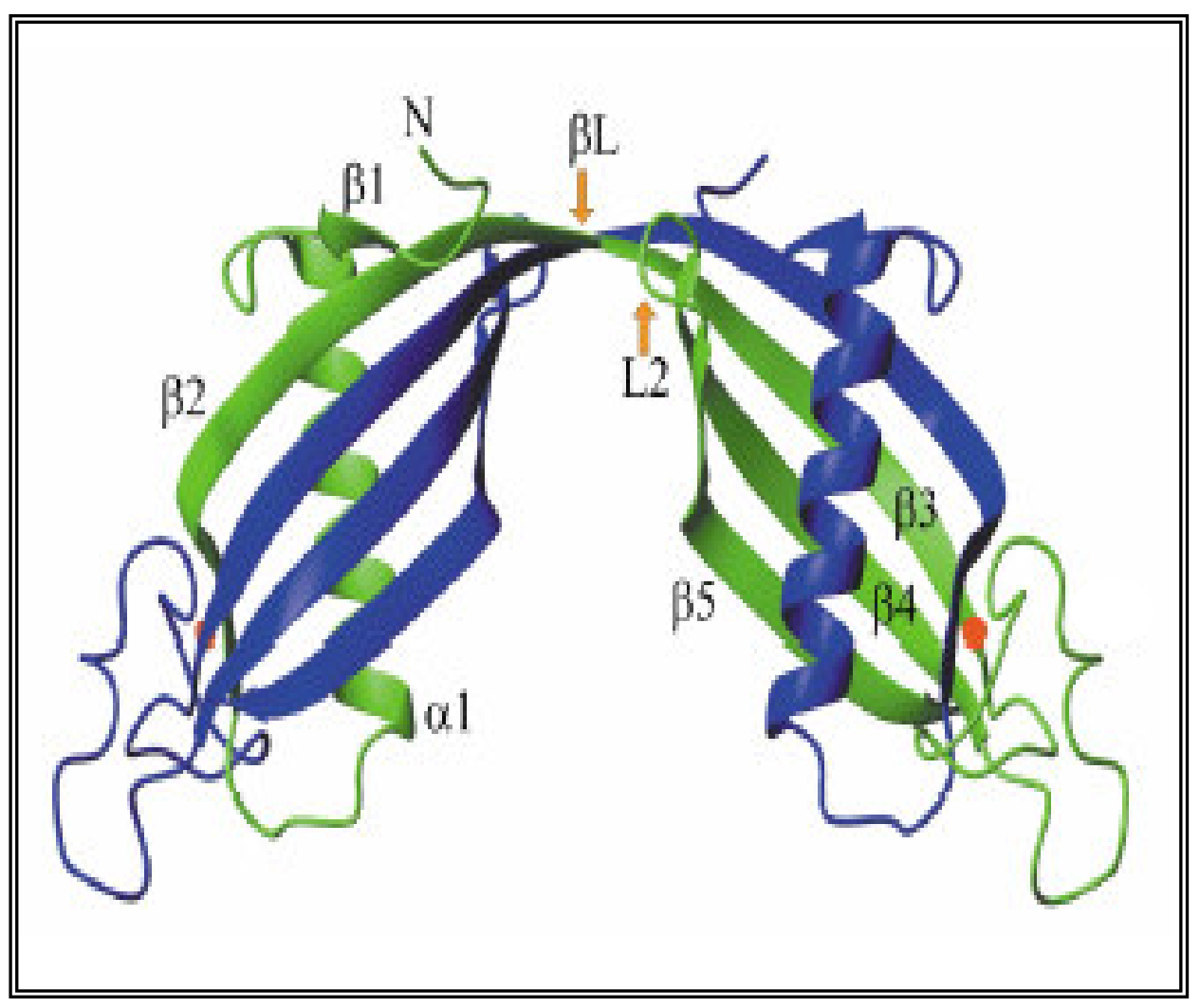

Figura 2 - Dímero da cistatina C. Modificado de Janowski R, $2001^{14}$.

\subsection{Função biológica}

Varias funções biológicas da cistatina são bem conhecidas. A principal é a inibição das cisteína peptidases endógenas e exógenas, modulando a 
proteólise extracelular em diversas situações, como na manutenção da integridade dos vasos sanguíneos. Ela está presente nas células do músculo liso da parede de vasos normais, mas seus níveis encontram-se muito diminuídos na presença de lesões ateroscleróticas. Nos portadores de aneurisma de aorta, ela também está muito diminuída, existindo mesmo correlação inversa entre os níveis de cistatina $\mathrm{C}$ e a incidência de aneurisma de aorta abdominal ${ }^{10,12}$.

A cistatina C também tem importância na modulação do sistema imune, uma vez que é secretada por monócitos e macrófagos, inibindo a atividade de neutrófilos. Essa secreção é diminuída pelo lipopolissacáride próinflamatório e pelo interferon $\gamma$. Além disso, apresenta atividade antiviral, por inibir as cisteína peptidases intracelulares necessárias para que ocorra a replicação viral. Ela é capaz particularmente de inibir a replicação do vírus Herpes simplex e do Coronavirus ${ }^{10}$.

Além disso, foi descrito que, quando há lesão cerebral, pode-se observar aumento dos níveis de cistatina $\mathrm{C}$ nas regiões lesadas. Porém, ainda não foi determinado se sua ação é realmente protetora ${ }^{10}$.

\subsection{Determinação laboratorial}

Apesar de se propor, desde 1985, o uso da dosagem sérica da cistatina C para inferir o $\mathrm{RFG}^{18}$, os métodos inicialmente disponíveis não eram suficientemente rápidos nem sensíveis para que pudessem ser incluídos na rotina dos laboratórios de análises clínicas. O primeiro imunoensaio para a 
quantificação da cistatina C em fluidos biológicos foi desenvolvido em 1979 por Löefberg e Grubb ${ }^{19}$. No entanto, era um método demorado (2 dias) e tinha baixa sensibilidade para a detecção de níveis baixos de cistatina $\mathrm{C}$. Foram desenvolvidos vários outros testes, como RIA (radioimunoensaio) e ELISA (imunoensaio enzimático). Porém, apenas na década de 90 foram descritos imunoensaios totalmente automatizados para dosagem da cistatina C. Em 1994, Kyshse-Andersen ${ }^{20}$ descreveu o PETIA (particle-enhanced turbidimetric immunoassay), baseado na reação entre a cistatina $\mathrm{C}$ sérica $\mathrm{e}$ anticorpos de coelho anticistatina C humana, ligados covalentemente a partículas de látex. Com esta técnica, foi possível fazer determinações de até $0,15 \mathrm{mg} / \mathrm{L}$, em não mais do que 7 minutos. Somente no final da década, foi desenvolvido um método de dosagem por nefelometria, denominado PENIA (particle-enhanced nephelometric immunoassay), que utiliza anticorpos de coelho anticistatina C humana, ligados covalentemente a partículas de clorometilestireno ${ }^{21}$. A capacidade de detecção é de $0,17 \mathrm{mg} / \mathrm{L}$ e o tempo de execução de 6 minutos. Estes dois métodos (PETIA e PENIA) são atualmente os de escolha para a dosagem da cistatina $\mathrm{C}$ em fluidos biológicos, pela sua precisão, simplicidade, automatismo e rapidez. Ambos sofrem pouca influência da presença de lípides, fator reumatóide, bilirrubina ou hemoglobina, embora possam alterar-se na presença de hemólise intensa $^{10}$. Estudos comparativos entre os dois métodos mostraram que, na dosagem por nefelometria (PENIA), a correlação entre o RFG e a cistatina C é significantemente mais forte do que na realizada por turbidimetria ${ }^{22}$. 


\section{Cistatina $\mathrm{C}$ como marcador do RFG}

\subsection{Adultos}

Várias pesquisas foram realizadas com o intuito de avaliar a acurácia da dosagem de cistatina C para estimar o RFG.

Dharnidharka, em 2002, publicou uma metanálise na qual foram incluídos 54 estudos, com um total de 4492 indivíduos, que comparavam a acurácia da cistatina $\mathrm{C}$ e da creatinina séricas com métodos considerados como padrões de medida do RFG, como o clearance de inulina, ${ }^{51} \mathrm{Cr}$-EDTA, ${ }^{99}$ Tm-DTPA, iothalamato e iohexol. O autor concluiu que a correlação da cistatina $C$ com o RFG $(r=0,816)$ é superior à da creatinina com o RFG $(r=0,742)$, de forma estatisticamente significante ${ }^{22}$.

Por sua vez, Coll, em 2000, comparou a cistatina C sérica, a creatinina sérica e o clearance de creatinina como marcadores do RFG, considerando o clearance de iothalamato como padrão-ouro. Mostrou que a cistatina $\mathrm{C}$ sérica começa a elevar-se com um RFG menor do que $88 \mathrm{~mL} / \mathrm{min} / 1,73 \mathrm{~m}^{2}$, enquanto a creatinina sérica não se altera para RFG mantidos acima de $75 \mathrm{~mL} / \mathrm{min} / 1,73 \mathrm{~m}^{2}$. Portanto, a cistatina C permitiria a detecção de alterações renais ainda incipientes, que a creatinina não seria capaz de identificar $^{23}$. Considerando esta capacidade da cistatina C de detectar

precocemente a diminuição do RFG, Dworkin, em 2001, propôs que a cistatina C não deveria substituir a creatinina em todas as situações, mas ser utilizada como um marcador mais sensível, em situações nas quais fosse 
importante a detecção e intervenção precoce, como nos pacientes portadores de diabetes mellitus ${ }^{15}$.

Roos, em 2007, realizou uma metanálise que incluiu 24 estudos, com um total de 2007 pacientes de 0,2 a 93 anos, que comparavam a acurácia da cistatina $C$ sérica e da creatinina sérica para diagnóstico de disfunção renal, considerando como padrão o clearance de inulina, Cr-EDTA, Tc-DTPA, iothalamato ou iohexol. Observou que a cistatina $\mathrm{C}$ tende a apresentar maior acurácia diagnóstica para a identificação de insuficiência renal do que a creatinina. Para valores de RFG entre 60 e $79 \mathrm{~mL} / \mathrm{min} / 1,73 \mathrm{~m}^{2}$, a cistatina $\mathrm{C}$ é conclusiva na detecção de alteração da função renal ${ }^{24}$.

\subsection{Crianças}

Também foram realizados estudos em crianças, para analisar a acurácia da cistatina C na avaliação do RFG. Eles mostraram que a cistatina C apresenta correlação com o RFG igual ou melhor do que a creatinina, tanto quando a função renal é normal como quando está alterada ${ }^{25-30}$.

Zaffanello, em 2007, publicou uma revisão, que incluiu 11 estudos, que comparavam a cistatina $C$ e a creatinina séricas na avaliação do RFG em crianças. Mostrou que em apenas 1 estudo a creatinina foi superior. Em 6 estudos a cistatina foi superior à creatinina para avaliação do RFG e em 4 as duas foram equivalentes ${ }^{31}$.

Bökenkamp, em 1998, mostrou que a cistatina C reflete o RFG, não 
sofrendo interferência de sexo, raça, peso ou composição corporal da criança $^{27}$. Já Takuma, em 2002, verificou que os níveis séricos de cistatina C não são influenciados pelo estado de hidratação da criança ${ }^{32}$.

No entanto, os níveis de cistatina $C$ níveis variam com a idade. São mais elevados ao nascimento, reduzindo-se progressivamente até os 18 meses, quando atingem níveis semelhantes aos do adulto. Esta diminuição refletiria a maturação do RFG que ocorre nesse período ${ }^{33-35}$.

Já Hoek, em 2003, comparando a cistatina C sérica, a creatinina sérica e o clearance de creatinina pela fórmula de Cockcroft e Gault, concluiu que a cistatina $C$ é o melhor marcador endógeno do RFG, o qual pode ser estimado a partir da cistatina $C$, usando equação específica ${ }^{36}$.

Filler, em 2003, desenvolveu outra equação para estimar o RFG pela cistatina $\mathrm{C}$ em crianças, a qual, segundo sua análise, seria melhor do que a fórmula de Schwartz ${ }^{37}$. Várias outras equações foram propostas, tanto para adultos quanto para crianças. Zahran, em 2007, analisando 43 estudos que compararam a performance da cistatina C sérica e da estimativa do RFG por equações baseadas na cistatina $C$, com a creatinina sérica e o RFG por equações baseadas na creatinina, considerou que a maioria dos estudos favorecia a cistatina $\mathrm{C}$ sérica em relação à creatinina. Fez, porém, a ressalva de que seriam necessárias mais pesquisas para avaliação das equações baseadas na cistatina $\mathrm{C}^{38}$. 


\subsection{Período neonatal}

Foram feitos alguns estudos no intuito de avaliar a cistatina C no período neonatal. Bökenkamp, em 1998, realizou um estudo que incluiu 258 crianças sem evidências de nefropatia, com idades que variavam de 1 dia a 18 anos. Ele determinou os níveis séricos de cistatina $C$ em 23 recémnascidos de 1 a 3 dias de vida e em 14 de 3 a 30 dias. No entanto, este autor não especificou a idade gestacional, nem o momento da coleta, nem as intercorrências clínicas porventura presentes ${ }^{34}$.

Em 2000, Finney, em um estudo que englobou 291 crianças de 1 dia a 17 anos, incluiu 16 recém-nascidos com idade gestacional de 24 a 28 semanas, 14 com 29 a 36 semanas e 17 recém-nascidos de termo. Nenhum destes recém-nascidos teve asfixia perinatal grave, nem fez uso de fármacos nefrotóxicos. Contudo, a dosagem dos níveis séricos de cistatina $\mathrm{C}$ dos recém-nascidos pré-termo foram realizadas com 1 dia de vida, enquanto nos recém-nascidos de termo a determinação foi feita com 7 dias. As dosagens laboratoriais foram realizadas por técnicas diferentes e os valores dos recém-nascidos de termo foram analisados dentro de um grupo que incluía também crianças de até 3 meses, com exclusão dos prematuros. Os níveis de cistatina $C$ foram mais elevados nos recém-nascidos prematuros do que nos de termo, mas dentro do grupo de prematuros não se verificou correlação entre a cistatina $\mathrm{C}$ e a idade gestacional ${ }^{33}$.

Já Harmoinen, em 2000, determinou os níveis séricos de cistatina C em

50 recém-nascidos de termo e em 58 com idade gestacional de 25 a 37 
semanas. Nenhum recém-nascido apresentou asfixia perinatal grave, mas 5 estavam hipotensos, 8 receberam indometacina e 14 receberam aminoglicosídeos. As avaliações foram realizadas em algum momento entre o nascimento e o $7^{0}$ dia de vida. Os níveis de cistatina $C$ foram mais elevados nos recém-nascidos prematuros do que nos de termo ${ }^{39}$.

Bahar, em 2003, dosou a cistatina C sérica e a bilirrubina total de 112 recém-nascidos saudáveis (98 de termo) em sangue de cordão umbilical e com 3 dias de vida. Não encontrou correlação entre a cistatina $C$ e a bilirrubina, sexo ou idade gestacional. Contudo, não levou em consideração a idade gestacional de cada recém-nascido, apenas classificando-os como menor do que 37 semanas ou maior ou igual a 37 semanas $^{40}$.

Treiber, em 2006, determinou os níveis de cistatina C em 75 recémnascidos com idade gestacional de 34 a 41 semanas (65 de termo), em cordão umbilical e com 3 dias de vida. Destes, 10 eram pequenos para a idade gestacional e 14 apresentaram acidose metabólica. A cistatina C em cordão umbilical não diferiu da encontrada no $3^{\circ}$ dia de vida, nem se correlacionou com sexo, peso, estado de hidratação ou idade gestacional, mas apresentou correlação negativa com o pH de cordão umbilical ${ }^{41}$.

Apesar de terem avaliado a cistatina $C$ de recém-nascidos, estes estudos não foram delineados de forma longitudinal, nem consideraram grupos bem delimitados de idade gestacional ou condições clínicas maternas ou fetais que pudessem interferir nos valores de cistatina C. Estudos mais recentes vêm evidenciando a influência de outros fatores sobre os níveis de cistatina $\mathrm{C}$, como o tipo de parto, tendo se observando 
valores mais elevados em partos vaginais ${ }^{42}$. Já Malamitsi-Puchner, em 2007, mostrou que recém-nascidos com crescimento intra-uterino restrito apresentavam níveis mais baixos de cistatina $\mathrm{C}$. $\mathrm{O}$ autor sugere que isso poderia ser decorrente de menor síntese proteica, por menor oferta de nutrientes ${ }^{43}$.

No entanto, Cataldi, em 1999, não encontrou correlação entre os níveis séricos de cistatina $\mathrm{C}$ de gestantes saudáveis no momento do parto e os de seus recém-nascidos de termo nos primeiros dias de vida ${ }^{44}$.

O fato de a cistatina $C$ sérica do recém-nascido não ser influenciada pela função renal materna pode contribuir para fortalecer a sua utilização para inferir o RFG logo após o nascimento. Assim, os dados de literatura fazem-nos supor que a cistatina $C$ possa ser um marcador endógeno muito promissor da função renal, especialmente na primeira semana de vida. Contudo, ainda não existe padrão de normalidade definido neste período, nem mesmo para os recém-nascidos de termo sem patologias. Considerando-se que a cistatina $C$ possa ter uma evolução própria na primeira semana de vida, é necessário que seus níveis nesse período sejam determinados de forma longitudinal em recém-nascidos que obedeçam a critérios restritos de normalidade. 
Objetivos

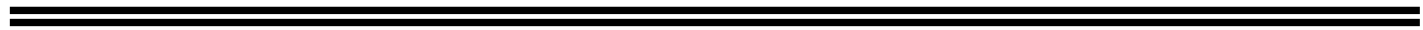




\section{Objetivo geral}

Determinar a evolução dos níveis séricos da cistatina $C$ em recémnascidos de termo adequados para a idade gestacional, sem intercorrências, ao longo do primeiro mês de vida.

\section{Objetivos específicos}

Em relação aos níveis séricos de cistatina $\mathrm{C}$ durante o primeiro mês de vida, em recém-nascidos de termo adequados para a idade gestacional, sem intercorrências, analisar:

1- a relação entre a cistatina $C$ da mãe e do recém-nascido ao nascimento;

2- a evolução durante o primeiro mês de vida;

3- a relação com os níveis de creatinina sérica e com o clearance de creatinina. 
Métodos

ב


Foi realizado um estudo prospectivo, com dosagem de cistatina C sérica em uma coorte de recém-nascidos (RN) admitidos no Berçário Anexo à Maternidade, Serviço de Pediatria Neonatal e Intensiva do Instituto da Criança, Hospital das Clínicas da Faculdade de Medicina da Universidade de São Paulo (HCFMUSP), no período de julho de 2005 a janeiro de 2006. As dosagens laboratoriais foram realizadas no Laboratório de Investigação Médica - LIM36, Pediatria Clínica, HCFMUSP.

Este estudo recebeu auxílio-pesquisa da Fundação de Amparo à Pesquisa do Estado de São Paulo - FAPESP, processo número 2005/50075-0.

\section{1. Ética}

Esta pesquisa foi aprovada pela Comissão de Ética para Análise de Projetos de Pesquisa - CAPPesq da Diretoria Clínica do HCFMUSP, em 24 de março de 2005 (Anexo A).

Todas as mães consentiram na inclusão no estudo após adequadamente informadas, através do Termo de Consentimento Livre e Esclarecido, conforme as recomendações da Resolução $n^{0} 196$, de 10 de outubro de 1996, do Conselho Nacional de Saúde (Anexo B). 


\section{Desenho do estudo}

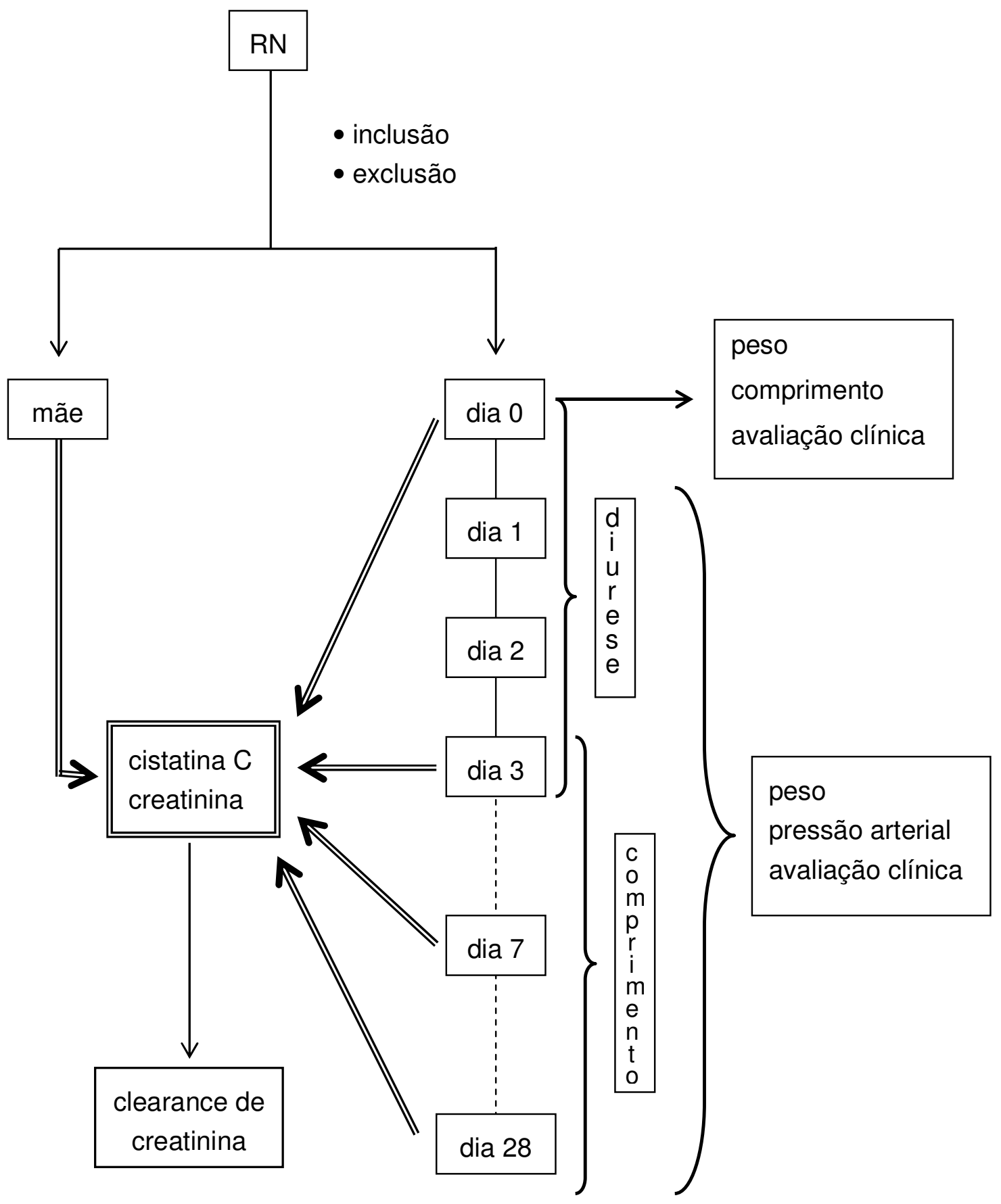




\section{Casuística}

Os RN foram selecionados para o estudo segundo os seguintes critérios de inclusão e exclusão:

\subsection{Critérios de inclusão}

- Idade gestacional definitiva entre 37 e $41 \frac{6}{7}$ semanas (RN de termo). A idade gestacional definitiva foi baseada na data da última menstruação, confirmada por ultrassonografia fetal realizada no primeiro trimestre de gestação, desde que a diferença entre elas fosse de até 2 semanas. Em caso de diferença maior ou de não haver ultrassonografia fetal no primeiro trimestre, foi considerada a informação materna, desde que a avaliação da idade gestacional pelo método de Capurro não diferisse desta em mais de 2 semanas $^{45,46}$

- Peso de nascimento adequado para a idade gestacional, segundo os percentis 10 e 90 da curva de Alexander ${ }^{47}$;

- Nota de Apgar de primeiro e quinto minutos igual ou maior do que 7

- Mães que não apresentassem alteração da função renal;

- Mães que não apresentassem elevação da pressão arterial, seja por hipertensão arterial crônica ou doença hipertensiva específica da gestação; 
- Mães que não tivessem utilizado, durante a gestação, fármacos que pudessem interferir com a função renal do feto, tais como: furosemida, metildopa, captopril ou enalapril ${ }^{48}$;

- Consentimento dos pais ou responsável, após adequadamente informados.

\subsection{Critérios de exclusão}

- Má-formação major ou renal;

- Ausência de diurese nas primeiras 12 horas de vida ou oligúria entre 24 e 72 horas de vida;

- Perda de peso até o terceiro dia de vida maior do que $10 \%$ do peso de nascimento;

- Pressão arterial alterada com 1, 3, 7 ou 28 dias de vida, considerando-se como alterada a pressão sistólica ou diastólica que não estivesse contida no intervalo de confiança de $95 \%$ dos valores normais de pressão arterial segundo Zubrow, de acordo com a idade gestacional pós-conceptual ${ }^{49}$.

- Insuficiência cardíaca;

- Insuficiência renal;

- Presença de sinais sugestivos de infecção;

- Doença hemolítica ou icterícia com necessidade de fototerapia;

- Necessidade de hidratação por via intravenosa; 
- Necessidade de fármacos vasopressivos, diuréticos ou que pudessem interferir com a avaliação da função renal;

- Alteração de função tireoidiana;

- Impossibilidade de coleta de todas as amostras programadas.

Os RN permaneceram internados por três dias, de acordo com a conduta do Berçário Anexo à Maternidade. Neste período, foram submetidos a avaliação ao nascimento (dia 0) e com 1 dia (dia 1), 2 dias (dia 2) e 3 dias (dia 3) de vida. Todos retornaram para reavaliação ambulatorial aos 7 (dia 7) e 28 dias (dia 28). Todas as avaliações foram realizadas pela mesma pesquisadora.

\section{Metodologia}

Todas as informações obtidas foram registradas em formulário específico (Anexo C).

\subsection{Características maternas, gestação e parto}

Os dados referentes às características maternas, intercorrências na gestação e parto foram obtidos a partir do prontuário materno e de informações fornecidas pela mãe diretamente à pesquisadora. 


\subsection{Evolução do RN}

A evolução pós-natal do $\mathrm{RN}$ foi acompanhada diretamente pela pesquisadora, por meio das avaliações clínicas diárias durante a internação e nos retornos ambulatoriais com 7 e 28 dias. Todos os $R N$ seguiram os procedimentos de rotina do Berçário.

\subsection{Peso}

A medida do peso foi realizada em balança eletrônica Filizolaß, com aproximação de 5 gramas.

Cada RN foi pesado ao nascimento e com 1, 2, 3, 7 e 28 dias de vida. Quando o peso do $7^{\circ}$ dia ainda era menor do que o peso de nascimento, o $\mathrm{RN}$ retornava para ser novamente pesado com 14 dias de vida.

\subsection{Comprimento}

O comprimento foi avaliado sempre com antropômetro de metal, calibrado em milímetros. A parte fixa foi ajustada na cabeça e a parte móvel na base dos pés. A aproximação foi para o milímetro superior encontrado.

O comprimento de cada $\mathrm{RN}$ foi medido ao nascimento, com 3,7 e 28 dias de vida. 


\subsection{Controle de diurese}

A avaliação da diurese foi inferida através do peso de fraldas, realizado pela enfermagem do Berçário Anexo à Maternidade no momento dos cuidados habituais do RN. Quando havia presença de mecônio espesso, este era retirado da fralda antes da pesagem. Utilizou-se balança eletrônica apropriada, com aproximação de 1 grama. Foi considerado como tendo oligúria o RN que teve peso de fralda menor que $1 \mathrm{~g} / \mathrm{kg} / \mathrm{h}$, o que corresponderia aproximadamente a diurese menor que $1 \mathrm{~mL} / \mathrm{kg} / \mathrm{h}$.

Este controle foi realizado durante toda a internação, com cuidado especial em registrar o momento da primeira micção do $\mathrm{RN}$.

\subsection{Pressão arterial}

A medida da pressão arterial foi feita com 1, 2, 3, 7 e 28 dias de vida. Em cada momento foram realizadas 3 medidas de pressão arterial, sendo considerado como resultado a média dos 2 últimos valores encontrados.

A pressão arterial foi avaliada seguindo o procedimento descrito por Zubrow $^{49}$. Foi utilizado um monitor de pressão arterial não invasivo, oscilométrico (DINAMAP® Pro-100). O exame foi realizado em ambiente tranquilo, com o $\mathrm{RN}$ em decúbito dorsal, na ausência de choro ou movimentos amplos dos membros. As medidas foram aferidas no membro superior direito, estendido paralelo ao tronco, sendo o manguito posicionado no ponto médio do braço. Foram utilizados manguitos de $4,0 \mathrm{~cm} \times 20 \mathrm{~cm}$ ou 
$5,0 \mathrm{~cm} \times 20 \mathrm{~cm}$, de forma que a porção inflável do balão envolvesse pelo menos $75 \%$ da circunferência do braço e seu comprimento correspondesse a pelo menos $2 / 3$ do comprimento do braço.

\subsection{Ultrassonografia de rins e vias urinárias}

Durante o período de internação, foi realizada ultrassonografia (USG) de rins e vias urinárias em todos os RN. O exame, cujo objetivo era detectar a presença de más-formações estruturais, foi feito sempre pelo mesmo radiologista.

\subsection{Avaliação laboratorial}

Foi obtido sangue para a determinação laboratorial da cistatina $C$ e da creatinina séricas da mãe, no momento do parto, e do $\mathrm{RN}$, ao nascimento (cordão umbilical), com 3, 7 e 28 dias. Junto com a coleta realizada no terceiro dia de vida, foi colhido também sangue para a dosagem do hormônio estimulante da tireóide (TSH) neonatal, para a triagem de função tireoidiana. 


\subsubsection{Técnica de coleta de sangue}

\section{- Cordão umbilical}

Realizada punção de veia umbilical, da porção do cordão umbilical próxima à placenta, logo após a extração da mesma. A seguir, o sangue era aspirado com seringa e colocado em tubo seco.

\section{- Veia periférica}

No $3^{\circ}, 7^{\circ}$ e $2^{\circ}$ dias de vida, foi colhido sangue de todos os $\mathrm{RN}$ por meio de punção venosa de vaso superficial de dorso de mão, sendo o sangue colocado em tubo seco. Todas as coletas foram realizadas pela pesquisadora.

\subsubsection{Processamento e armazenamento}

As amostras colhidas foram encaminhadas ao Laboratório de Investigação Médica - LIM36 em até 2 horas após a coleta, onde foram centrifugadas a 2500 rpm (rotações por minuto) durante 5 minutos. O soro foi separado e colocado em 2 eppendorfs com volumes iguais, que foram armazenados em freezer com temperatura de $20^{\circ} \mathrm{C}$ negativos.

\subsubsection{Determinações laboratoriais}

As determinações laboratoriais foram realizadas todas em duplicata e 
em um mesmo momento.

Os métodos utilizados para as determinações laboratoriais foram os seguintes:

\section{- Cistatina C}

A determinação da cistatina $\mathrm{C}$ foi realizada por imunonefelometria, utilizando-se o kit de teste N Latex Cystatin C, código OQNM, fabricado pela Dade Behring®, sendo usado o nefelômetro BN II, também da Dade Behring®

Nesta técnica, são utilizadas partículas de poliestireno recobertas por anticorpos específicos contra a cistatina C humana. Uma vez misturadas com amostras contendo cistatina C, formam-se aglutinados, que dispersam a luz irradiada. A intensidade da luz dispersada é quantificada, sendo proporcional à concentração da cistatina $\mathrm{C}$ presente na amostra. A concentração da cistatina $\mathrm{C}$ (em $\mathrm{mg} / \mathrm{L})$ é calculada a partir de uma curva elaborada com um soro padrão com concentração conhecida (fornecida pelo kit da Dade Behring®), testado em diferentes concentrações.

Com base nas informações do fabricante, algumas especificações devem ser salientadas, como se segue. A dosagem pode ser realizada em amostras de soro ou plasma, tão frescas quanto possível (conservada por até 7 dias sob temperatura entre 2 e $8^{\circ}$ C) ou congeladas. Neste caso, as amostras devem ser congeladas em até 24 horas após a coleta e mantidas a uma temperatura de $20^{\circ} \mathrm{C}$ negativos. Como vimos, no nosso estudo foram usadas amostras congeladas. 
Podem ocorrer interferências nas dosagens na presença de fator reumatóide ou quando as amostras estão lipêmicas ou contêm partículas que não são removidas, mesmo após centrifugação.

Este teste apresenta sensibilidade de $0,005 \mathrm{mg} / \mathrm{L}$ e especificidade de $100 \%$. Não se conhecem reações cruzadas dos anticorpos utilizados ${ }^{10,50}$.

\section{- Creatinina}

A dosagem de creatinina foi realizada pelo método de Jaffé, sem desproteinização, automatizado, utilizando-se o equipamento Integra 400 da Roche Diagnostic Systems®.

Esta técnica baseia-se na reação descrita por Jaffé em 1886, na qual a creatinina tratada com uma solução de picrato alcalino produz um composto de cor alaranjada. A intensidade da cor, medida por absorbância, é diretamente proporcional à quantidade de creatinina presente. Como outras substâncias possuem a mesma propriedade que a creatinina, utilizam-se técnicas, como a adição de absorventes, para aumentar a especificidade da dosagem $^{51,52}$.

\section{- TSH neonatal}

No $3^{\circ}$ dia de vida foi colhido sangue em papel de filtro para a dosagem de $\mathrm{TSH}$, juntamente com o restante dos exames de triagem neonatal, realizados na rotina do Berçário. Essa determinação foi realizada no Laboratório da Associação de Pais e Amigos dos Excepcionais de São Paulo (APAE-São Paulo) e o método utilizado foi a imunonefelometria. 


\subsection{Clearance de Creatinina}

Foi realizada uma estimativa do clearance de creatinina $(\mathrm{ClCr})$, em $\mathrm{mL} / \mathrm{min} / 1,73 \mathrm{~m}^{2}$, pela fórmula de Schwartz: $\mathrm{ClCr}=k^{*} \mathrm{~L} / \mathrm{Cr}$, onde $\mathrm{L}$ correspondeu ao comprimento em centímetros, $\mathrm{Cr}$ ao valor da creatinina sérica ( $\mathrm{mg} / \mathrm{dL})$ e $k$ a uma constante, que equivale a 0,45 em recém-nascidos de termo adequados para a idade gestacional ${ }^{7}$.

\section{Análise estatística}

Para o cálculo do $\mathrm{n}$, considerou-se a média da concentração sérica de cistatina $C$ de $1,36 \mathrm{mg} / \mathrm{L}$, com desvio padrão de $0,35 \mathrm{mg} / \mathrm{L}$ e a média da concentração sérica de creatinina de $0,5 \mathrm{mg} / \mathrm{dL}$, com desvio padrão de $0,3 \mathrm{mg} / \mathrm{dL}^{7,40}$. Considerou-se como significativa uma diferença na média das concentrações de cistatina C maior ou igual a $0,24 \mathrm{mg} / \mathrm{L}$ (18\%), assim como uma diferença na média das concentrações de creatinina maior ou igual a $0,20 \mathrm{mg} / \mathrm{dL}(40 \%)$. Para um a de 0,05 e um poder de teste $(\beta)$ de $0,8,0$ número de casos calculado (n) foi 20.

A avaliação da distribuição dos dados (teste de normalidade) foi feita utilizando-se o teste de Kolmogorov-Smirnov. A comparação de médias foi feita pelo teste ANOVA one way para medidas repetidas e pelo teste de Tukey. Quando a distribuição dos dados não foi normal, utilizou-se o teste não paramétrico de Friedman. Para as análises de correlação, foi utilizado o coeficiente de correlação de Pearson. Consideraram-se estatisticamente significantes os valores de $p$ menores do que 0,05 . 
Resultados

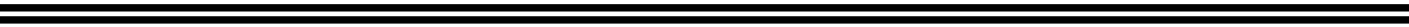


Foram considerados elegíveis para inclusão no estudo 35 RN. Destes, 14 foram excluídos, devido aos seguintes motivos:

- 5 RN: a mãe não autorizou o estudo;

- 1 RN: apresentou perda de peso maior do que 10\% do peso de nascimento;

- $1 \mathrm{RN}$ : apresentava situs inversus;

- 2 RN: apresentaram alterações detectadas na USG de rins e vias urinárias, sendo 1 caso de pieloectasia e 1 caso de tumoração cística de suprarrenal;

- 3 RN: apresentaram intercorrências na evolução:

- 1 RN: icterícia em níveis que indicaram fototerapia;

- 1 RN: insuficiência respiratória, que determinou necessidade de jejum e hidratação intravenosa;

- $1 \mathrm{RN}$ : uso de ranitidina;

- 2 RN: não compareceram ao retorno programado para os 28 dias de vida.

Portanto, a casuística deste estudo incluiu $21 \mathrm{RN}$.

\section{Características maternas}

As características maternas estão resumidas no Quadro 1. As mães apresentaram idade de $29,1 \pm 8,2$ anos (média \pm desvio padrão), sendo 7 primigestas $(33,3 \%)$ e 9 primíparas $(42,8 \%)$. Todas fizeram acompanhamento pré-natal, sendo que $18(85,7 \%)$ o fizeram no Hospital das 
Clínicas. Durante o acompanhamento pré-natal, todas as mães foram submetidas a USG obstétrica, não sendo detectada nenhuma má-formação fetal. Destas mães, $6(28,6 \%)$ apresentavam afecções anteriores à gestação, sendo a mais frequente o hipotireoidismo em 3 delas (14,3\%). Uma mãe era portadora do vírus HIV, sem manifestação clínica da doença e com carga viral zero antes e durante toda a gestação. Uma mãe tinha esclerose múltipla, uma apresentava asma e uma das mães com hipotireoidismo tinha também transtorno bipolar. Em todos os casos os processos estavam controlados, não tendo ocorrido descompensações durante a gestação ou no puerpério.

Quadro 1 - Características maternas

\begin{tabular}{lc}
\hline \hline Idade em anos (média \pm dp) & $29,1 \pm 8,2$ \\
Primigesta & $7(33,3 \%)$ \\
Primípara & $9(42,8 \%)$ \\
Pré-natal & $21(100 \%)$ \\
Pré-natal no HCFMUSP & $17(85,7 \%)$ \\
USG fetal normal & $21(100 \%)$ \\
Alguma doença antes da gestação & $6(28,6 \%)$ \\
Hipotireoidismo & $3(14,3 \%)$ \\
Alguma intercorrência na gestação & $3(14,3 \%)$ \\
Síndrome antifosfolípide & $2(9,5 \%)$ \\
Uso de alguma medicação & $7(33,3 \%)$ \\
Uso de L-tiroxina sódica & $3(14,3 \%)$ \\
\hline \hline
\end{tabular}


Durante a gestação, 3 mães (14,3\%) apresentaram agravos à saúde, sendo diabetes gestacional em $2(9,5 \%)$ e síndrome antifosfolípide em 1 mãe (4,8\%). Nenhuma mãe apresentou hipertensão ou alteração de função renal.

Nenhuma mãe fez uso de medicação nefrotóxica ou que pudesse interferir com a função renal do feto. A medicação mais utilizada foi a L-tiroxina sódica, por 3 mães (14,3\%). Outros fármacos utilizados foram lamivudina, zidovudina, nelfinavir, clorpromazina, quetiapina, ácido acetilsalicílico (em baixas doses), heparina, insulina e fenoterol. Nenhuma mãe apresentou efeitos colaterais significativos decorrentes do uso de medicações.

As características maternas estão discriminadas de forma mais detalhada no Anexo D.

Em relação ao parto, 11 mães $(52,4 \%)$ foram submetidas a parto cesáreo e 10 a parto vaginal (47,6\%). Nenhuma mãe apresentou intercorrências no parto ou no puerpério.

\section{Características dos $\mathrm{RN}$}

Os $\mathrm{RN}$ receberam os cuidados habituais em sala de parto conforme norma do Berçário Anexo à Maternidade, que segue as recomendações do Programa de Reanimação Neonatal da Sociedade Brasileira de Pediatria. Em todos os partos houve a presença de médico neonatologista, com 
treinamento pelo referido Programa. Todos os $\mathrm{RN}$ apresentaram Apgar de $1^{\circ}$ e 5ำ minutos maior do que 7 .

O Quadro 2 mostra as características dos RN. A mediana da idade gestacional foi 39,4 semanas e o peso de nascimento $3224,3 \pm 306,7 \mathrm{~g}$ (média \pm desvio padrão). $12 \mathrm{RN}$ eram do sexo masculino $(57,1 \%)$, com uma relação masculino:feminino de 1,3:1. No Anexo E pode-se ver de forma mais detalhada as características dos RN.

Quadro 2 - Características dos RN

Idade gestacional (semanas)

(mediana)

Peso ao nascimento $(\mathrm{g})$

(média $\pm \mathrm{dp}$ )

Sexo masculino

Tipo de parto

cesárea

fórceps

normal
39,4

$3224,3 \pm 306,7$

$12(57,1 \%)$

$11(52,4 \%)$

$7(33,3 \%)$

$3(14,3 \%)$

\subsection{Evolução neonatal}

A evolução dos RN durante todo o período de estudo está resumida no Quadro 3. $17 \mathrm{RN}(81,0 \%)$ receberam aleitamento materno exclusivo até o 28ํ dia de vida. O aleitamento materno foi contra-indicado em $2 \mathrm{RN}$ por causa materna (1 mãe portadora do vírus HIV e 1 mãe fazendo uso de 
quetiapina). Em 2 casos foi iniciada complementação com leite artificial no $14^{\circ}$ dia de vida, por baixo ganho ponderal. 2 mães $(9,5 \%)$ fizeram uso de L-tiroxina durante a amamentação. $13 \mathrm{RN}(61,9 \%)$ apresentaram icterícia, sem necessidade de fototerapia. Em 1 RN foi detectada comunicação interatrial e em $1 \mathrm{RN}$ comunicação interventricular. Nenhuma delas teve repercussão e ambas estavam já fechadas no terceiro mês de vida. $\mathrm{O} R$ cuja mãe era portadora do vírus HIV apresentou HIV-RNA negativo.

Quadro 3 - Evolução neonatal

Aleitamento materno exclusivo

Perda de peso (\% do peso de nascimento)

(média $\pm \mathrm{dp}$ )

Idade em dias da maior perda de peso

(mediana)

Icterícia

Cardiopatia

comunicação interatrial*

comunicação interventricular*

Tempo de internação em dias (mediana)
$17(81,0 \%)$

$7,1 \pm 1,7$

2,0

$13(61,9 \%)$

$1(4,8 \%)$

$1(4,8 \%)$

3

*Fecharam na evolução

O tempo de internação foi de 3 dias (mediana), sendo que apenas $1 \mathrm{RN}$ ficou internado por 4 dias, pois estava aguardando avaliação odontológica, por presença de dente neonatal. Em todos os RN, a USG de rins e vias 
urinárias e o TSH neonatal foram normais. A evolução de cada RN está detalhada no Anexo F.

\subsection{Diurese}

A primeira micção ocorreu com 6 horas de vida (mediana), tendo sido a mais tardia com 11 horas. O peso de fralda variou de 1,4 a $3,7 \mathrm{~g} / \mathrm{kg} / \mathrm{h}$. No $2^{\circ}$ dia de vida foi $2,1 \pm 0,6 \mathrm{~g} / \mathrm{kg} / \mathrm{h}$ (média \pm desvio padrão) e no $3^{\circ}$ dia de vida 2,4 \pm 0,7 g/kg/h (média \pm desvio padrão), não havendo diferença significativa entre o peso de fralda destes dois dias $(p=0,148)$. O peso de fralda de cada RN está discriminado no Anexo G.

\subsection{Evolução ponderal e crescimento}

A perda inicial de peso, em porcentagem do peso de nascimento, foi de 7,1 \pm 1,7 (média \pm desvio padrão) e ocorreu com 2 dias de vida (mediana). A recuperação do peso de nascimento deu-se até $07^{\circ}$ dia de vida em $11 \mathrm{RN}(52,4 \%)$ e até o $14^{\circ}$ - dia nos outros $10(47,6 \%)$.

A evolução do peso e do crescimento no $1^{\circ}$ mês de vida está expressa no Quadro 4 e no Gráfico 1. Com 28 dias de vida, o peso e o comprimento de todos os RN encontravam-se entre o percentil 5 e 95 das curvas de crescimento do National Center for Health Statistics ${ }^{53}$. Os pesos e comprimentos de cada RN encontram-se nos Anexos $\mathrm{H}$ e I, respectivamente. 
Quadro 4 - Evolução de peso e comprimento no período neonatal

\begin{tabular}{ccc}
\hline $\begin{array}{r}\text { Idade } \\
\text { (dias) }\end{array}$ & $\begin{array}{c}\text { Peso }(\mathrm{g}) \\
(\text { média } \pm \mathrm{dp})\end{array}$ & $\begin{array}{c}\text { Comprimento }(\mathrm{cm}) \\
(\text { média } \pm \mathrm{dp})\end{array}$ \\
\hline 0 & $3224,3 \pm 306,7$ & $48,9 \pm 1,4$ \\
1 & $3097,6 \pm 289,2$ & \\
2 & $3020,5 \pm 301,7$ & $49,0 \pm 1,5$ \\
3 & $3015,9 \pm 320,0$ & $49,9 \pm 1,6$ \\
7 & $3165,2 \pm 333,7$ & \\
$14^{*}$ & $3336,5 \pm 334,4$ & $53,4 \pm 1,7$ \\
28 & $4017,6 \pm 376,3$ & \\
\hline
\end{tabular}

${ }^{*} \mathrm{n}=10 \mathrm{RN}$

Peso: $\quad d 0 X d 1, p=0,176 ; d 1 X d 2, p=0,403 ; d 2 X d 3, p=0,963 ; d 0 X d 3, p=0,037$; d3 $X d 7, p=0,147 ; d 7 X d 28, p<0,001$.

Comprimento: $d 0 X d 3, p=0,834 ; d 3 X d 7, p=0,050 ; d 0 X d 7, p=0,030$;

d7 $X$ d28, $p<0,001$.

Gráfico 1 - Evolução de peso e comprimento no período neonatal
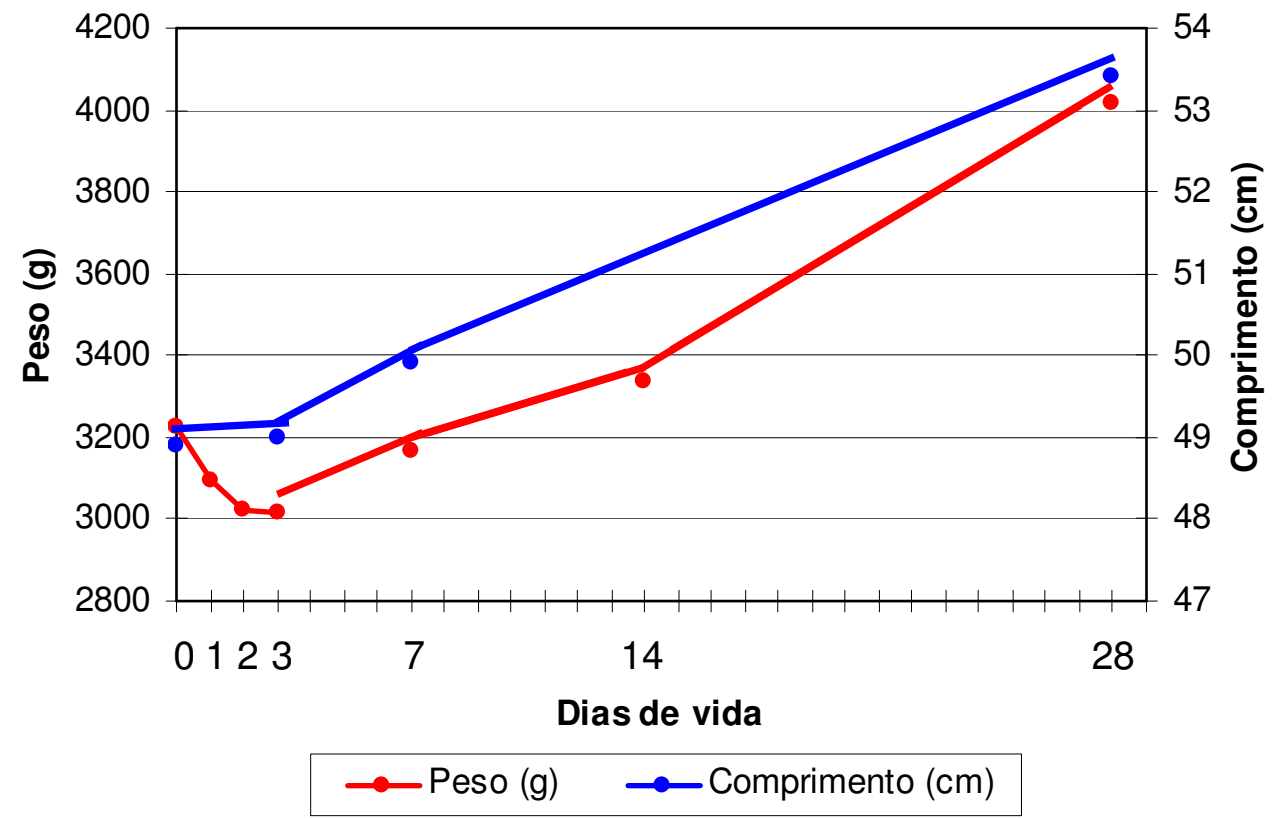


\subsection{Pressão arterial}

Os valores médios de pressão arterial estão apresentados no Quadro 5. No Anexo $\mathrm{J}$ estão discriminadas todas as medidas de pressão arterial de cada RN.

Nenhum RN apresentou pressão arterial elevada. Todas as medidas de pressão arterial sistólica e diastólica, segundo a idade gestacional pósconceptual, ficaram dentro do limite do intervalo de confiança considerado normal segundo Zubrow, como pode ser visto no Gráfico $2^{49}$.

Quadro 5 - Evolução da pressão arterial

\begin{tabular}{cccc}
\hline $\begin{array}{c}\text { Idade } \\
(\text { dias })\end{array}$ & $\begin{array}{c}\text { Sistólica }(\mathrm{mmHg}) \\
(\text { média } \pm \mathrm{dp})\end{array}$ & $\begin{array}{c}\text { Diastólica }(\mathrm{mmHg}) \\
(\text { média } \pm \mathrm{dp})\end{array}$ & $\begin{array}{c}\text { Média }(\mathrm{mmHg}) \\
(\text { média } \pm \mathrm{dp})\end{array}$ \\
\hline 1 & $63,2 \pm 5,9$ & $34,3 \pm 3,8$ & $46,8 \pm 5,1$ \\
2 & $66,8 \pm 7,1$ & $37,9 \pm 5,6$ & $50,2 \pm 5,9$ \\
3 & $68,4 \pm 8,7$ & $37,4 \pm 5,8$ & $50,3 \pm 7,6$ \\
7 & $75,6 \pm 9,4$ & $44,1 \pm 7,2$ & $57,3 \pm 8,8$ \\
28 & $80,8 \pm 9,1$ & $47,2 \pm 7,5$ & $60,1 \pm 8,3$
\end{tabular}

Sistólica: d1 X d2, $p=0,029 ; d 2 X d 3, p=0,380 ; d 3 X d 7, p=0,002 ; d 7 X$ d28, $p=0,044$.

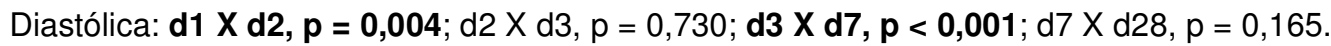
Média: d1 X d2, $p=0,005 ; d 2 X d 3, p=0,906 ; d 3 X d 7, p=0,005 ; d 7 X d 28, p=0,266$. 
Gráfico 2 - Comparação da pressão arterial dos $\mathrm{RN}$ com os valores normais de pressão arterial segundo $Z_{\text {ubrow }}{ }^{49}$, de acordo com a idade pós-conceptual
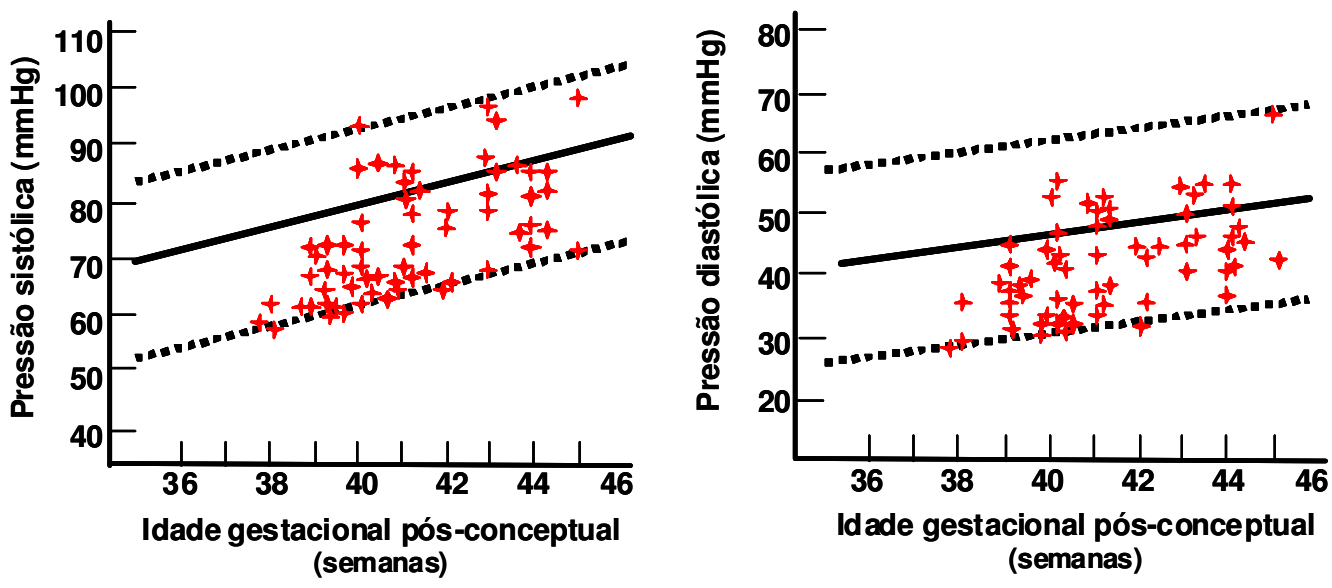

Pressão arterial encontrada: + Valores de referência

a

\section{Avaliação laboratorial}

As amostras de sangue colhidas para a dosagem de cistatina $\mathrm{C}$ e de creatinina não estavam hemolisadas, nem lipêmicas, não tendo sido verificada a presença de partículas não removidas após a centrifugação. Foi possível realizar todas as dosagens programadas, exceto por uma dosagem de creatinina, por volume de amostra insuficiente. 
Os valores séricos de cistatina $\mathrm{C}$ e de creatinina e o clearance de creatinina apresentaram distribuição normal. Nos Anexos K e L estão todos os valores encontrados de cistatina $\mathrm{C}$ e creatinina para cada $\mathrm{RN}$.

\subsection{Cistatina C}

Os níveis de cistatina C da mãe e do RN estão no Quadro 6 e no Gráfico 3. Ao nascimento, os valores de cistatina $\mathrm{C}$ do $\mathrm{RN}$ foram signitivamente mais elevados do que os da mãe $(p<0,001)$ e não se verificou correlação entre eles (Gráfico 4). Os valores máximos de cistatina C do RN ocorreram no dia 0 , ficando estáveis a partir do dia 3.

Quadro 6 - Níveis de cistatina C (mg/L) da mãe e do RN no primeiro mês de vida

\begin{tabular}{ccc}
\hline \multicolumn{2}{c}{ Cistatina C } \\
\hline Mãe & $1,00 \pm 0,20$ & Intervalo de confiança (95\%) \\
\hline RN & & \\
dia 0 & $1,70 \pm 0,91$ a 1,09 \\
dia 3 & $1,51 \pm 0,19$ & 1,58 a 1,82 \\
dia 7 & $1,54 \pm 0,15$ & 1,42 a 1,60 \\
dia 28 & $1,51 \pm 0,15$ & 1,47 a 1,61 \\
\hline
\end{tabular}

mãe $X$ dia $0, p<0,001$; dia $0 X$ dia 3, $p=0,003$;

dia $3 \times$ dia 7, $p=0,971$; dia $7 X$ dia 28, $p=0,990$. 
Gráfico 3 - Evolução dos níveis de cistatina $C(\mathrm{mg} / \mathrm{L})$ da mãe e do RN no primeiro mês de vida (média $\pm 2 \mathrm{dp}$ )

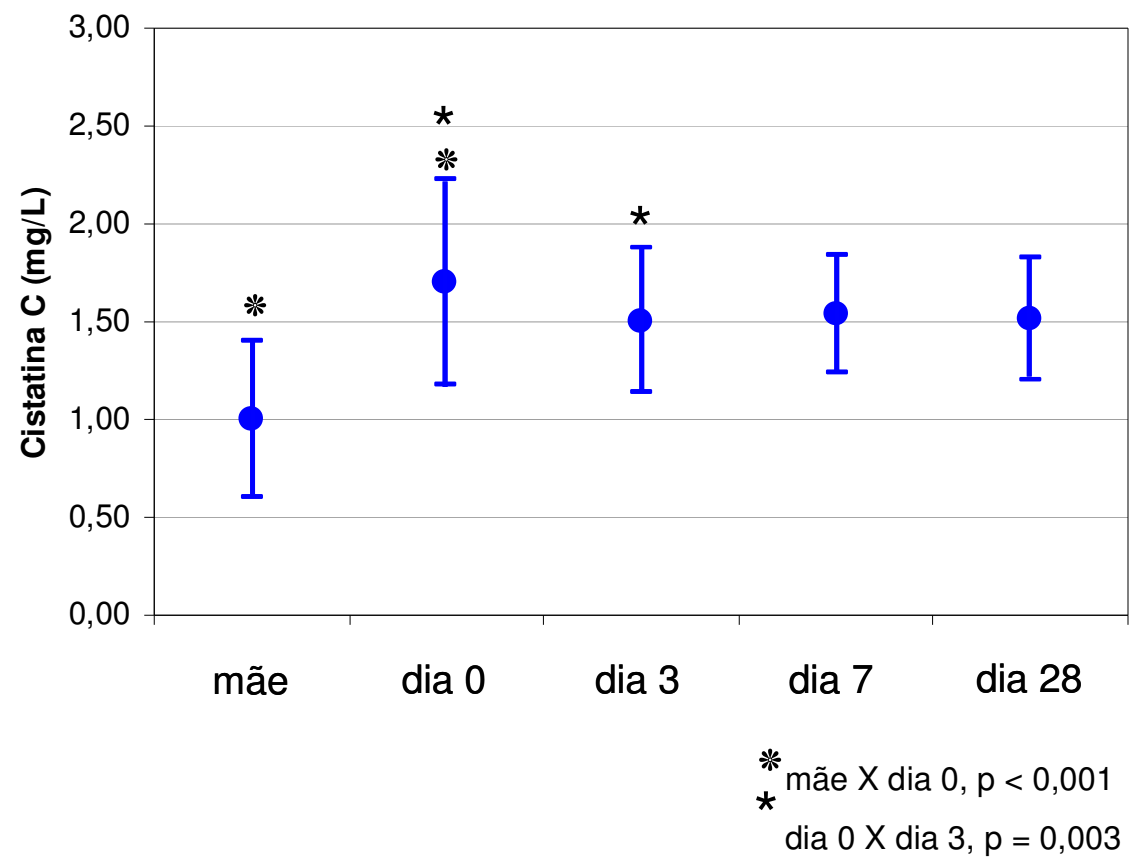

Gráfico 4 - Correlação entre os valores de cistatina C maternos e do RN ao nascimento

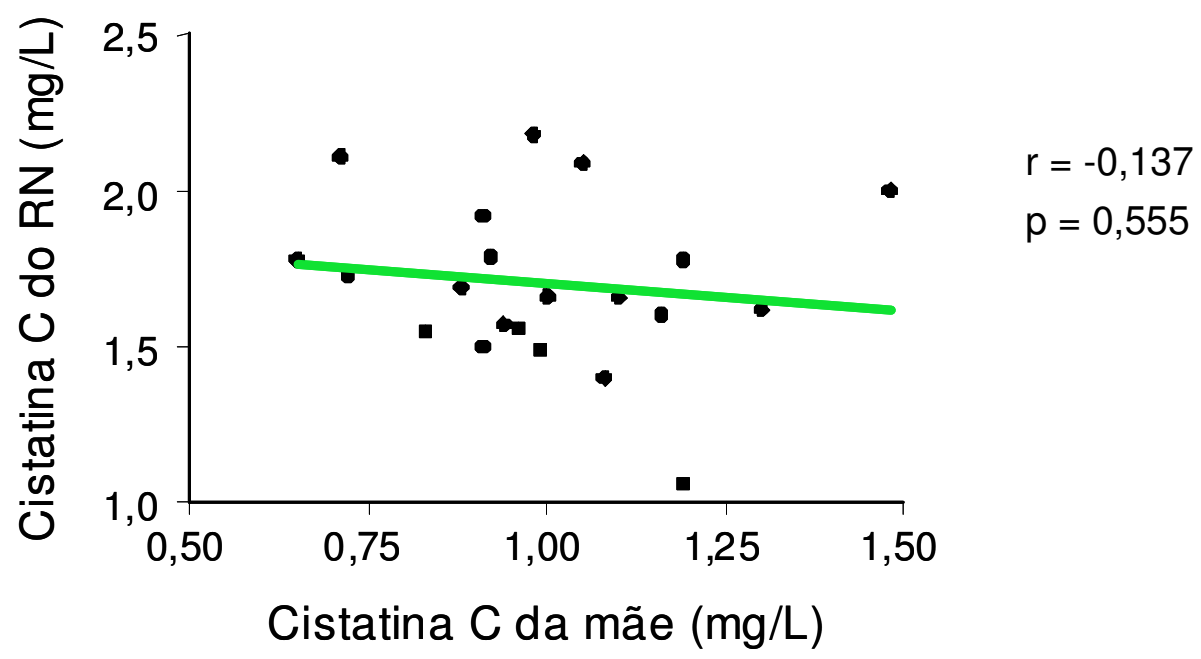




\subsection{Creatinina}

Os níveis de creatinina do $\mathrm{RN}$ no dia 0 não diferiram dos maternos, diminuindo progressivamente até o dia 28, de forma estatisticamente significante (Quadro 7 e Gráfico 5).

Quadro 7 - Níveis de creatinina $(\mathrm{mg} / \mathrm{dL})$ da mãe e do $\mathrm{RN}$ no primeiro mês de vida

\begin{tabular}{ccc}
\hline \multicolumn{2}{c}{ Creatinina } \\
\hline Mãe & Média $\pm d p$ & 0,56 a 0,70 \\
RN & $0,63 \pm 0,15$ & \\
dia 0 & $0,63 \pm 0,15$ & 0,56 a 0,70 \\
dia 3 & $0,48 \pm 0,16$ & 0,41 a 0,55 \\
dia 7 & $0,37 \pm 0,10$ & 0,32 a 0,42 \\
dia 28 & $0,26 \pm 0,05$ & 0,23 a 0,27 \\
\hline
\end{tabular}

mãe $X$ dia $0, p=0,998$; dia $0 X$ dia 3, $p<0,001$; dia $3 X$ dia 7, $p=0,012$;

dia $7 X$ dia 28, $p=0,014$. 
Gráfico 5 - Evolução dos níveis de creatinina $(\mathrm{mg} / \mathrm{dL})$ da mãe e do $\mathrm{RN}$ no primeiro mês de vida (média $\pm 2 \mathrm{dp}$ )

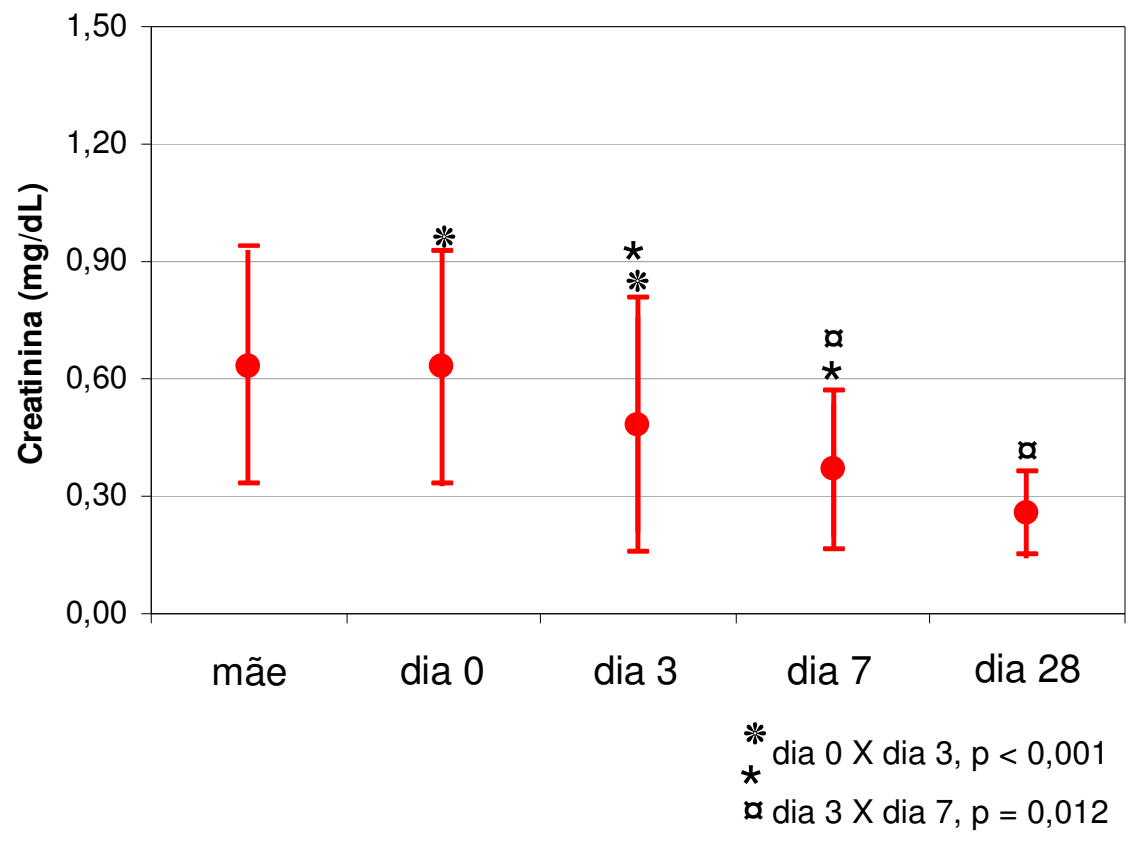

\subsection{Clearance de creatinina}

O clearance de creatinina aumentou ao longo dos 28 dias, também de forma estatisticamente significante (Quadro 8 e Gráfico 6).

Quadro 8 - Clearance de creatinina $\left(\mathrm{mL} / \mathrm{min} / 1,73 \mathrm{~m}^{2}\right)$ do $\mathrm{RN}$ no primeiro mês de vida

\begin{tabular}{|c|c|c|}
\hline \multirow{2}{*}{$\begin{array}{l}\text { Idade } \\
\text { (dias) }\end{array}$} & \multicolumn{2}{|c|}{ Clearance de creatinina } \\
\hline & Média $\pm \mathrm{dp}$ & Intervalo de confiança (95\%) \\
\hline 0 & $36,72 \pm 7,75$ & 32,8 a 39,2 \\
\hline 3 & $52,27 \pm 21,83$ & 42,4 a 61,6 \\
\hline 7 & $65,99 \pm 19,96$ & 56,4 a 73,6 \\
\hline 28 & $97,52 \pm 23,45$ & 86,5 a 107,5 \\
\hline
\end{tabular}

dia $0 X$ dia 3, $p=0,014$; dia $3 X$ dia 7, $p=0,029$; dia $7 X$ dia 28, $p<0,001$. 
Gráfico 6 - Evolução do clearance de creatinina $\left(\mathrm{mL} / \mathrm{min} / 1,73 \mathrm{~m}^{2}\right)$ do RN no primeiro mês de vida (média $\pm 2 \mathrm{dp}$ )

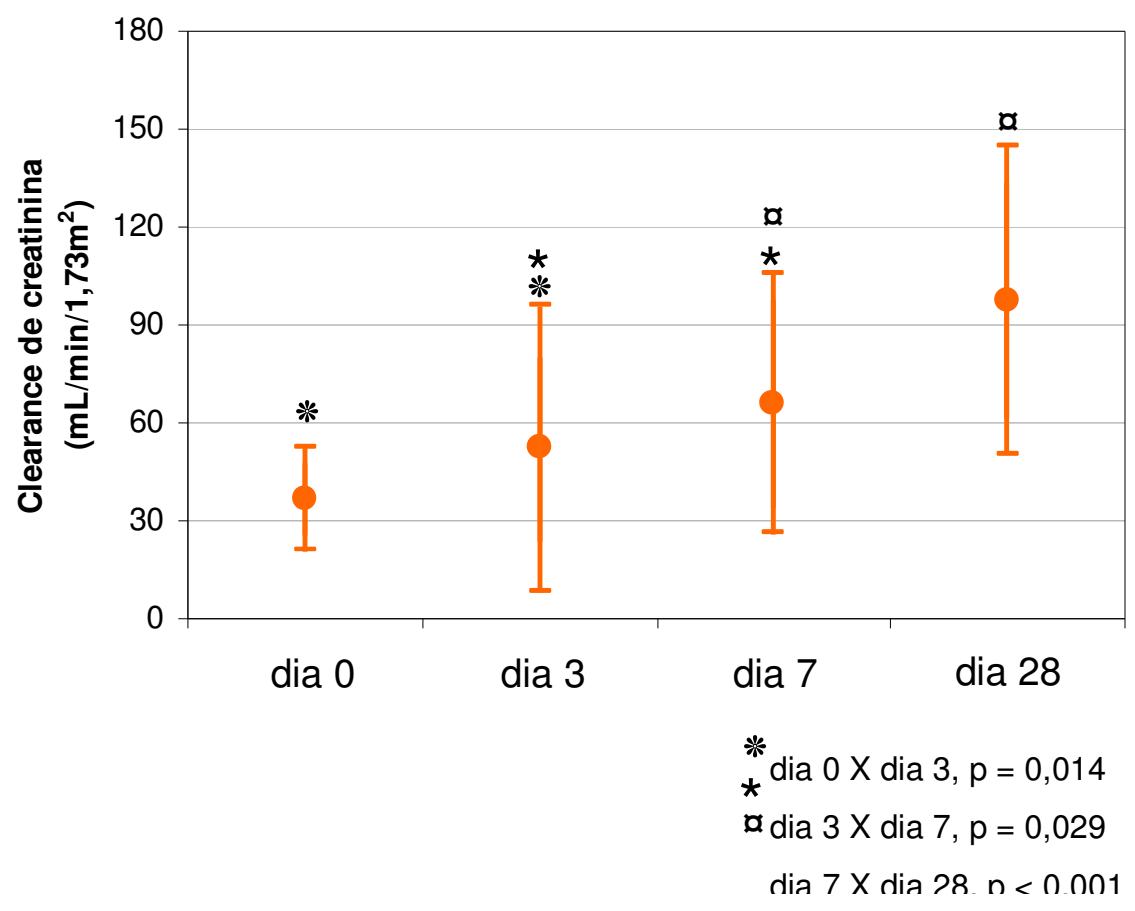

3.4. Evolução comparativa da cistatina $\mathrm{C}$, da creatinina e do clearance de creatinina

Os Gráficos 7 e 8 mostram comparativamente a evolução, ao longo do período neonatal, dos valores da cistatina $\mathrm{C}$ e da creatinina e da cistatina $\mathrm{C}$ e do clearance de creatinina, respectivamente. 
Gráfico 7 - Evolução dos níveis de cistatina C (mg/L) e de creatinina $(\mathrm{mg} / \mathrm{dL})$ do $\mathrm{RN}$ no $1^{\circ}$ mês de vida

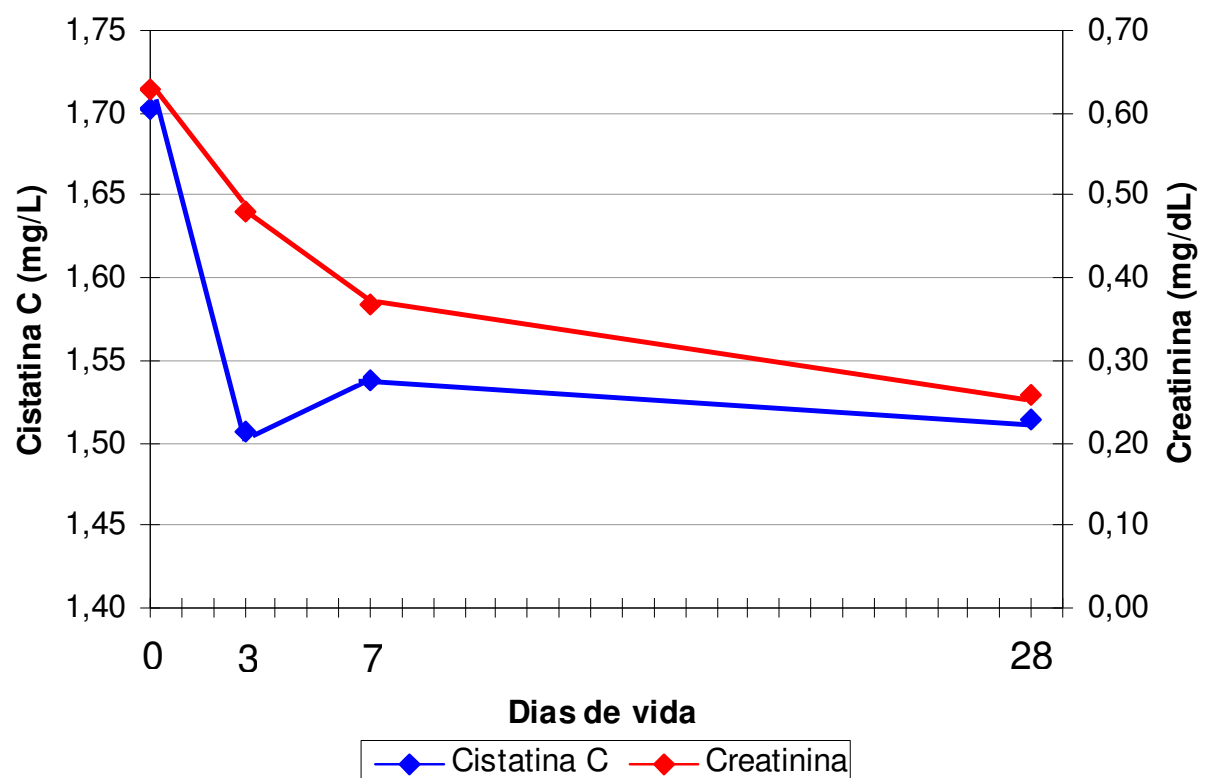

Gráfico 8 - Evolução dos níveis de cistatina C (mg/L) e do clearance de creatinina $\left(\mathrm{mL} / \mathrm{min} / 1,73 \mathrm{~m}^{2}\right)$ do $\mathrm{RN}$ no $1^{\circ}$ mês de vida

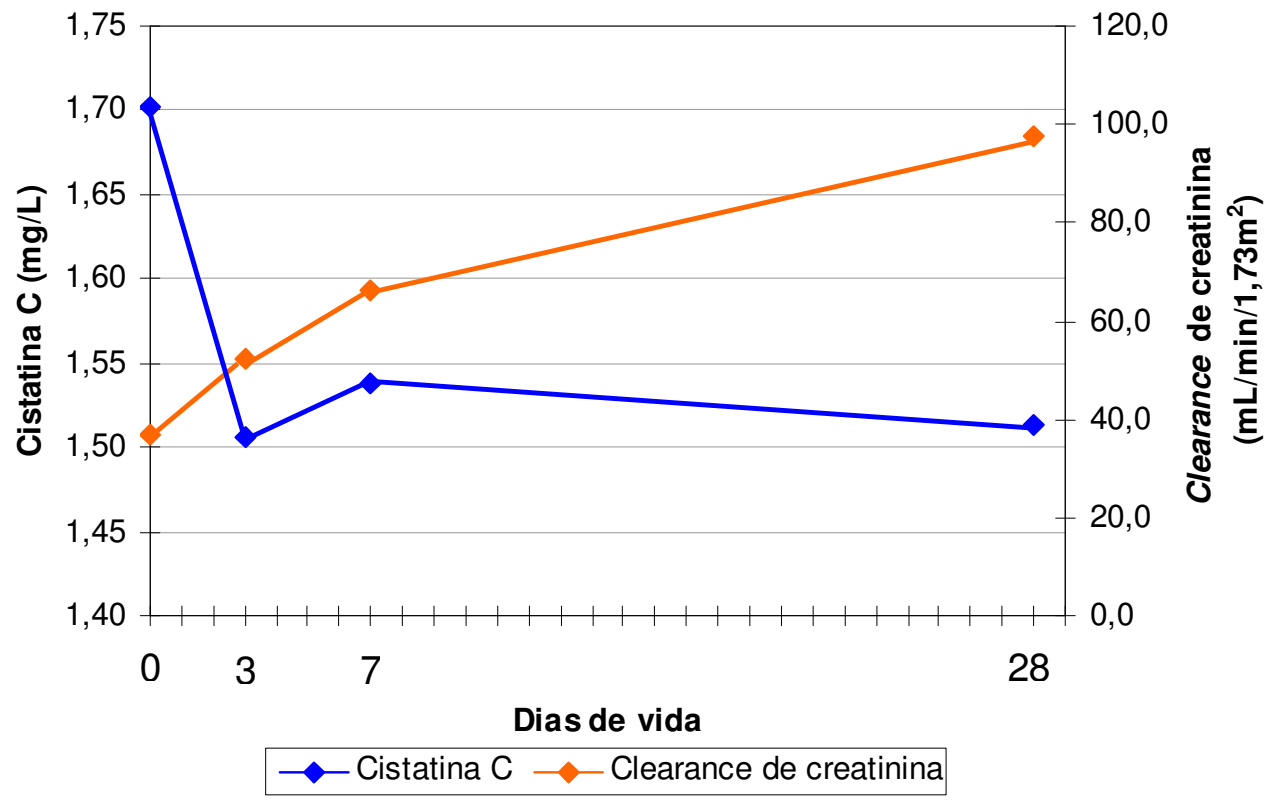




\subsection{Correlações}

A cistatina $\mathrm{C}$ e a creatinina maternas apresentaram correlação positiva $(r=0,537 ; p=0,012)$ (Gráfico 9).
Gráfico 9 - Correlação entre os valores maternos de creatinina e de cistatina C

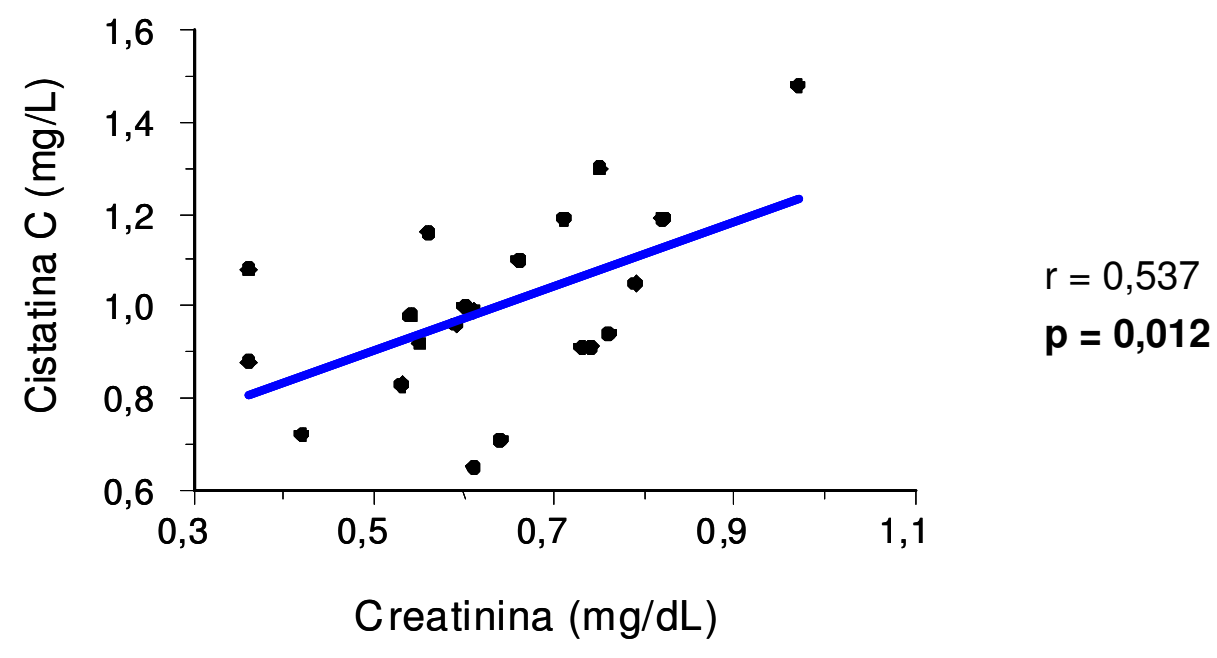

Em relação ao $\mathrm{RN}$, somente foi observada correlação positiva entre a cistatina $C$ e a creatinina nos dias $3(r=0,437 ; p=0,047)$ e $28(r=0,498$; $p=0,002)$ (Gráficos 10 a 13).

Nos dias 0,3 e 7 não se verificou correlação entre a cistatina $C$ e 0 clearance de creatinina do RN. Contudo, foi possível observar correlação negativa no $28^{\circ}$ dia de vida $(r=-0,443 ; p=0,044)$ (Gráficos 14 a 17). 
Gráfico 10 -Correlação entre os valores de cistatina C e de creatinina do RN no dia 0

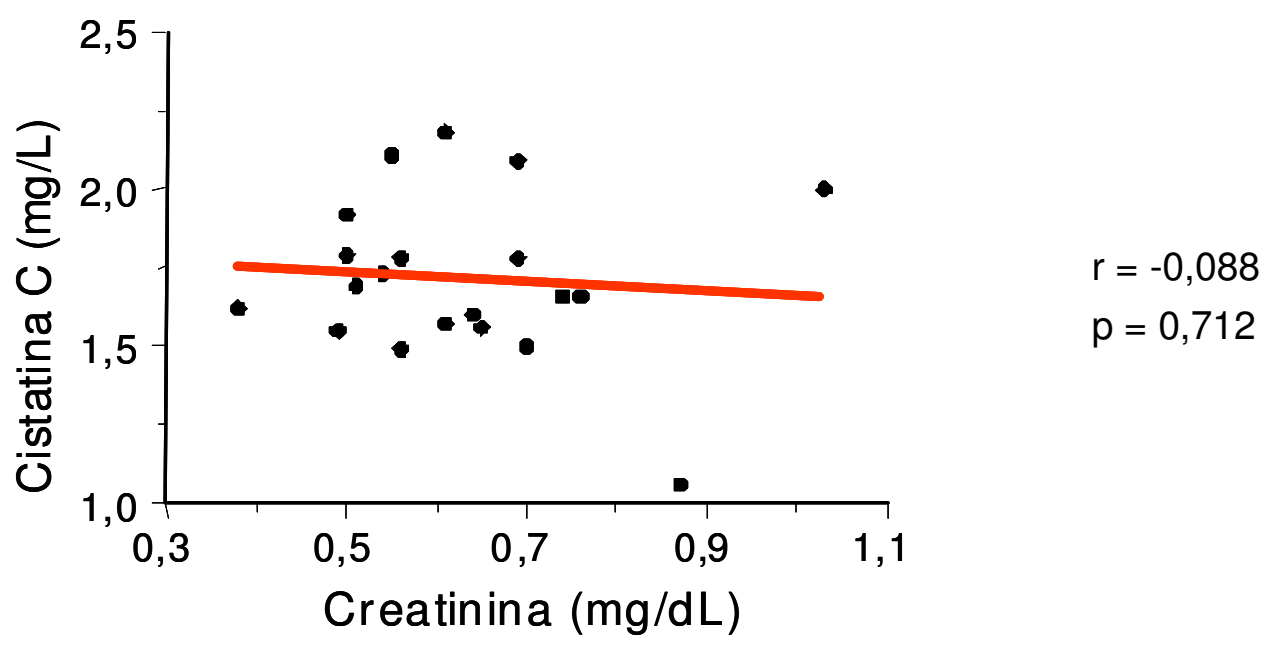

Gráfico 11 - Correlação entre os valores de cistatina C e de creatinina do RN no dia 3

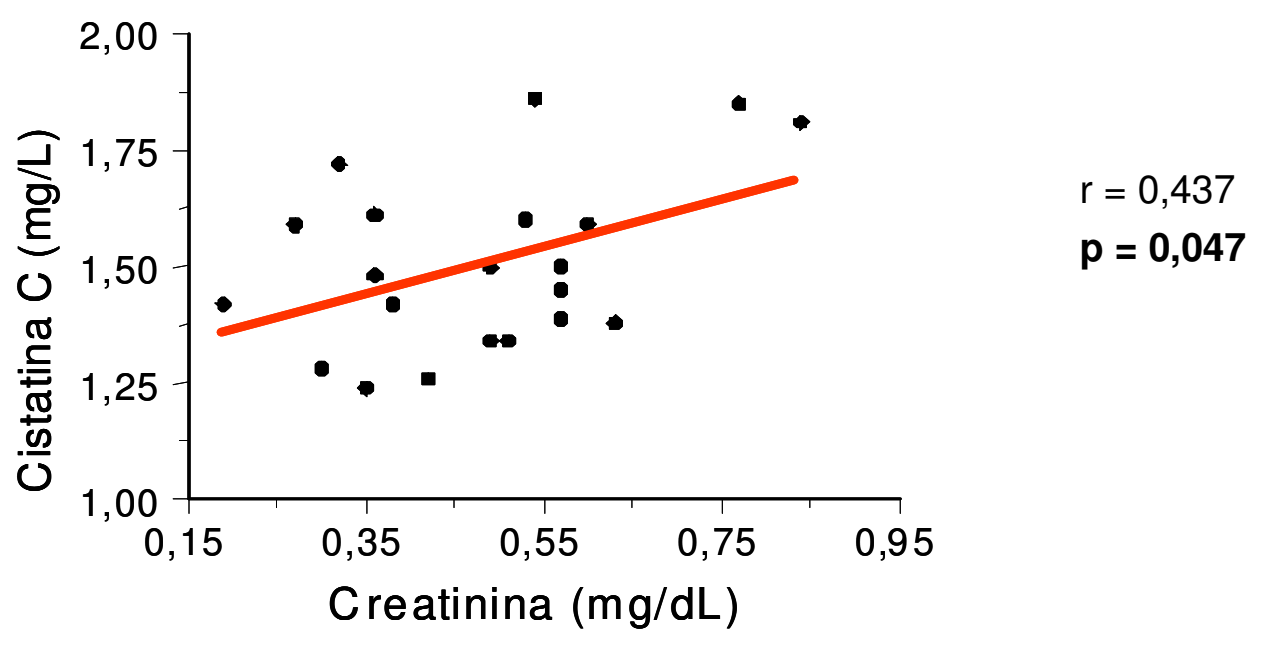


Gráfico 12 - Correlação entre os valores de cistatina C e de creatinina do RN no dia 7

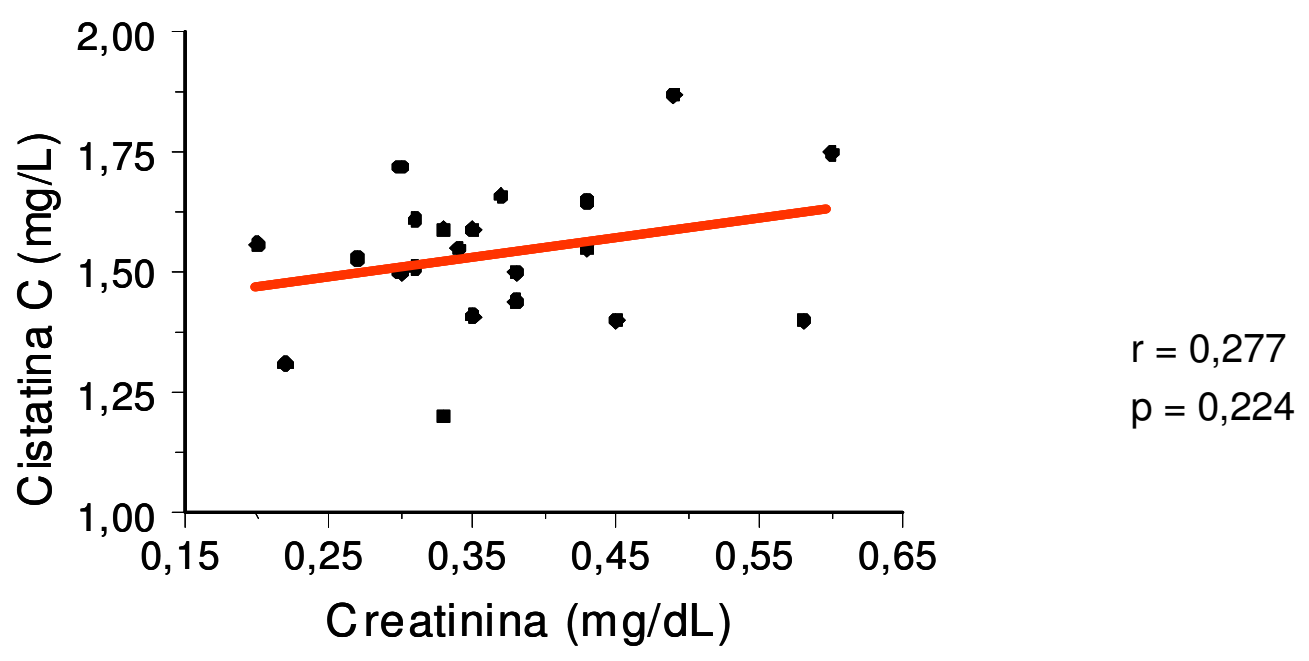

Gráfico 13 - Correlação entre os valores de cistatina C e de creatinina do RN no dia 28

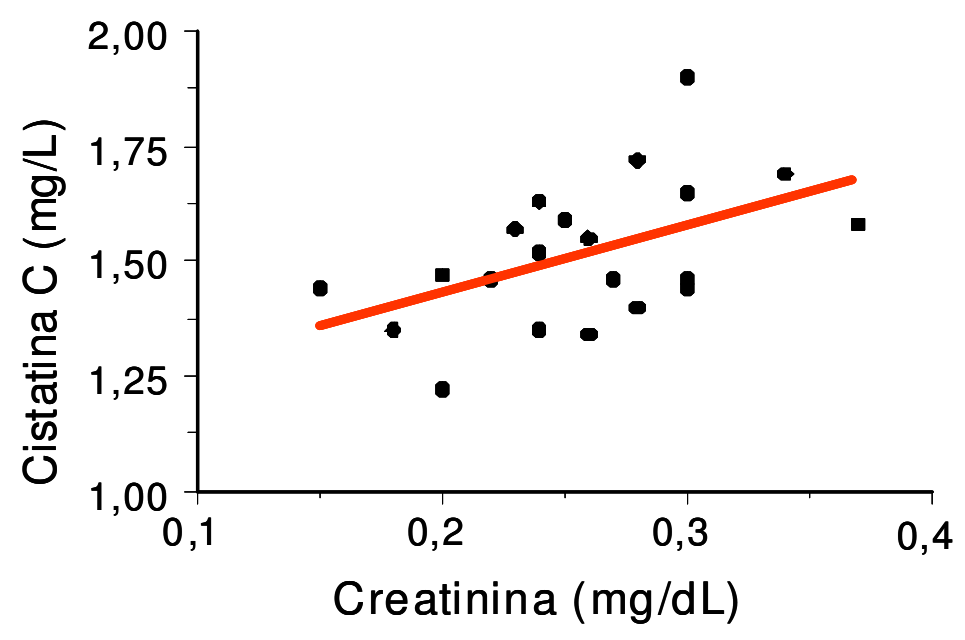

$$
\begin{aligned}
& r=0,498 \\
& p=\mathbf{0 , 0 2 2}
\end{aligned}
$$


Gráfico 14 - Correlação entre os valores de cistatina C e o clearance de creatinina do $\mathrm{RN}$ no dia 0

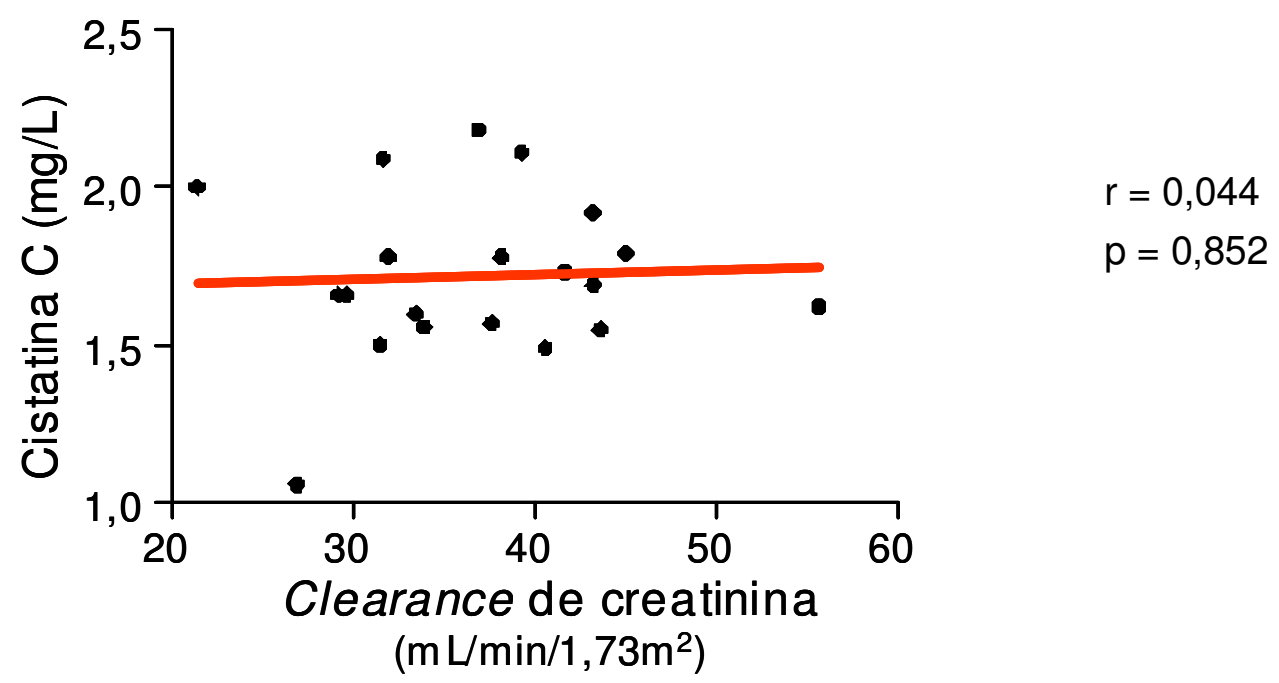

Gráfico 15 - Correlação entre os valores de cistatina C e o clearance de creatinina do RN no dia 3

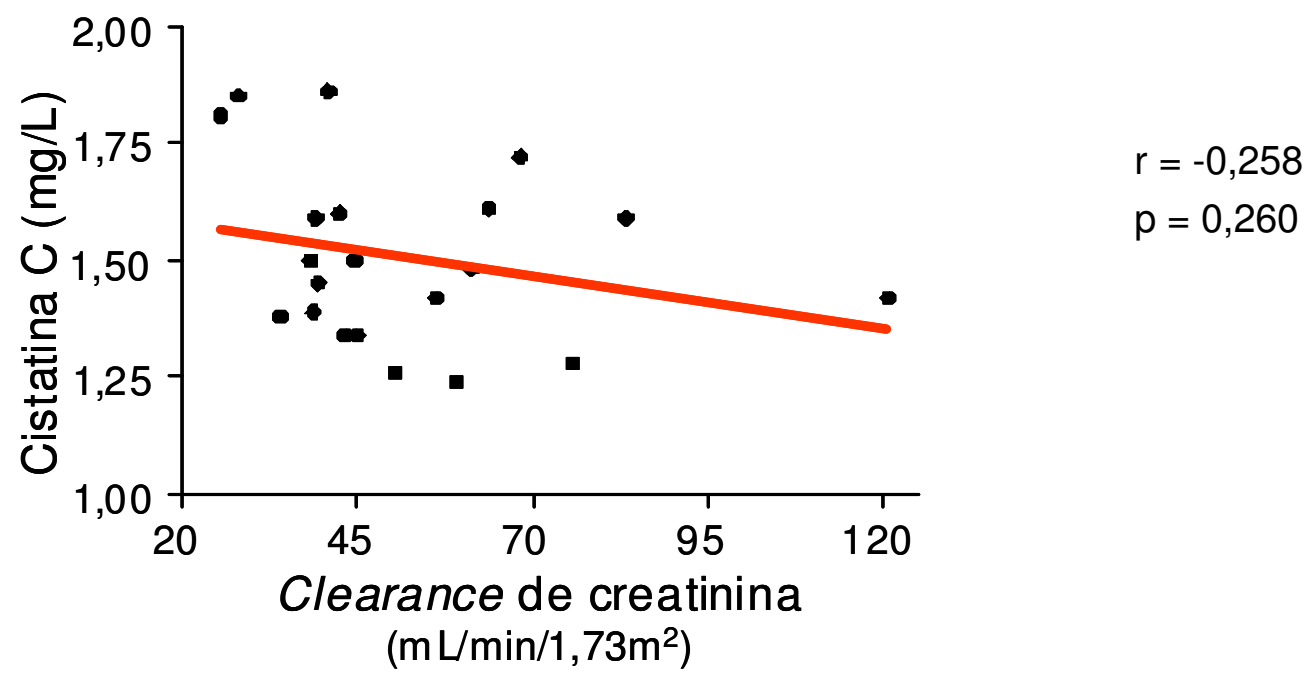


Gráfico 16 - Correlação entre os valores de cistatina C e o clearance de creatinina do $\mathrm{RN}$ no dia 7

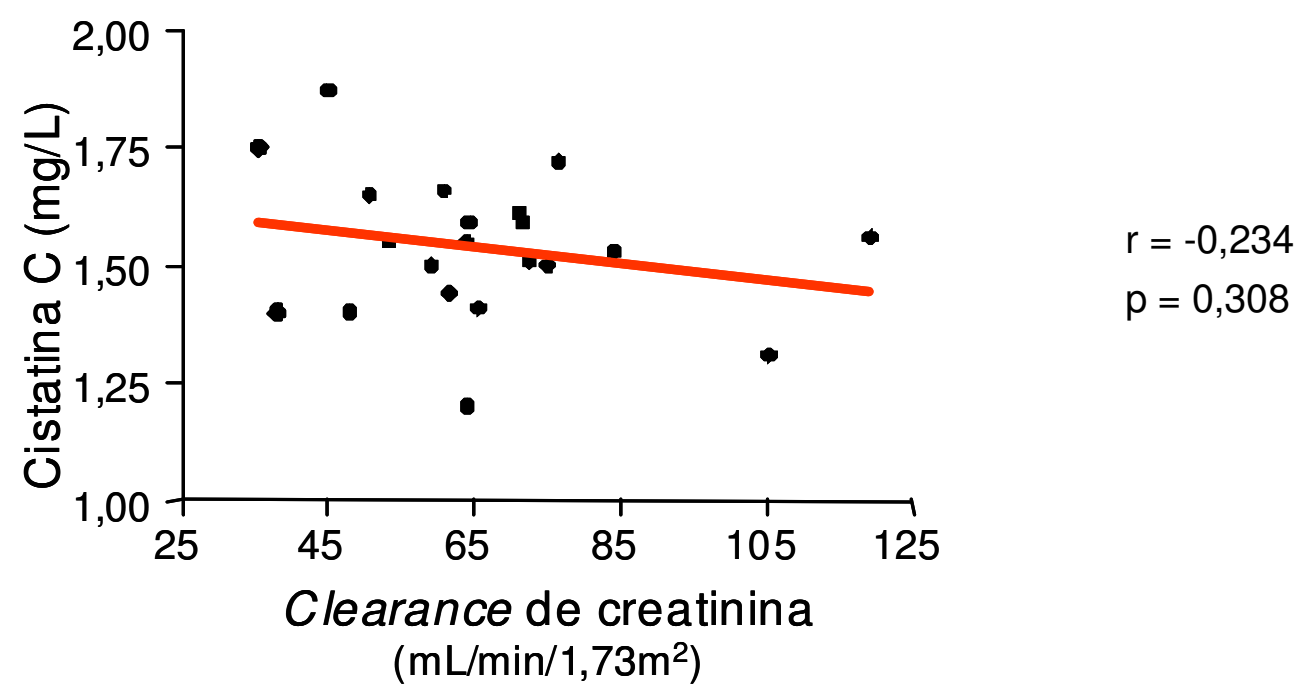

Gráfico 17 - Correlação entre os valores de cistatina C e o clearance de creatinina do $\mathrm{RN}$ no dia 28

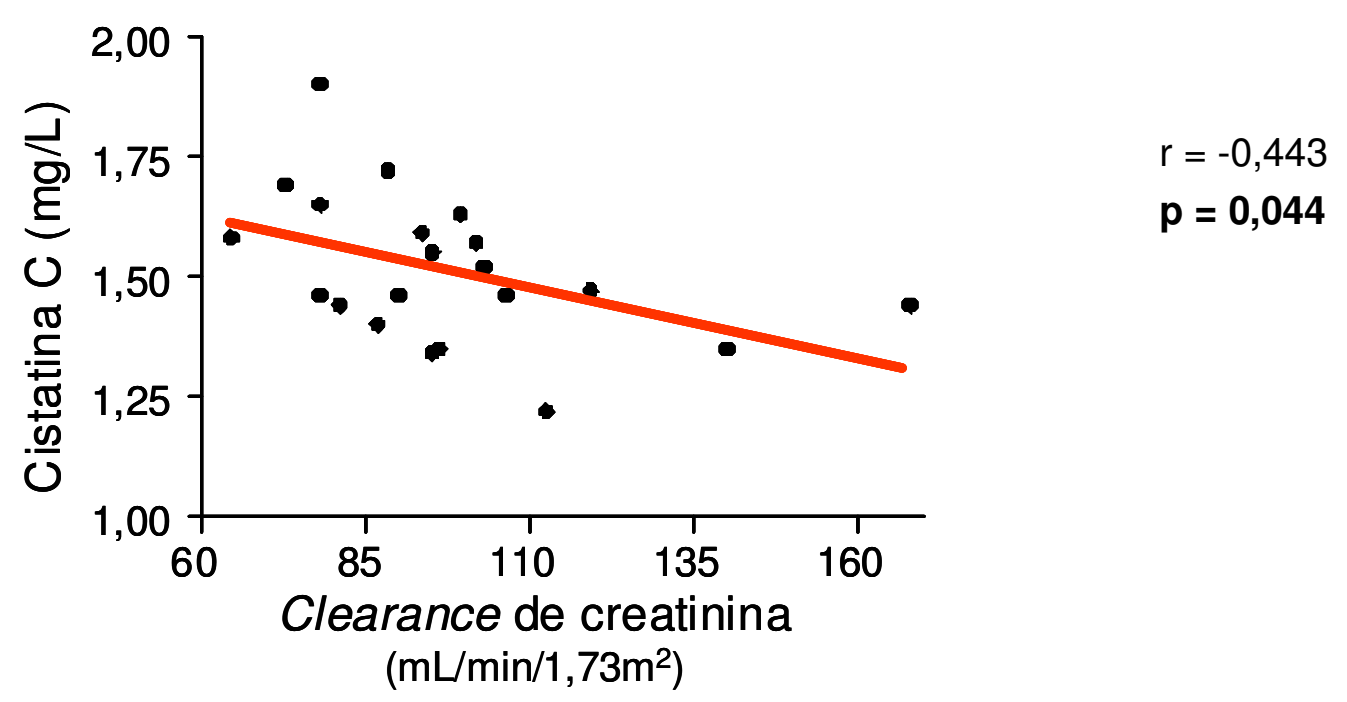


Discussão

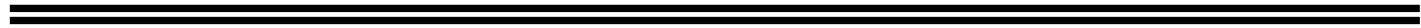


A cistatina C é uma proteína não glicosilada produzida de forma constante por todas as células nucleadas do organismo. Ela é filtrada e metabolizada nos rins, de tal forma que seu nível sérico depende fundamentalmente da filtração glomerular. Uma série de estudos já realizados em adultos e crianças mostrou que a cistatina $C$ sérica apresenta boa correlação com o RFG, o que faz dela um marcador confiável da função renal.

No período neonatal, a avaliação da função renal é realizada principalmente por meio da dosagem de creatinina sérica. Contudo, a creatinina do $\mathrm{RN}$ ao nascimento correlaciona-se diretamente com a creatinina materna. De forma diversa, os níveis séricos de cistatina $C$ do $R N$ parecem não ser influenciados pelos valores maternos. Isto tornaria a cistatina C especialmente útil para avaliação da função renal na primeira semana de vida. No entanto, ainda não há na literatura uma avaliação longitudinal dos níveis séricos da cistatina $\mathrm{C}$ em recém-nascidos de termo sem patologias, durante o período neonatal.

Neste estudo, foi possível selecionar um grupo de $\mathrm{RN}$ de termo saudáveis e verificar que os níveis séricos de cistatina $C$, ao nascimento, não se correlacionaram com os níveis maternos e ficaram estáveis após o $3^{\circ}$ dia de vida. 


\section{Análise do método}

\subsection{Desenho do estudo}

Neste estudo foi estabelecida uma seleção baseada em critérios restritos de inclusão, a fim de que a casuística fosse a mais próxima possível do normal. Além disso, o estudo foi delineado de forma prospectiva, com o intuito de que dados clínicos, como peso, diurese e pressão arterial, pudessem ser avaliados de forma mais fidedigna, para melhor caracterizar a função renal dos RN.

Somente foram incluídos os $\mathrm{RN}$ dos quais foi possível colher todas as amostras programadas, para que se pudesse considerar de forma mais confiável que a variação encontrada dos níveis séricos de cistatina $C$ fosse devida à evolução temporal e não às diferenças individuais.

Optou-se por realizar as dosagens de cistatina C e creatinina ao nascimento, com 3 e 7 dias, pois até o final da primeira semana de vida ocorre estabilização da função renal. A coleta com 28 dias permitiu melhor avaliação desta evolução no período neonatal como um todo.

\subsection{Casuística}

A seleção da casuística foi baseada em critérios restritos de inclusão, a fim de que a população estudada fosse a mais próxima possível do normal, procurando-se excluir todos os $\mathrm{RN}$ que porventura pudessem apresentar 
alteração da função renal.

Ao nascimento, o $\mathrm{RN}$ já traz toda uma história própria. O seu desenvolvimento é resultado das diversas influências às quais foi submetido na vida antenatal. Daí a importância de se excluir fatores que pudessem interferir com a função renal, mesmo que antes do nascimento.

\subsubsection{Idade gestacional}

Foram incluídos apenas RN de termo, dado que ao nascimento o RFG se eleva paralelamente ao aumento da massa renal e se correlaciona diretamente com a idade gestacional. Desta forma, pode-se afirmar que não houve alteração da função renal decorrente de imaturidade renal ${ }^{1,54}$.

\subsubsection{Adequação do crescimento intra-uterino}

O peso de nascimento adequado para a idade gestacional, assim como a não detecção de alteração do crescimento fetal durante a gestação, visaram a exclusão daqueles $\mathrm{RN}$ que porventura tivessem sofrido crescimento intra-uterino restrito (CIUR). O CIUR pode acarretar comprometimento da nefrogênese, menor tamanho renal e menor número de néfrons, o que, por sua vez, estaria possivelmente relacionado a doença renal e hipertensão arterial na vida adulta, não sendo possível descartar alguma influência sobre a filtração glomerular ao nascimento ${ }^{55}$. 
Por outro lado, Malamitsi-Puchner, em estudo comparando RN de termo com e sem CIUR, mostrou que RN com CIUR apresentavam níveis mais baixos de cistatina $\mathrm{C}$, possivelmente por terem menor síntese proteica $^{43}$.

\subsubsection{Condições de nascimento}

Foram incluídos apenas $\mathrm{RN}$ que receberam os cuidados em sala de parto por médico neonatologista, não apresentaram intercorrências no período perinatal e receberam nota de Apgar de $1^{\circ}$ e $5^{\circ}$ minutos maior do que 7. O intuito destes critérios foi garantir a inclusão apenas de RN que não tivessem sofrido asfixia perinatal. O escore de Apgar permite avaliação padronizada do $\mathrm{RN}$ ao nascimento, porém isoladamente um escore baixo não é um marcador conclusivo da asfixia perinatal. Um escore de 7 a 10 no $5^{\circ}$ minuto de vida é considerado normal ${ }^{56,57}$. A asfixia perinatal está muitas vezes associada a disfunção de múltiplos órgãos. Em 1995, Martin-Ancel mostrou, em estudo que incluiu $72 \mathrm{RN}$ de termo com asfixia perinatal grave, que $82 \%$ deles apresentaram comprometimento de pelo menos um órgão. Em $42 \%$ desses $72 \mathrm{RN}$, ocorreu comprometimento renal, em parte pela redistribuição do débito cardíaco que ocorre nesta situação ${ }^{58}$. 


\subsubsection{Má-formação}

Más-formações dos rins ou do trato urinário são relativamente comuns, acometendo de 3 a 6 indivíduos a cada 1000 nascidos vivos. Muitas vezes são assintomáticas ao nascimento e a USG, tanto fetal quanto pós-natal, é recomendada para o diagnóstico destas anomalias. Dada a possibilidade de comprometimento da função renal na presença de má-formação, foi optado por se excluir todos os RN que apresentassem má-formação renal. Também foram excluídos os RN com qualquer má-formação major, devido a sua frequente associação com má-formação renal ${ }^{59}$.

Dos RN incluídos no estudo, 1 apresentou comunicação interatrial e em outro RN foi achada comunicação interventricular. Nenhum deles apresentou repercussão hemodinâmica, que poderia interferir com a função renal.

\subsubsection{Avaliação ultrassonográfica}

Em função principalmente da evolução tecnológica ocorrida nas últimas décadas, a USG obstétrica permite a avaliação do desenvolvimento fetal e a detecção de más-formações. Nesse sentido, para avaliar a acurácia da USG pré-natal para a detecção de más-formações, foi realizado um estudo multicêntrico, prospectivo, que incluiu 4615 casos de más-formações. A sensibilidade para esta detecção foi de 56,2\%. No entanto, quando se considerou apenas as más-formações do sistema urinário, a sensibilidade foi de $88,5 \%{ }^{60}$. 
Uma vez detectada má-formação pela USG fetal, é necessária a investigação pós-natal, que começa pela USG. Teoricamente, nas primeiras horas de vida, poderia ocorrer desidratação relativa por baixa oferta, com baixo débito urinário. Isto acarretaria menor grau de dilatação renal, dificultando a detecção da alteração renal pela USG. Docimo, em 1997, realizou estudo com o intuito de determinar a capacidade de deteç̧ão de alteração renal pela USG realizada nas primeiras 48 horas de vida. Analisando $101 \mathrm{RN}$ com hidronefrose detectada na USG pré-natal, mostrou que, dos RN com USG normal nas primeiras 48 horas de vida, nenhum apresentou hidronefrose ou obstrução com indicação cirúrgica, nem alteração de função renal no primeiro ano de vida ${ }^{61}$.

Os RN deste estudo apresentaram USG pré-natal e pós-natal normais. A USG pós-natal foi realizada entre 24 e 72 horas de vida, período em que não apresentaram nenhuma evidência de hipovolemia ou oligúria. Tudo isso permitiu maior confiabilidade na exclusão de más-formações que pudessem porventura comprometer a função renal.

\subsubsection{Doenças maternas}

A composição do fluido extracelular do feto é regulada pela placenta e não pelo rim fetal, de modo que as concentrações séricas de creatinina do feto e da mãe estão em equilíbrio. Desta forma, ao nascimento, a creatinina do RN reflete a função renal materna. Por esta razão, não foram incluídos os RN cujas mães apresentassem alteração renal, pois estes poderiam 
apresentar dosagens elevadas de creatinina, mesmo com função renal normal ${ }^{1}$.

Também não foram incluídos os RN cujas mães apresentavam hipertensão arterial, fosse ela crônica ou gestacional. A hipertensão acomete 5 a $8 \%$ das gestantes, levando a maior mortalidade e morbidade perinatal, com maior risco de crescimento intra-uterino restrito. Mas também são muitas as possíveis complicações maternas decorrentes da hipertensão, como o comprometimento da função renal. Por outro lado, a disfunção renal aumenta o risco de hipertensão materna ${ }^{62}$.

Apesar de algumas mães incluídas neste estudo apresentarem afecções anteriores à gestação ou agravos durante a gestação, nenhuma apresentou hipertensão ou comprometimento da função renal.

\subsubsection{Fármacos utilizados pela mãe}

O feto em desenvolvimento pode ser afetado pelos fármacos e outros compostos químicos aos quais a mãe é exposta. Eles podem ter ação teratogênica ou levar a disfunção de diferentes órgãos. O efeito da substância sobre cada feto vai depender não só do seu mecanismo de ação propriamente dito, mas também do estágio de desenvolvimento no momento da exposição, da dose utilizada, da suscetibilidade individual e da passagem placentária. Esta última, por sua vez, varia conforme o peso molecular da substância, a lipossolubilidade e a polarização da molécula ${ }^{48,63}$. 
Também pode ocorrer passagem para o leite materno de fármacos ingeridos pela mãe. Esta passagem também depende do peso molecular da substância, da lipossolubilidade e da polarização da molécula, assim como do nível sérico materno ${ }^{48}$.

A L-tiroxina, utilizada por 3 mães deste estudo, apresenta passagem placentária mínima. Sua concentração no leite materno também é muito baixa, não havendo registro de efeitos deletérios para o feto ou $\mathrm{RN}^{48}$.

A zidovudina e a lamivudina são inibidores da transcriptase reversa, que apresentam passagem placentária por difusão simples, mas que não têm efeito teratogênico. As duas podem levar a alterações no desenvolvimento neurocomportamental de ratos. O efeito adverso observado com maior frequência com o uso da zidovudina é a anemia. Também há referência a toxicidade mitocondrial e acidose lática transitória. Quanto ao nelfinavir, um inibidor de protease, não é conhecido se há passagem placentária, mas não são descritos efeitos deletérios ${ }^{48,64,65}$.

A quetiapina é um antipsicótico. Utilizada nas doses habituais, não é teratogênica, nem provoca efeitos adversos no feto. A clorpromazina, utilizada na terapia antipsicótica, é considerada segura para o feto, havendo relato de síndrome extrapiramidal em alguns $\mathrm{RN}$ cujas mães utilizaram a medicação próximo ao nascimento ${ }^{48}$.

O ácido acetilsalicílico passa a placenta e pode levar a alterações de hemostasia e fechamento prematuro do canal arterial. Mas estudos que analisaram o uso de baixas doses (até $100 \mathrm{mg} / \mathrm{dia}$ ) não mostraram efeitos deletérios para o feto ou $\mathrm{RN}^{48}$. 
A heparina e a insulina não passam a placenta, não tendo efeitos sobre o feto. Também não há relato de efeitos adversos do fenoterol ${ }^{48}$.

\subsubsection{Diurese}

A demora para a ocorrência da primeira micção de um $\mathrm{RN}$, assim como o baixo débito urinário, podem ser sinais de hipovolemia ou mesmo de disfunção renal. Mais de $90 \%$ dos $\mathrm{RN}$ de termo saudáveis apresentam a primeira micção nas primeiras 24 horas de vida. O débito urinário depende de vários fatores, como a oferta de água e eletrólitos e a capacidade de concentração urinária dos rins. Para que se mantenha o equilíbrio hidroeletrolítico, após o primeiro dia de vida é necessário débito urinário mínimo de $1 \mathrm{~mL} / \mathrm{kg} / \mathrm{h}$. A oligúria no período neonatal pode ser definida como diurese menor do que $1 \mathrm{~mL} / \mathrm{kg} / \mathrm{h}$ após 24 horas de vida ${ }^{5,54}$.

Todos os RN incluídos neste estudo apresentaram a primeira micção com menos de 12 horas de vida e a diurese, estimada por peso de fralda, foi sempre maior do que $1,3 \mathrm{~mL} / \mathrm{kg} / \mathrm{h}$.

Quanto ao débito urinário, existem várias técnicas para a sua medida. A sondagem vesical permite avaliação bastante fidedigna, porém apresenta riscos, como trauma uretral e infecção. O uso de sacos coletores também pode ocasionar lesões cutâneas no períneo. A estimativa da diurese por pesagem de fraldas é um método não invasivo, mas pode ser menos preciso. Baseia-se no princípio de que $1 \mathrm{~mL}$ de urina pesa $1 \mathrm{~g}$ e que a variação do peso da fralda seja devida à presença de urina. No entanto, a 
diurese pode ser superestimada, pela presença de fezes ou quando o RN está sob umidificação muito elevada, ou subestimada, quando não há umidificação e a temperatura ambiente está elevada ${ }^{66,67}$.

Os RN avaliados neste estudo eram saudáveis e a quantificação da diurese foi realizada somente para o estudo em questão, não por indicação clínica. Assim sendo, não seria eticamente possível utilizar técnica invasiva e potencialmente prejudicial ao $\mathrm{RN}$. Apesar de menos precisa, a pesagem de fraldas permite uma estimativa da diurese suficientemente acurada para afastar a oligúria.

\subsubsection{Evolução do peso}

Em situações de normalidade, os RN perdem 5 a $10 \%$ do peso de nascimento e recuperam esse peso até o final da segunda semana de vida ${ }^{68-70}$. Os RN deste estudo apresentaram evolução ponderal dentro destes parâmetros de normalidade. Eles também chegaram ao final do primeiro mês de vida com peso e estatura entre o percentil 5 e 95 das curvas de crescimento do National Center for Health Statistics ${ }^{53}$.

Estes dados são importantes para afastar possível baixa oferta hídrica e calórica, que poderia, principalmente nos primeiros dias de vida, determinar hipovolemia e possivelmente alteração da função renal do RN. Por outro lado, a evolução ponderal inadequada pode ser um dos primeiros sinais de que o RN apresenta alguma intercorrência. Assim, o crescimento e 
ganho de peso adequados corroborariam o diagnóstico de normalidade destas crianças.

\subsubsection{Pressão arterial}

Foram excluídos do estudo os RN que apresentassem, nos controles realizados, pressão arterial fora dos parâmetros considerados normais.

A hipotensão pode acarretar diminuição da pressão de perfusão renal e, consequentemente, da filtração glomerular ${ }^{4}$. Por sua vez, a hipertensão arterial pode estar associada a disfunção renal. No período neonatal, a hipertensão é geralmente secundária, sendo as causas mais frequentes a trombose de artéria renal, a má-formação renal, a coarctação de aorta e a displasia broncopulmonar ${ }^{71}$.

Em relação à medida de pressão arterial, existem algumas formas: direta, de forma invasiva, através de cateter arterial umbilical ou radial, ou indireta.

A medida indireta da pressão arterial baseia-se no princípio de que a compressão da artéria braquial por um manguito inflável permite a determinação da pressão intra-arterial. Existem várias técnicas para fazer esta medida. Os métodos auscultatórios baseiam-se na associação entre os sons de Korotkoff e as pressões sistólica e diastólica. Por outro lado, a oscilometria é baseada no princípio de que o fluxo sanguíneo através da artéria cria oscilações da parede arterial. A pressão arterial média é, então, medida de acordo com a amplitude das oscilações detectadas. A partir do 
valor medido de pressão arterial média, são calculadas as pressões sistólica e diastólica, utilizando-se para isso algoritmos específicos em um microprocessador. O primeiro aparelho oscilométrico foi desenvolvido na década de 1970 e foi denominado DINAMAP, um acrônimo para "device for indirect noninvasive mean arterial pressure" ${ }^{, 2,73}$.

O padrão de normalidade considerado foi baseado nas curvas de pressão arterial sistólica e diastólica, segundo a idade gestacional corrigida, conforme descrito por Zubrow. Este autor analisou $600 \mathrm{RN}$, usando aparelhos oscilométricos DINAMAP para medir a pressão arteriall $^{49}$.

Neste estudo foi utilizado o aparelho DINAMAP® Pro-100, que permite a determinação da insuflação a ser utilizada, evitando compressão excessiva pelo manguito, que provocaria desconforto ao $\mathrm{RN}$ e levaria a possível erro de medida. A medida da pressão arterial foi feita com a mesma técnica e com aparelho equivalente ao descrito por Zubrow. Assim, foi possível ter maior confiabilidade quanto à normalidade da pressão arterial aferida.

\subsubsection{Evolução no período neonatal}

Além dos casos já descritos de oligúria, perda de peso excessiva ou ganho de peso inadequado e hipo ou hipertensão, foram excluídos todos os RN que apresentassem outras intercorrências que pudessem acarretar alguma interferência direta na função renal ou na sua avaliação ou no equilíbrio hemodinâmico.

Os RN sob fototerapia apresentam aumento do fluxo sanguíneo 
periférico, que pode levar a aumento na perda de água insensível. Também podem apresentar maior perda de água nas fezes. Esta, se não for compensada por maior oferta hídrica, pode levar a hipovolemia ${ }^{74,75}$.

Quando há necessidade de hidratação intravenosa, a oferta hídrica e nutricional que o RN recebe poderá ocasionar variações em sua volemia.

$\mathrm{Na}$ vigência de quadros infecciosos de maior gravidade, com liberação de mediadores da resposta inflamatória, assim como em cardiopatias descompensadas, também pode ocorrer desequilíbrio hemodinâmico.

\subsubsection{Fármacos utilizados pelos $R N$}

Alguns fármacos interferem na avaliação da função renal, como a cimetidina, que inibe competitivamente a secreção tubular de creatinina ${ }^{4}$. Também não foram incluídos $\mathrm{RN}$ que utilizaram diuréticos, os quais têm ação direta sobre os rins, ou fármacos vasopressivos, que atuam sobre o equilíbrio hemodinâmico do $\mathrm{RN}$.

Apenas $1 \mathrm{RN}$ fez uso de um fármaco, a zidovudina, durante o período de estudo. O efeito adverso mais frequente da zidovudina é a anemia, mas pode ocorrer comprometimento de toda a hematopoiese. Também é descrita toxicidade mitocondrial, esteatose hepática, pancreatite e maior incidência de convulsão febril ${ }^{64,65,76}$. No entanto, não existem relatos de alteração da função renal em decorrência de seu uso. 


\subsubsection{Alteração da função tireoidiana}

Os níveis séricos de cistatina $C$ podem alterar-se na vigência de disfunção tireoidiana, possivelmente por influência direta do hormônio tireoidiano na taxa de produção desta proteína ${ }^{16,17}$.

A triagem neonatal foi realizada pela dosagem do TSH em papel de filtro. Caso o TSH estivesse elevado, seria realizada nova coleta com dosagem plasmática do TSH e da tiroxina (T4). Isto não ocorreu, pois a coleta do sangue para a primeira dosagem em papel de filtro foi realizada entre 48 e 96 horas de vida, o que torna o número de casos falso-negativos praticamente desprezível ${ }^{77}$.

\subsection{Avaliação laboratorial}

Não há na literatura referência a diferença entre os níveis arteriais ou

venosos de cistatina C. Contudo, a coleta das amostras de sangue foi realizada sempre em veia umbilical ou veia periférica, para que houvesse maior uniformidade.

Também a técnica de coleta das amostras foi cuidadosa, no sentido de que não houvesse hemólise, que poderia interferir com a dosagem da cistatina C. Apesar de $61,9 \%$ dos RN apresentarem icterícia, a presença de bilirrubina não interfere com a dosagem de cistatina $C^{10}$.

Todas as dosagens de creatinina e cistatina $\mathrm{C}$ foram realizadas por um mesmo profissional capacitado e em um mesmo momento, de forma a 
minimizar possíveis alterações nas medidas, decorrentes de fatores externos. O resultado destes cuidados pode ser verificado pelo baixo desviopadrão obtido neste estudo para os valores de cistatina C nas diversas amostras. Ele variou de 0,15 a 0,26 mg/L, enquanto na literatura, para $\mathrm{RN}$ de termo no período neonatal, os valores de desvio-padrão encontrados variam de 0,26 a $0,44 \mathrm{mg} / \mathrm{L}^{39-42}$.

O método utilizado para a dosagem foi a nefelometria. Estudo comparativo entre a dosagem por nefelometria e por turbidimetria mostrou que, na nefelometria, a correlação entre o RFG e a cistatina $C$ é significantemente mais forte ${ }^{22}$.

\subsection{Clearance de creatinina}

A creatinina sérica é usualmente utilizada como indicador do RFG. Contudo, apesar de seus níveis variarem inversamente com o RFG, esta relação não é tão direta em crianças. Com o crescimento, ocorre elevação da creatinina, mesmo com função renal normal, uma vez que a creatinina depende não só do RFG, mas também da massa muscular do indivíduo.

O valor do clearance de creatinina, por sua vez, é corrigido para uma superfície corpórea de 1,73 $\mathrm{m}^{2}$, o que facilita a comparação entre indivíduos de diferentes tamanhos. Além disso, é mais fácil detectar alterações quando se utilizam números grandes, como os do clearance, do que pequenos, como os da creatinina. Por exemplo, a diminuição de $40 \mathrm{~mL} / \mathrm{min} / 1,73 \mathrm{~m}^{2}$ no 
clearance de creatinina corresponde a uma elevação de apenas $0,2 \mathrm{mg} / \mathrm{dL}$ no valor da creatinina ${ }^{7}$.

A fórmula de Schwartz permite estimar o clearance de creatinina a partir da creatinina sérica e de parâmetros associados ao tamanho corporal (comprimento) e à idade (constante $\mathrm{k}$ ). A constante $\mathrm{k}$ é função da quantidade de creatinina excretada na urina por unidade de superfície corpórea. Ela é diretamente proporcional ao componente muscular do peso corpóreo. Em indivíduos com composição corpórea normal, sem excesso de massa muscular, desnutrição ou obesidade, o clearance de creatinina estimado pela fórmula de Schwartz apresenta boa correlação com o clearance de inulina e com o clearance de creatinina medido ${ }^{7}$.

\section{Análise dos resultados}

Neste estudo, a cistatina $\mathrm{C}$ do $\mathrm{RN}$ foi maior ao nascimento, reduzindose a seguir até $03^{\circ}$ dia e depois manteve níveis constantes, sempre maiores do que os maternos. Alguns autores já procuraram determinar os valores normais da cistatina $\mathrm{C}$ em $\mathrm{RN}$ de termo, no período neonatal: Bökenkamp (1998) - 1,64 a 2,59 mg/L de 0 a 3 dias e 1,52 a 2,40 de 3 a 30 dias; Finney (2002) - 0,81 a 2,32 mg/L de 0 a 3 meses; Harmoinen (2000) - 1,36 a 2,23 mg/L de 0 a 7 dias; Bahar (2003) - 0,69 a 2,43 mg/L no cordão e 0,78 a 2,40 mg/L com 3 dias; Treiber (2006) - 1,97 \pm 0,36 mg/L no cordão e 1,93 \pm 0,33 $\mathrm{mg} / \mathrm{L}$ no $3^{\circ}$ dia e Jedrasiak $(2007)-1,65 \pm 0,44 \mathrm{mg} / \mathrm{L}$ no cordão umbilical $^{33,34,39-42}$. Os resultados aqui obtidos estão contidos em cada uma 
destas faixas, que são muito amplas, uma vez que as faixas de idade nem sempre são tão restritas e os critérios de inclusão para garantir a normalidade da função renal não foram tão rigorosos como os aqui utilizados. Além disso, como consequência deste rigor, a variabilidade dos níveis de cistatina $\mathrm{C}$ neste estudo foi muito pequena.

Outro indicador de função renal avaliado foi a concentração de creatinina sérica. Os valores obtidos, dentro da faixa de normalidade, reforçam a normalidade da função renal dos $\mathrm{RN}$ estudados. Ao nascimento, a creatinina foi igual à materna, diminuindo progressivamente até o $28^{\circ}$ dia. Estes resultados estão de acordo com os valores normais de creatinina sérica (média $\pm \mathrm{dp}$ ) para $\mathrm{RN}$ de termo encontrados na literatura: Rudd (1983) - 0,85 $\pm 0,21 \mathrm{mg} / \mathrm{dL}$ com 2 dias, 0,56 \pm 0,20 mg/dL com 7 dias, 0,43 \pm $0,11 \mathrm{mg} / \mathrm{dL}$ com 14 dias, $0,40 \pm 0,11 \mathrm{mg} / \mathrm{dL}$ com 21 dias e 0,34 \pm $0,10 \mathrm{mg} / \mathrm{dL}$ com 28 dias (valores originalmente em $\mu \mathrm{mol} / \mathrm{L}$ ); Brion (1986) $0,5 \pm 0,1 \mathrm{mg} / \mathrm{dL}$ com 1 semana e 0,4 $\pm 0,1 \mathrm{mg} / \mathrm{dL}$ de 2 a 8 semanas; Bueva (1994) - 0,75 $\pm 0,03 \mathrm{mg} / \mathrm{dL}$ com 1 a 2 dias, 0,45 $\pm 0,04 \mathrm{mg} / \mathrm{dL}$ com 8 a 9 dias, 0,34 \pm 0,09 mg/dL com 15 a 16 dias e 0,31 $\pm 0,08 \mathrm{mg} / \mathrm{dL}$ com 22 a 23 dias (valores originalmente em $\mu \mathrm{mol} / \mathrm{L}$ ) e Awad (2002) - 0,79 $\pm 0,14 \mathrm{mg} / \mathrm{dL}$ com 1 dia e $0,77 \pm 0,19 \mathrm{mg} / \mathrm{dL}$ com 3 dias $^{78-81}$.

Em relação aos níveis de cistatina $C$ maternos, à semelhança do que ocorreu com os do RN, eles foram compatíveis com os valores descritos por Cataldi (variação de 0,64 a 2,30 mg/L) e por Babay $(0,94 \pm 0,12 \mathrm{mg} / \mathrm{L}$, média $\pm d p)^{44,82}$.

A creatinina da mãe também ficou dentro dos valores normais citados 
na literatura. Nas gestações normais tem sido descrito aumento do RFG, o que leva a diminuição de 20 a 30\% nos valores da creatinina sérica. Lain, em 2005, estudando 63 gestantes, encontrou valores de creatinina de 0,57 $\pm 0,03 \mathrm{mg} / \mathrm{dL}$ (média $\pm \mathrm{dp}$ ) no final do terceiro trimestre de gestação e nas primeiras 24 horas pós-parto ${ }^{83,84}$.

No nosso estudo, observou-se correlação positiva entre a creatinina e a cistatina $\mathrm{C}$ maternas, o que era esperado, uma vez que várias pesquisas já mostraram a acurácia da cistatina C para estimar o ritmo de filtração glomerular e sua correlação com a creatinina $22-25,36,38$.

A análise da creatinina e da cistatina C maternas permitem, ainda, afirmar que estas mães realmente apresentavam função renal normal.

A cistatina $\mathrm{C}$ materna foi diferente e não apresentou correlação com a do $\mathrm{RN}$ ao nascimento, à semelhança do que já havia sido descrito por Cataldi $^{44}$. Isto sugere que a concentração sérica de cistatina $\mathrm{C}$ do $\mathrm{RN}$ devese mais à síntese e metabolização da proteína pelo próprio $\mathrm{RN}$ do que à passagem placentária.

Por outro lado, a creatinina materna não foi diferente da do $\mathrm{RN}$ ao nascimento, o que era esperado. A creatinina, assim como outros solutos hidrofílicos não eletrolíticos de baixo peso molecular, passa do feto para a mãe e vice-versa, por difusão passiva através do sinciciotrofoblasto, por via transcelular. Deste modo, os valores séricos de creatinina ao nascimento costumam ser semelhantes aos maternos ${ }^{85,86}$.

Quanto à avaliação da evolução da função renal do $\mathrm{RN}$, foram realizados alguns estudos durante o primeiro mês de vida utilizando o 
clearance de inulina. Além de apresentar boa correlação com a idade gestacional $(r=0,81)$ e com a idade gestacional pós-conceptual $(r=0,89), o$ clearance de inulina aumenta progressivamente com o passar dos dias, chegando a dobrar de valor pelo $14^{\circ}$ dia de vida ${ }^{28,87,88}$. Em alguns estudos em RN, também foi realizado simultaneamente o clearance de inulina e de creatinina e foi possível mostrar boa correlação entre eles ${ }^{8,89}$.

Quando se analisou a evolução da creatinina plasmática ao longo do período neonatal, observou-se que houve redução progressiva de seus níveis. Por sua vez, o clearance de creatinina, estimado pela fórmula de Schwartz, aumentou, conforme esperado ${ }^{3,4,78,80}$. Esta variação é explicada não só pelo término da influência materna, mas também pelo aumento do RFG do RN.

Já em relação à evolução da cistatina $\mathrm{C}$ no $\mathrm{RN}$, verificou-se nível mais elevado ao nascimento, diminuindo até $\circ 3^{\circ}$ dia e estabilizando-se a partir de então, embora com níveis sempre maiores do que os maternos. Se os níveis séricos de cistatina $C$ fossem reflexo apenas do RFG, seria de se esperar que houvesse diminuição progressiva ao longo de todo o período neonatal, compatível com a elevação do RFG, o que não ocorreu em nossos resultados.

O comportamento dos níveis de cistatina C sérica verificados nesta pesquisa diverge do esperado, se considerarmos a evolução do RFG medido pelo clearance de inulina que, sabidamente, aumenta ao longo do período neonatal. Estes resultados sugerem a necessidade de realização de estudos que possam identificar outras interferências sobre esses níveis. 
Dentre estas, poderão estar variações na síntese da cistatina $C$ ou até a existência de outra via metabólica secundária, ainda não conhecida.

Além disso, foi possível verificar correlação positiva entre cistatina $\mathrm{C}$ e creatinina apenas no $3^{\circ}$ e $28^{\circ}$ dias e correlação negativa entre cistatina $\mathrm{C}$ e clearance de creatinina somente no $28^{\circ}$ dia de vida.

A ausência de correlação no $7^{0}$ dia pode ter sido devida a influência da creatinina materna, uma vez que na primeira semana de vida a creatinina do RN não depende somente da função renal deste. Ela também é reflexo da creatinina materna e, consequentemente, da função renal da mãe. Já as correlações observadas no $28^{\circ}$ dia de vida podem ser explicadas pelo fato de que, neste momento, a cistatina $C$ e a creatinina refletem o RFG. Contudo, apesar de significativas, estas correlações não são fortes. 


\section{Considerações finais}

Este trabalho permitiu determinar a evolução da cistatina $\mathrm{C}$ ao longo do período neonatal de forma controlada. Assim, é possível afirmar que os resultados aqui apresentados correspondem aos níveis séricos de cistatina C em RN de termo saudáveis.

A falta de correlação com outros indicadores e a evolução ao longo do primeiro mês de vida, diferente da evolução do clearance de inulina, sugerem a possibilidade de influência de outros fatores, diversos do RFG, sobre os valores séricos da cistatina $C$ durante o período neonatal. Ainda serão necessários mais estudos para confirmar a existência de tais fatores e permitir sua caracterização. 
Conclusões

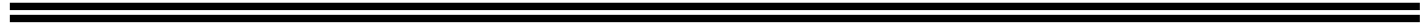


1. Em recém-nascidos de termo saudáveis, os níveis séricos de cistatina $\mathrm{C}$ :

1.1. foram significativamente mais elevados, ao nascimento, do que os maternos;

1.2. reduziram-se significativamente do nascimento até $03^{\circ}$ dia de vida;

1.3. permaneceram estáveis entre $03^{\circ}$ e $028^{\circ}$ dias de vida.

2. Houve correlação entre os níveis séricos maternos de cistatina $\mathrm{C}$ e de creatinina.

3. Os níveis séricos de cistatina $C$ no recém-nascido correlacionaram-se:

3.1. com os níveis de creatinina sérica no $3^{\circ}$ e no $28^{\circ}$ dias de vida;

3.2. com o clearance de creatinina no $28^{\circ}$ dia de vida. 
Anexos

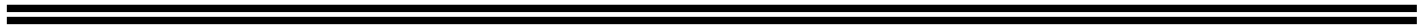




\section{Anexo A - Aprovação da Comissão de Ética}

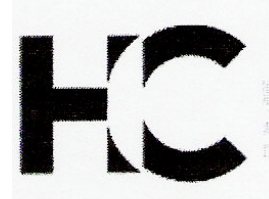

\section{APROVAÇÃO}

A Comissão de Ética para Análise de Projetos de Pesquisa - CAPPesq da Diretoria Clínica do Hospital das Clínicas e da Faculdade de Medicina da Universidade de São Paulo, em sessão de 24.03.05, APROVOU c Protocolo de Pesquisa $n^{\circ}$ 007/05, intitulado: "Evolução dos níveis séricos de cistatina $C$ em recém-nascidos de termo saudáveis, ao longo do primeiro mês de vida" apresentado pelo Departamento de PEDIATRIA, inclusive o Termo de Consentimento Livre e Esclarecido.

Cabe ao pesquisador elaborar e apresentar à CAPPesq, os relatórios parciais e final sobre a pesquisa (Resolução do Conselho Nacional de Saúde $n^{\circ} 196$, de 10.10.1996, inciso IX.2, letra "c").

Pesquisador(a) Responsável: Profa. Dra. Cléa Rodrigues Leone

Pesquisador(a) Executante: Dra. Ana Carolina de A Cavalcanti Ferreira Novo CAPPesq, 24 de Março de 2005.

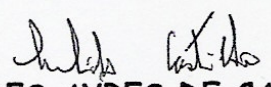

PROF. DR. EUCLIDES AYRES DE CASTILHO

Presidente da Comissão de Ética para Análise de Projetos de Pesquisa 


\section{Anexo B - Termo de consentimento livre e esclarecido}

\section{HOSPITAL DAS CLÍNICAS}

DA

FACULDADE DE MEDICINA DA UNIVERSIDADE DE SÃO PAULO

\section{TERMO DE CONSENTIMENTO LIVRE E ESCLARECIDO}

(Instruções para preenchimento no verso)

\section{I - DADOS DE IDENTIFICAÇÃO DO SUJEITO DA PESQUISA OU RESPONSÁVEL LEG^}

1. NOME DO PACIENTE .

DOCUMENTO DE IDENTIDADE № :

SEXO: $\mathrm{M} \square$ F $\square$ NASCIMENTO

APTO:

ENDEREÇO

№

CIDADE

BAIRRO

TELEFONE:DDD

..)

2.RESPONSÁVEL LEGAL

NATUREZA (grau de parentesco, tutor, curador etc.)

DOCUMENTO DE IDENTIDADE :

SEXO: $\mathrm{M} \square \mathrm{F} \square$ NASCIMENTO: ............

ENDEREÇO

BAIRRO:

№

CIDADE:

CEP

TELEFONE:DDD

)...

APTO:

\section{II - DADOS SOBRE A PESQUISA CIENTÍFICA}

1. TÍTULO DO PROTOCOLO DE PESQUISA:

Evolução dos níveis séricos de cistatina $\mathrm{C}$ em recém-nascidos de termo no primeiro mês de vida.

2.PESQUISADOR: Cléa Rodrigues Leone

CARGO/FUNÇÃO: médica chefe INSCRIÇÃO CONSELHO REGIONAL № 15481

UNIDADE DO HCFMUSP: Berçário Anexo à Maternidade do HC da FMUSP

3. AVALIAÇÃO DO RISCO DA PESQUISA:

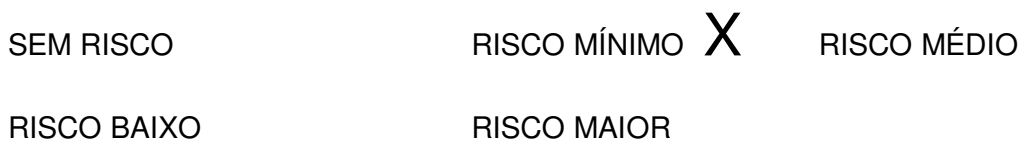

(probabilidade de que o indivíduo sofra algum dano como conseqüência imediata ou tardia do estur 


\section{III - REGISTRO DAS EXPLICAÇÕES DO PESQUISADOR AO PACIENTE OU SEU REPRESENTANTE LEGAL SOBRE A PESQUISA, CONSIGNANDO:}

Alguns recém-nascidos já nascem com alteração do funcionamento dos rins, porém ainda não existe um exame que permita na prática a avaliação do funcionamento dos rins nos primeiros dias de vida. Recentemente surgiu um novo exame de sangue que permite essa avaliação, que é a dosagem no sangue de uma substância chamada cistatina C. Porém, ainda é necessário estudar melhor essas dosagens em bebês normais para poder depois usar em recém-nascidos com problemas renais. Para isso será necessário fazer coleta de pequena quantidade de sangue $(1 \mathrm{~mL})$ da mãe no momento do parto, da placenta logo depois do nascimento, e do recém-nascido com 3, 7 e 28 dias de vida, $1 \mathrm{~mL}$ de cada vez, num total de $3 \mathrm{~mL}$ do recém-nascido. Se o recém-nascido precisar colher algum outro exame nestes dias, sempre que possível, eles serão colhidos ao mesmo tempo, para só precisar de uma punção. Como no 3 o dia de vida é colhido o "exame do pezinho", este exame será colhido na mesma punção, não sendo necessário outra punção no pé para colher. O sangue será sempre colhido com seringas e agulhas descartáveis, e por médico acostumado a colher exames de recém-nascidos. No local pode ficar uma pequena mancha arroxeada que sumirá em alguns dias. Também será realizada uma ultrassonografia dos rins para descartar uma má-formação dos rins, a qual não provoca dor. Seu filho não tem risco de apresentar problemas renais, mas sua colaboração vai permitir no futuro ajudar recém-nascidos doentes. Se seu filho participar do estudo, eu farei seu acompanhamento na internação e após a alta, até completar um mês de idade. Caso não participe, ele vai receber o acompanhamento normal com um retorno no ambulatório de puericultura.

\section{IV - ESCLARECIMENTOS DADOS PELO PESQUISADOR SOBRE GARANTIAS DO SUJEITO DA PESQUISA:}

Em qualquer momento o responsável pelo recém-nascido pode ter acesso a informações sobre procedimentos, riscos e benefícios relacionados à pesquisa, inclusive para esclarecer eventuais dúvidas. Terá toda a liberdade de retirar seu consentimento a qualquer momento e de deixar de participar do estudo, sem que isto traga prejuízo à continuidade da assistência. Os dados serão mantidos em sigilo e será garantida a privacidade dos pacientes. Terá toda a assistência necessária no HCFMUSP, no caso de eventuais danos à saúde decorrentes da pesquisa.

\section{INFORMAÇÕES DE NOMES, ENDEREÇOS E TELEFONES DOS RESPONSÁVEIS PE ACOMPANHAMENTO DA PESQUISA, PARA CONTATO EM CASO DE INTERCORRÊNCIAS CLÍNICAS OU REAÇÕES ADVERSAS.}

Ana Carolina de Albuquerque Cavalcanti Ferreira Novo Endereço: Berçário Anexo à Maternidade do HCFMUSP

Rua Dr. Enéas de Carvalho Aguiar, nำ 375, 10ํandar

Telefones: 3069-6395 e 3069-6081

\section{OBSERVAÇÕES COMPLEMENTARES:}

\section{VII - CONSENTIMENTO PÓS-ESCLARECIDO}

Declaro que, após convenientemente esclarecido pelo pesquisador e ter entendido o que me foi explicado, consinto em participar do presente Protocolo de Pesquisa.

São Paulo de de $200 \ldots \ldots \ldots$ 
Anexo C - Formulário para registro de informações

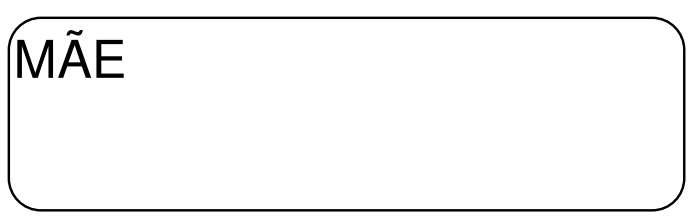

\section{$\mathrm{RN}$}

Mãe:

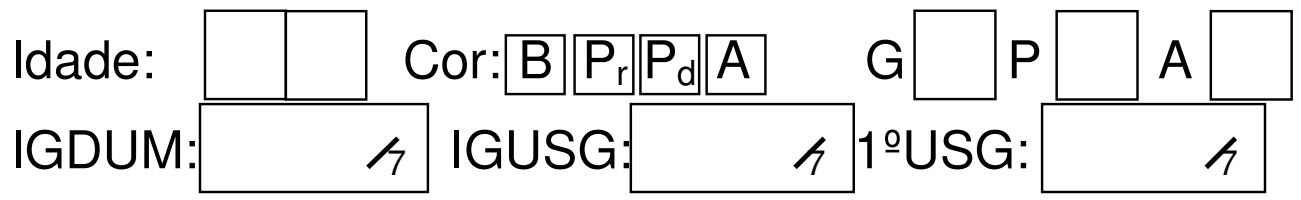

Patologias:
Medicação: vitam
$\mathrm{PN}: \mathrm{N} \mathrm{S} \rightarrow \mathrm{HC}$
Parto: $\mathrm{C} N \mathrm{~N}$

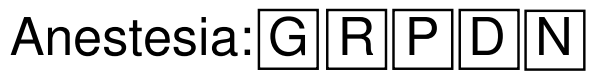

$\mathrm{RN}$ :

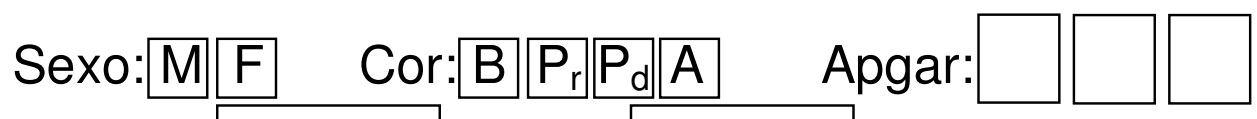
Capurro: $\quad / 7$ IG def: Peso:

\begin{tabular}{|l|l|l|l|}
\hline & & & \\
\hline
\end{tabular}

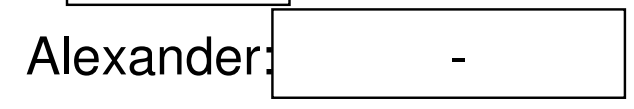

Evolução:
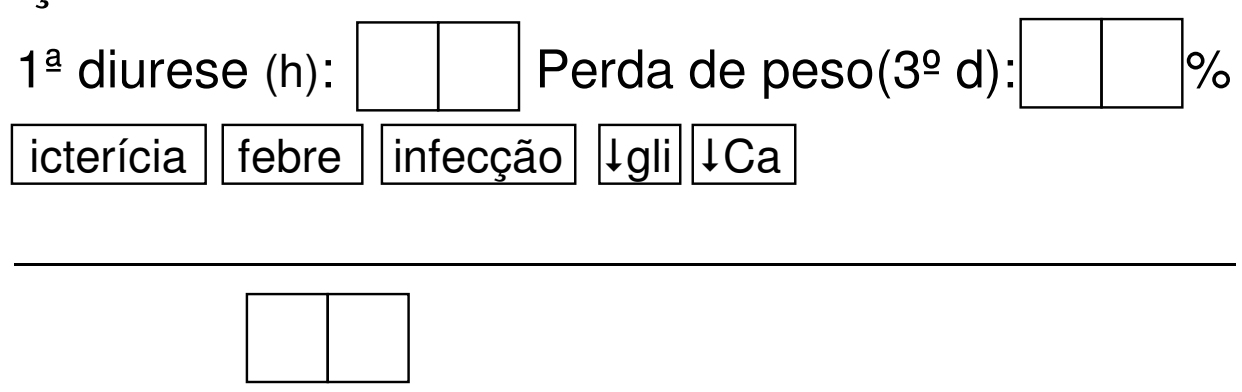

USG: Idade (d):

$\mathrm{nl}$ alt $\rightarrow$

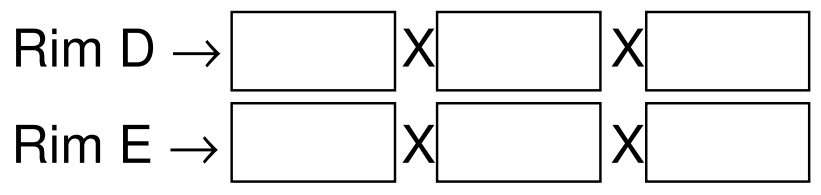

espessura espessura 


\begin{tabular}{|c|c|c|c|c|c|c|c|}
\hline & O h & $24 \mathrm{~h}$ & $48 \mathrm{~h}$ & $72 \mathrm{~h}$ & $7 \mathrm{~d}$ & $14 \mathrm{~d}$ & $28 \mathrm{~d}$ \\
\hline Peso (g) & & & & & & & \\
\hline Compr (cm) & & & & & & & \\
\hline PA1 S & & & & & & & \\
\hline M & & & & & & & \\
\hline D & & & & & & & \\
\hline M & & & & & & & \\
\hline S & & & & & & & \\
\hline D & & & & & & & \\
\hline M & & & & & & & \\
\hline Piurese(24hs) & & & & & & & \\
\hline Hb/Ht & & & & & & & \\
\hline Cistatina C & & & & & & & \\
\hline Creatinina & & & & & & & \\
\hline
\end{tabular}

\begin{tabular}{l|l|l|l|}
\hline MÃE & Cistatina $C$ & & Creatinina \\
\hline
\end{tabular}

TSH neo

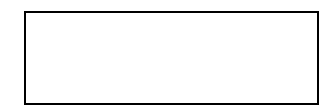




\section{Anexo D - Características maternas}

\begin{tabular}{|c|c|c|c|c|c|}
\hline Mãe & $\begin{array}{l}\text { Idade } \\
\text { (anos) }\end{array}$ & Gestações & Paridade & $\begin{array}{c}\text { Afecções antes } \\
\text { da gestação }\end{array}$ & $\begin{array}{c}\text { Intercorrências } \\
\text { na gestação }\end{array}$ \\
\hline 1 & 19 & 2 & 0 & $\begin{array}{c}\mathrm{HIV}(+) \quad \text { carga } \\
\text { viral indetectável }\end{array}$ & \\
\hline 2 & 34 & 5 & 2 & & \\
\hline 3 & 18 & 1 & 0 & & \\
\hline 4 & 22 & 1 & 0 & & \\
\hline 5 & 39 & 4 & 2 & & \\
\hline 6 & 19 & 1 & 0 & & \\
\hline 7 & 38 & 2 & 1 & $\begin{array}{l}\text { esclerose } \\
\text { múltipla }\end{array}$ & $\begin{array}{l}\text { diabetes } \\
\text { gestacional }\end{array}$ \\
\hline 8 & 25 & 1 & 0 & & \\
\hline 9 & 22 & 3 & 1 & & \\
\hline 10 & 18 & 1 & 0 & & \\
\hline 11 & 26 & 2 & 0 & & \\
\hline 12 & 41 & 2 & 1 & hipotireoidismo & \\
\hline 13 & 31 & 1 & 0 & & \\
\hline 14 & 31 & 3 & 2 & & \\
\hline 15 & 33 & 2 & 1 & $\begin{array}{l}\text { transtorno } \\
\text { bipolar } \\
\text { hipotireoidismo }\end{array}$ & \\
\hline 16 & 40 & 8 & 2 & hipotireoidismo & \\
\hline 17 & 33 & 5 & 3 & & $\begin{array}{l}\text { síndrome } \\
\text { antifosfolípide }\end{array}$ \\
\hline 18 & 39 & 7 & 2 & & $\begin{array}{l}\text { diabetes } \\
\text { gestacional }\end{array}$ \\
\hline 19 & 20 & 2 & 1 & asma & \\
\hline 20 & 24 & 1 & 0 & & \\
\hline 21 & 38 & 6 & 4 & & \\
\hline
\end{tabular}


Anexo D - Características maternas (continuação)

\begin{tabular}{|c|c|c|c|c|}
\hline Mãe & $\begin{array}{c}\text { Medicações na } \\
\text { gestação }\end{array}$ & Pré-natal & $\begin{array}{l}\text { Local do } \\
\text { pré-natal }\end{array}$ & USG fetal \\
\hline 1 & \begin{tabular}{|l} 
lamivudina, \\
zidovudina \\
nelfinavir
\end{tabular} & $\operatorname{sim}$ & $\mathrm{HC}$ & normal \\
\hline 2 & & $\operatorname{sim}$ & $\mathrm{HC}$ & normal \\
\hline 3 & & $\operatorname{sim}$ & $\mathrm{HC}$ & normal \\
\hline 4 & & $\operatorname{sim}$ & $\mathrm{HC}$ & normal \\
\hline 5 & & $\operatorname{sim}$ & $\mathrm{HC}$ & normal \\
\hline 6 & & $\operatorname{sim}$ & $\mathrm{HC}$ & normal \\
\hline 7 & & $\operatorname{sim}$ & $\mathrm{HC}$ & normal \\
\hline 8 & & $\operatorname{sim}$ & $\mathrm{HC}$ & normal \\
\hline 9 & & $\operatorname{sim}$ & $\mathrm{HC}$ & normal \\
\hline 10 & & $\operatorname{sim}$ & outro & normal \\
\hline 11 & & $\operatorname{sim}$ & outro & normal \\
\hline 12 & L-tiroxina & $\operatorname{sim}$ & $\mathrm{HC}$ & normal \\
\hline 13 & & $\operatorname{sim}$ & $\mathrm{HC}$ & normal \\
\hline 14 & & $\operatorname{sim}$ & $\mathrm{HC}$ & normal \\
\hline 15 & \begin{tabular}{|l} 
L-tiroxina, \\
clorpromazina e \\
quetiapina
\end{tabular} & $\operatorname{sim}$ & $\mathrm{HC}$ & normal \\
\hline 16 & L-tiroxina & $\operatorname{sim}$ & $\mathrm{HC}$ & normal \\
\hline 17 & \begin{tabular}{|l} 
ácido \\
acetilsalicílico e \\
heparina
\end{tabular} & $\operatorname{sim}$ & $\mathrm{HC}$ & normal \\
\hline 18 & insulina & $\operatorname{sim}$ & $\mathrm{HC}$ & normal \\
\hline 19 & fenoterol & $\operatorname{sim}$ & $\mathrm{HC}$ & normal \\
\hline 20 & & $\operatorname{sim}$ & outro & normal \\
\hline 21 & & $\operatorname{sim}$ & $\mathrm{HC}$ & normal \\
\hline
\end{tabular}




\section{Anexo E - Características dos recém-nascidos}

\begin{tabular}{|c|c|c|c|c|}
\hline $\mathrm{RN}$ & Parto & Sexo & Apgar $1^{\circ} \min$ & Apgar $5^{\circ} \min$ \\
\hline 1 & cesárea & M & 9 & 9 \\
\hline 2 & cesárea & $M$ & 9 & 10 \\
\hline 3 & fórceps & $\mathrm{F}$ & 9 & 10 \\
\hline 4 & fórceps & M & 9 & 10 \\
\hline 5 & cesárea & $\mathrm{F}$ & 8 & 9 \\
\hline 6 & fórceps & $\mathrm{F}$ & 9 & 10 \\
\hline 7 & cesárea & M & 9 & 9 \\
\hline 8 & fórceps & $\mathrm{F}$ & 8 & 9 \\
\hline 9 & cesárea & M & 9 & 9 \\
\hline 10 & fórceps & $\mathrm{F}$ & 9 & 9 \\
\hline 11 & fórceps & $\mathrm{F}$ & 8 & 9 \\
\hline 12 & cesárea & $\mathrm{F}$ & 9 & 9 \\
\hline 13 & normal & $M$ & 9 & 10 \\
\hline 14 & cesárea & $M$ & 9 & 10 \\
\hline 15 & cesárea & $M$ & 9 & 9 \\
\hline 16 & cesárea & $\mathrm{F}$ & 8 & 9 \\
\hline 17 & normal & $M$ & 8 & 10 \\
\hline 18 & cesárea & $\mathrm{F}$ & 8 & 9 \\
\hline 19 & cesárea & $M$ & 8 & 10 \\
\hline 20 & normal & M & 9 & 9 \\
\hline 21 & fórceps & $M$ & 9 & 9 \\
\hline
\end{tabular}

(continua) 
Anexo E - Características dos recém-nascidos (continuação)

\begin{tabular}{|c|c|c|c|}
\hline $\mathrm{RN}$ & $\begin{array}{c}\text { Idade gestacional } \\
\text { (semanas) }\end{array}$ & $\begin{array}{c}\text { Peso } \\
(\mathrm{g}) \\
\end{array}$ & $\begin{array}{l}\text { Alexander } \\
\text { (percentil) } \\
\end{array}$ \\
\hline 1 & 40,1 & 3010 & 10 a 50 \\
\hline 2 & 40,0 & 3660 & 50 a 90 \\
\hline 3 & 39,1 & 2900 & 10 a 50 \\
\hline 4 & 37,7 & 2600 & 10 a 50 \\
\hline 5 & 39,0 & 3320 & 10 a 50 \\
\hline 6 & 40,4 & 3190 & 10 a 50 \\
\hline 7 & 40,0 & 3280 & 10 a 50 \\
\hline 8 & 40,6 & 3240 & 10 a 50 \\
\hline 9 & 40,1 & 3270 & 10 a 50 \\
\hline 10 & 40,7 & 3060 & 10 a 50 \\
\hline 11 & 38,6 & 3240 & 10 a 50 \\
\hline 12 & 40,0 & 3290 & 10 a 50 \\
\hline 13 & 40,1 & 3560 & 50 a 90 \\
\hline 14 & 39,0 & 3060 & 10 a 50 \\
\hline 15 & 37,6 & 3180 & 50 a 90 \\
\hline 16 & 39,9 & 2890 & 10 a 50 \\
\hline 17 & 38,4 & 3000 & 10 a 50 \\
\hline 18 & 38,7 & 2940 & 10 a 50 \\
\hline 19 & 40,0 & 3600 & 50 a 90 \\
\hline 20 & 38,7 & 3480 & 50 a 90 \\
\hline 21 & 39,1 & 3940 & 50 a 90 \\
\hline
\end{tabular}




\section{Anexo F - Evolução dos recém-nascidos}

\begin{tabular}{|c|c|c|c|c|c|}
\hline RN & Dieta recebida & Intercorrências & $\begin{array}{c}\text { Dias de } \\
\text { internação } \\
\end{array}$ & $\begin{array}{c}\text { TSH } \\
\text { neonatal } \\
\end{array}$ & $\begin{array}{l}\text { USG } \\
\text { renal }\end{array}$ \\
\hline 1 & Nan I & $\begin{array}{l}\text { HIV-RNA } \\
\text { negativo }\end{array}$ & 3 & normal & normal \\
\hline 2 & seio materno & $\begin{array}{c}\text { Icterícia } \\
\text { eritema tóxico }\end{array}$ & 3 & normal & normal \\
\hline 3 & $\begin{array}{c}\text { seio materno } \\
+ \text { Nan após } 14 d\end{array}$ & CIA fechada & 3 & normal & normal \\
\hline 4 & seio materno & icterícia & 3 & normal & normal \\
\hline 5 & seio materno & icterícia & 3 & normal & normal \\
\hline 6 & seio materno & & 3 & normal & normal \\
\hline 7 & seio materno & CIV fechada & 3 & normal & normal \\
\hline 8 & seio materno & icterícia & 3 & normal & normal \\
\hline 9 & seio materno & & 3 & normal & normal \\
\hline 10 & seio materno & $\begin{array}{c}\text { bossa } \\
\text { serossanguínea }\end{array}$ & 3 & normal & normal \\
\hline 11 & seio materno & $\begin{array}{c}\text { Icterícia } \\
\text { eritema tóxico }\end{array}$ & 3 & normal & normal \\
\hline 12 & seio materno & icterícia & 3 & normal & normal \\
\hline 13 & seio materno & icterícia & 3 & normal & normal \\
\hline 14 & seio materno & icterícia & 3 & normal & normal \\
\hline 15 & Nan I & icterícia & 3 & normal & normal \\
\hline 16 & seio materno & icterícia & 3 & normal & normal \\
\hline 17 & seio materno & $\begin{array}{c}\text { Icterícia } \\
\text { cefaloematoma }\end{array}$ & 3 & normal & normal \\
\hline 18 & seio materno & dente neonatal & 4 & normal & normal \\
\hline 19 & seio materno & & 3 & normal & normal \\
\hline 20 & $\begin{array}{c}\text { seio materno } \\
+ \text { Nan após 14d }\end{array}$ & icterícia & 3 & normal & normal \\
\hline 21 & seio materno & icterícia & 3 & normal & normal \\
\hline
\end{tabular}




\section{Anexo G - Evolução da diurese}

\begin{tabular}{|c|c|c|c|}
\hline \multirow[t]{2}{*}{$\mathrm{RN}$} & \multirow{2}{*}{$\begin{array}{c}1^{\text {a }} \text { micção } \\
\text { (horas de vida) }\end{array}$} & \multicolumn{2}{|c|}{ Peso de fralda $(\mathrm{g} / \mathrm{kg} / \mathrm{h})$} \\
\hline & & $2^{\circ}$ dia & 3ㅇdia \\
\hline 1 & 0 & 1,7 & 1,4 \\
\hline 2 & 0 & 1,4 & 1,3 \\
\hline 3 & 6 & 2,4 & 2,1 \\
\hline 4 & 7 & 1,8 & 2,2 \\
\hline 5 & 7 & 2,8 & 1,7 \\
\hline 6 & 11 & 3,1 & 1,9 \\
\hline 7 & 0 & 2,3 & 2,2 \\
\hline 8 & 6 & 2,0 & 4,2 \\
\hline 9 & 11 & 1,5 & 1,9 \\
\hline 10 & 6 & 2,6 & 2,4 \\
\hline 11 & 7 & 2,4 & 2,1 \\
\hline 12 & 4 & 1,4 & 3,1 \\
\hline 13 & 0 & 2,5 & 2,7 \\
\hline 14 & 7 & 1,5 & 3,1 \\
\hline 15 & 0 & 3,7 & 2,9 \\
\hline 16 & 7 & 1,3 & 2,0 \\
\hline 17 & 8 & 1,4 & 2,6 \\
\hline 18 & 8 & 2,3 & 2,4 \\
\hline 19 & 0 & 2,3 & 3,0 \\
\hline 20 & 0 & 2,3 & 2,6 \\
\hline 21 & 9 & 1,8 & 2,9 \\
\hline
\end{tabular}




\section{Anexo H - Evolução do peso}

\begin{tabular}{|c|c|c|c|c|c|c|c|c|c|}
\hline \multirow[t]{2}{*}{ RN } & \multicolumn{7}{|c|}{ Peso (g) } & \multirow{2}{*}{$\begin{array}{c}>\text { perda } \\
\text { de } \\
\text { peso }(\%)\end{array}$} & \multirow{2}{*}{\begin{tabular}{|c} 
Dia da \\
$>$ \\
perda
\end{tabular}} \\
\hline & Dia 0 & Dia 1 & Dia 2 & Dia 3 & Dia 7 & Dia 14 & Dia 28 & & \\
\hline 1 & 3010 & 2935 & 2830 & 2840 & 3040 & & 3970 & 6,0 & 2 \\
\hline 2 & 3660 & 3575 & 3500 & 3500 & 3770 & & 4860 & 4,4 & 2 \\
\hline 3 & 2900 & 2750 & 2635 & 2630 & 3015 & & 3840 & 9,3 & 3 \\
\hline 4 & 2600 & 2570 & 2475 & 2460 & 2525 & & 3650 & 5,4 & 3 \\
\hline 5 & 3320 & 3250 & 3155 & 3270 & 3410 & & 3910 & 5,0 & 2 \\
\hline 6 & 3190 & 3100 & 3000 & 3000 & 3210 & & 3850 & 6,0 & 2 \\
\hline 7 & 3280 & 3260 & 3000 & 3015 & 3120 & & 4145 & 8,5 & 2 \\
\hline 8 & 3240 & 3120 & 3040 & 3090 & 3200 & & 4430 & 6,2 & 2 \\
\hline 9 & 3270 & 3210 & 3110 & 3110 & 3330 & & 3855 & 4,9 & 2 \\
\hline 10 & 3060 & 2870 & 2880 & 2780 & 2930 & 3120 & 3670 & 9,2 & 3 \\
\hline 11 & 3240 & 3185 & 3180 & 3040 & 3150 & 3320 & 3900 & 6,2 & 3 \\
\hline 12 & 3290 & 3120 & 3100 & 3075 & 3125 & 3420 & 4125 & 6,5 & 3 \\
\hline 13 & 3560 & 3310 & 3350 & 3380 & 3600 & & 4670 & 7,0 & 1 \\
\hline 14 & 3060 & 2890 & 2830 & 2840 & 3125 & & 3820 & 7,5 & 2 \\
\hline 15 & 3180 & 3020 & 2930 & 2885 & 950 & 3210 & 4005 & 9 & 3 \\
\hline 16 & 2890 & 2710 & 2630 & 2610 & 2690 & 2985 & 3670 & 9,7 & 3 \\
\hline 17 & 3000 & 2945 & 2835 & 2740 & 2820 & 3060 & 3450 & 8,7 & 3 \\
\hline 18 & 2940 & 2810 & 2710 & 2745 & 2790 & 2990 & 3480 & 7,8 & 2 \\
\hline 19 & 3600 & 3455 & 3400 & 3390 & 3500 & 3710 & 4320 & 5,8 & 3 \\
\hline 20 & 3480 & 3235 & 3165 & 3200 & 3390 & 3560 & 4300 & 9,1 & 2 \\
\hline 21 & 3940 & 3730 & 3675 & 3735 & 3780 & 3990 & 4450 & 6,7 & 2 \\
\hline
\end{tabular}




\section{Anexo I - Evolução do comprimento}

\begin{tabular}{|c|c|c|c|c|}
\hline \multirow[t]{2}{*}{$\mathrm{RN}$} & \multicolumn{4}{|c|}{ Comprimento $(\mathrm{cm})$} \\
\hline & Dia 0 & Dia 3 & Dia 7 & Dia 28 \\
\hline 1 & 49,0 & 49,0 & 50,0 & 54,0 \\
\hline 2 & 50,5 & 51,0 & 53,0 & 56,0 \\
\hline 3 & 47,0 & 47,0 & 48,3 & 51,3 \\
\hline 4 & 47,5 & 47,5 & 48,0 & 52,0 \\
\hline 5 & 47,5 & 47,5 & 49,0 & 52,0 \\
\hline 6 & 48,0 & 48,5 & 50,0 & 53,0 \\
\hline 7 & 49,0 & 49,0 & 50,5 & 54,0 \\
\hline 8 & 50,0 & 50,5 & 51,5 & 56,0 \\
\hline 9 & 48,0 & 48,0 & 48,5 & 52,0 \\
\hline 10 & 50,0 & 50,0 & 51,0 & 55,0 \\
\hline 11 & 49,0 & 49,0 & 50,0 & 53,0 \\
\hline 12 & 51,0 & 51,0 & 52,0 & 55,0 \\
\hline 13 & 50,0 & 50,0 & 51,0 & 55,0 \\
\hline 14 & 49,0 & 49,0 & 50,0 & 55,0 \\
\hline 15 & 47,5 & 47,5 & 47,5 & 53,0 \\
\hline 16 & 48,0 & 48,5 & 49,0 & 52,0 \\
\hline 17 & 48,5 & 48,5 & 49,0 & 52,0 \\
\hline 18 & 46,0 & 46,0 & 47,0 & 50,0 \\
\hline 19 & 50,0 & 50,0 & 51,0 & 54,0 \\
\hline 20 & 49,0 & 49,0 & 50,0 & 52,0 \\
\hline 21 & 52,0 & 52,0 & 52,5 & 55,0 \\
\hline
\end{tabular}




\section{Anexo J - Evolução da pressão arterial (mmHg)}

\begin{tabular}{|c|c|c|c|c|c|c|c|c|c|}
\hline \multirow[t]{2}{*}{$\mathrm{RN}$} & \multicolumn{3}{|c|}{ Dia 1} & \multicolumn{3}{|c|}{ Dia 2} & \multicolumn{3}{|c|}{ Dia 3} \\
\hline & Sist. & Diast. & Média & Sist. & Diast. & Média & Sist. & Diast. & Média \\
\hline 1 & 67,5 & 35,5 & 51,0 & 70,0 & 41,0 & 56,0 & 67,0 & 34,0 & 45,0 \\
\hline 2 & 66,5 & 33,5 & 45,0 & 74,0 & 42,5 & 57,0 & 74,0 & 38,0 & 48,5 \\
\hline 3 & 64,0 & 38,0 & 52,0 & 59,5 & 45,0 & 53,5 & 68,0 & 35,5 & 48,5 \\
\hline 4 & 50,0 & 28,5 & 34,0 & 55,5 & 30,5 & 41,5 & 59,0 & 32,0 & 45,5 \\
\hline 5 & 61,0 & 31,5 & 44,5 & 65,5 & 40,5 & 53,0 & 73,5 & 42,5 & 62,5 \\
\hline 6 & 53,5 & 30,5 & 41,0 & 59,0 & 30,0 & 43,0 & 68,0 & 35,0 & 49,0 \\
\hline 7 & 67,5 & 36,5 & 49,5 & 63,0 & 31,0 & 43,0 & 69,5 & 45,0 & 53,0 \\
\hline 8 & 68,5 & 34,0 & 45,5 & 64,0 & 34,0 & 45,0 & 54,5 & 29,0 & 41,0 \\
\hline 9 & 55,5 & 32,5 & 45,5 & 62,5 & 32,0 & 44,5 & 68,0 & 36,0 & 49,5 \\
\hline 10 & 67,0 & 38,0 & 56,5 & 67,0 & 40,0 & 55,5 & 74,5 & 41,5 & 55,5 \\
\hline 11 & 70,0 & 36,5 & 52,5 & 63,5 & 39,5 & 51,5 & 61,5 & 35,5 & 45,5 \\
\hline 12 & 64,0 & 29,5 & 44,5 & 65,5 & 38,0 & 48,5 & 78,5 & 45,0 & 58,5 \\
\hline 13 & 64,0 & 32,5 & 47,0 & 68,5 & 35,5 & 51,5 & 71,5 & 39,5 & 49,5 \\
\hline 14 & 72,5 & 40,5 & 49,0 & 62,0 & 35,0 & 46,0 & 66,5 & 37,0 & 44,5 \\
\hline 15 & 62,5 & 34,5 & 42,5 & 69,5 & 37,5 & 50,0 & 64,0 & 30,5 & 45,0 \\
\hline 16 & 65,0 & 40,5 & 51,5 & 74,5 & 39,0 & 54,0 & 64,0 & 35,0 & 50,5 \\
\hline 17 & 55,5 & 28,0 & 40,5 & 56,0 & 30,0 & 42,5 & 61,0 & 31,0 & 42,5 \\
\hline 18 & 68,0 & 37,5 & 51,0 & 83,5 & 52,5 & 63,5 & 86,0 & 48,0 & 65,5 \\
\hline 19 & 57,0 & 32,5 & 42,5 & 69,0 & 40,0 & 47,0 & 55,0 & 32,0 & 41,5 \\
\hline 20 & 61,0 & 33,0 & 48,0 & 76,5 & 38,5 & 49,5 & 64,0 & 35,0 & 48,5 \\
\hline 21 & 67,0 & 38,0 & 49,5 & 74,0 & 43,5 & 57,5 & 88,0 & 49,0 & 67,5 \\
\hline
\end{tabular}

(continua) 
Anexo J - Evolução da pressão arterial ( $\mathrm{mmHg}$ ) (continuação)

\begin{tabular}{c||c|c|c|c|c|c}
\multirow{2}{*}{ RN } & \multicolumn{3}{|c|}{ Dia 7 } & \multicolumn{3}{c}{ Dia 28 } \\
\cline { 2 - 7 } & Sist. & Diast. & Média & Sist. & Diast. & Média \\
\hline \hline 1 & 82,0 & 43,0 & 53,5 & 81,0 & 45,5 & 57,5 \\
\hline 2 & 83,0 & 49,0 & 62,0 & 87,0 & 48,5 & 63,0 \\
\hline 3 & 87,0 & 44,0 & 64,0 & 82,0 & 47,0 & 60,0 \\
\hline 4 & 72,5 & 44,0 & 56,0 & 63,5 & 35,0 & 43,5 \\
\hline 5 & 71,0 & 42,5 & 53,0 & 85,5 & 50,0 & 70,0 \\
\hline 6 & 68,5 & 35,0 & 45,0 & 75,0 & 40,0 & 53,0 \\
\hline 7 & 65,0 & 38,5 & 51,5 & 72,5 & 46,0 & 55,0 \\
\hline 8 & 63,5 & 31,0 & 44,0 & 72,0 & 42,5 & 58,0 \\
\hline 9 & 84,5 & 50,0 & 67,0 & 75,0 & 37,0 & 51,5 \\
\hline 10 & 75,5 & 42,5 & 60,0 & 98,5 & 67,5 & 67,0 \\
\hline 11 & 87,0 & 53,0 & 71,5 & 79,0 & 46,0 & 66,5 \\
\hline 12 & 80,5 & 51,0 & 66,5 & 85,0 & 47,0 & 66,5 \\
\hline 13 & 86,5 & 53,5 & 66,5 & 82,5 & 51,0 & 68,0 \\
\hline 14 & 69,0 & 47,0 & 55,5 & 68,0 & 39,5 & 51,0 \\
\hline 15 & 71,0 & 37,0 & 51,5 & 79,0 & 44,0 & 51,0 \\
\hline 16 & 72,5 & 48,0 & 61,0 & 85,5 & 55,5 & 68,5 \\
\hline 17 & 61,0 & 35,0 & 48,5 & 72,0 & 44,0 & 56,0 \\
\hline 18 & 77,0 & 42,0 & 51,5 & 87,5 & 53,5 & 64,5 \\
\hline 19 & 78,0 & 50,5 & 62,5 & 76,0 & 41,5 & 50,5 \\
\hline 20 & 60,0 & 33,5 & 41,5 & 96,5 & 55,5 & 75,5 \\
\hline 21 & 93,0 & 56,5 & 70,5 & 94,0 & 55,5 & 65,5
\end{tabular}




\section{Anexo K - Evolução da creatinina}

\begin{tabular}{|c|c|c|c|c|c|}
\hline \multirow[t]{2}{*}{$\mathrm{RN}$} & \multicolumn{5}{|c|}{ Creatinina (mg/dL) } \\
\hline & Mãe & Dia 0 & Dia 3 & Dia 7 & Dia 28 \\
\hline 1 & 0,59 & 0,65 & 0,49 & 0,38 & 0,30 \\
\hline 2 & 0,61 & 0,56 & 0,36 & 0,20 & 0,15 \\
\hline 3 & 0,75 & 0,38 & 0,42 & 0,34 & 0,24 \\
\hline 4 & 0,61 & 0,56 & 0,63 & 0,45 & 0,23 \\
\hline 5 & 0,53 & 0,49 & 0,38 & 0,31 & 0,22 \\
\hline 6 & 0,64 & 0,55 & 0,49 & 0,31 & 0,20 \\
\hline 7 & 0,36 & 0,51 & 0,36 & 0,27 & 0,27 \\
\hline 8 & 0,42 & 0,54 & 0,30 & 0,22 & 0,18 \\
\hline 9 & 0,73 & 0,50 & 0,77 & 0,43 & 0,30 \\
\hline 10 & 0,60 & 0,76 & 0,27 & 0,35 & 0,24 \\
\hline 11 & 0,97 & 1,03 & 0,54 & 0,37 & 0,24 \\
\hline 12 & 0,76 & 0,61 & 0,19 & 0,38 & 0,26 \\
\hline 13 & 0,54 & 0,61 & 0,53 & 0,43 & 0,28 \\
\hline 14 & 0,74 & 0,70 & 0,51 & 0,30 & 0,26 \\
\hline 15 & 0,56 & 0,64 & 0,84 & 0,60 & 0,37 \\
\hline 16 & 0,66 & 0,74 & 0,32 & 0,58 & 0,30 \\
\hline 17 & 0,79 & 0,69 & 0,57 & 0,49 & 0,30 \\
\hline 18 & 0,36 & & 0,35 & 0,33 & 0,20 \\
\hline 19 & 0,55 & 0,50 & 0,57 & 0,30 & 0,28 \\
\hline 20 & 0,71 & 0,69 & 0,57 & 0,35 & 0,25 \\
\hline 21 & 0,82 & 0,87 & 0,60 & 0,33 & 0,34 \\
\hline
\end{tabular}


Anexo L - Evolução da cistatina C

\begin{tabular}{|c|c|c|c|c|c|}
\hline \multirow[t]{2}{*}{$\mathrm{RN}$} & \multicolumn{5}{|c|}{ Cistatina C (mg/L) } \\
\hline & Mãe & Dia 0 & Dia 3 & Dia 7 & Dia 28 \\
\hline 1 & 0,96 & 1,56 & 1,34 & 1,50 & 1,44 \\
\hline 2 & 0,99 & 1,49 & 1,61 & 1,56 & 1,44 \\
\hline 3 & 1,30 & 1,62 & 1,26 & 1,55 & 1,35 \\
\hline 4 & 0,65 & 1,78 & 1,38 & 1,40 & 1,57 \\
\hline 5 & 0,83 & 1,55 & 1,42 & 1,61 & 1,46 \\
\hline 6 & 0,71 & 2,11 & 1,50 & 1,51 & 1,47 \\
\hline 7 & 0,88 & 1,69 & 1,48 & 1,53 & 1,46 \\
\hline 8 & 0,72 & 1,73 & 1,28 & 1,31 & 1,35 \\
\hline 9 & 0,91 & 1,92 & 1,85 & 1,65 & 1,46 \\
\hline 10 & 1,00 & 1,66 & 1,59 & 1,41 & 1,52 \\
\hline 11 & 1,48 & 2,00 & 1,86 & 1,66 & 1,63 \\
\hline 12 & 0,94 & 1,57 & 1,42 & 1,44 & 1,55 \\
\hline 13 & 0,98 & 2,18 & 1,60 & 1,55 & 1,72 \\
\hline 14 & 0,91 & 1,50 & 1,34 & 1,50 & 1,34 \\
\hline 15 & 1,16 & 1,60 & 1,81 & 1,75 & 1,58 \\
\hline 16 & 1,10 & 1,66 & 1,72 & 1,40 & 1,65 \\
\hline 17 & 1,05 & 2,09 & 1,50 & 1,87 & 1,90 \\
\hline 18 & 1,08 & 1,40 & 1,24 & 1,20 & 1,22 \\
\hline 19 & 0,92 & 1,79 & 1,45 & 1,72 & 1,40 \\
\hline 20 & 1,19 & 1,78 & 1,39 & 1,59 & 1,59 \\
\hline 21 & 1,19 & 1,06 & 1,59 & 1,59 & 1,69 \\
\hline
\end{tabular}


Referências

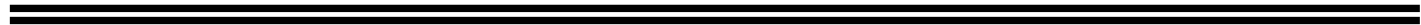


1. Haycock GM. Development of glomerular filtration and tubular sodium reabsorption in the human fetus and newborn. $\mathrm{Br} J$ Urol $1998 ; 81: 33-8$.

2. Kon V, Ichikawa I. Glomerular circulation and function. In: Avner E D, Harmon WE, Niaudet P, editors. Pediatric nephrology. $5^{\text {th }}$ ed. Philadelphia: Lippincott Williams \& Wilkins; 2004. p.25-44.

3. Drukker A, Guignard J. Renal aspects of the term and preterm infant: a selective update. Curr Opin Pediatr 2002;14:175-82.

4. Giebicsh G, Windhager E. Glomerular filtration and renal blood flow. In: Boron WF, Boulpaep E, editors. Medical physiology - updated edition. Philadelphia: Elsevier Saunders; 2005. p.757-73.

5. Aviles DH, Fildes RD, Jose PA. Evaluation of renal function. Clin Perinatol 1992;19:69-84.

6. Stevens LA, Levey AS. Measurements of kidney function. Med Clin N Am 2005;89:457-73.

7. Schwartz GJ, Brion LP, Spitzer A. The use of plasma creatinine concentration for estimating glomerular filtration rate in infants, children, and adolescents. Pediatr Clin North Am 1987;34:571-90.

8. Van Den Anker JN, Groot R, Broerse HM, Sauer PJ. Assessment of glomerular filtration rate in preterm infants by serum creatinine: comparison with inulin clearance. Pediatrics 1995;96:1156-8.

9. Guignard J, Drukker A. Why do newborn infants have a high plasma creatinine? Pediatrics 1999;103:e49. 
10. Mussap M, Plebani M. Biochemistry and clinical role of human cystatin C. Crit Rev Clin Lab Sci 2004;41:467-550.

11. Grubb A, Löfberg H. Human y-trace, a basic microprotein: amino acid sequence and presence in the adenohypophysis. Proc Natl Acad Sci USA 1982;79:3024-7.

12. Barrett AJ, Davies ME, Grubb A. The place of human gamma-trace (cystatin C) among the cysteine proteinase inhibitors. Biochem Biophys Res Commun 1984;120:632-6.

13. Grubb AO. Cystatin $\mathrm{C}$ - properties and use as diagnostic marker. Adv Clin Chem 2000;35:63-99.

14. Janowski R, Kozak M, Jankowska E, Grzonka Z, Grubb A. Human cystatin $\mathrm{C}$, an amyloidogenic protein, dimerizes through threedimensional domain swapping. Nature Struct Biol 2001;8:316-20.

15. Dworkin LD. Serum cystatin C as a marker of glomerular filtration rate. Curr Opin Nephrol Hypertens 2001;10:551-3.

16. Fricker M, Wiesli $P$, Brändle M, Schwegler B, Schmid C. Impact of thyroid dysfunction on serum cystatin C. Kidney Int 2003;63:1944-7.

17. Manetti I, Pardini E, Genovesi M, Campomori A, Grasso L, Morselli I. Thyroid function differently affects serum cystatin $\mathrm{C}$ and creatinine concentrations. J Endocrinol Invest 2005;28:346-9.

18. Grubb A, Simonsen G, Sturfelt G, Truedsson L, Thysell H. Serum concentration of cystatin $C$, factor $D$ and $\beta_{2}$-microglobulin as a measure of glomerular filtration rate. Acta Med Scand 1985;218:499-503. 
19. Löfberg H, Grubb A. Quantitation of gamma-trace in human biological fluids: indications for production in the central nervous system. Scand J Clin Lab Invest 1979;39:619-26.

20. Kyhse-Andersen J, Schmidt C, Nordin G, Andersson B, Nilsson-Ehle P, Lindstrom V, Grubb A. Serum cystatin C, determined by a rapid, automated particle-enhanced turbidimetric method, is a better marker than serum creatinine for glomerular filtration rate. Clin Chem 1994;40:1921-6.

21. Erlandsen EJ, Randers E, Kristensen JH. Evaluation of the Dade Behring N Latex Cystatin C assay on the Dade Behring Nephelometer II System. Scand J Clin Lab Invest 1999;59:1-8.

22. Dharnidharka VR, Kwon C, Stevens G. Serum cystatin C is superior to serum creatinine as a marker of kidney function: a meta-analysis. Am J Kidney Dis 2002;40:221-6.

23. Coll E, Botey A, Alvarez L, Poch E, Quinto L, Saurina A, Vera M, Piera C, Darnell A. Serum cystatin C as a marker for noninvasive estimation of glomerular filtration rate and as a marker for early renal impairment. Am J Kidney Dis 2000;36:29-34.

24. Roos J, Doust J, Tett S, Kirkpatrick C. Diagnostic accuracy of cystatin C compared to serum creatinine for the estimation of renal dysfunction in adults and children - a meta-analysis. Clin Biochem 2007;40:383-91. 
25. Ylinen EA, Ala-Houhala M, Harmoinen APT, Knip M. Cystatin C as a marker for glomerular filtration rate in pediatric patients. Pediatr Nephrol 1999;13:506-9.

26. Helin I, Axenram M, Grubb A. Serum cystatin C as a determinant of glomerular filtration rate in children. Clin Nephrol 1998;49:221-5.

27. Bökenkamp A, Domanetzki M, Zinck R, Schumann G, Byrd D, Brodehl J. Cystatin C - a new marker of glomerular filtration rate in children independent of age and height. Pediatrics 1998;101:875-81.

28. Leake R, Trygstad C, Oh W. Inulin clearance in the newborn infant: relationship to gestational and postnatal age. Pediatr Res 1976;10:759-62.

29. Stickle D, Cole B, Hock K, Hruska KA, Scott M. Correlation of plasma concentrations of cystatin $\mathrm{C}$ and creatinine to inulin clearance in a pediatric population. Clin Chem 1997;44:1334-8.

30. Willems HL, Hilbrands LB, Calseyde JF, Monnens LAH, Swinkels DW. Is serum cystatin $\mathrm{C}$ the marker of choice to predict glomerular filtration rate in paediatric patients? Ann Clin Biochem 2003;40:60-4.

31.Zaffanello M, Franchini M, Fanos V. Is serum cystatin C a suitable marker of renal function in children? Ann Clin Lab Sci 2007;37:233-40.

32. Takuwa S, Ito $\mathrm{Y}$, Ushijima K, Uchida K. Serum cystatin C values in children by age and their fluctuation during dehydration. Pediatr Int 2002;44:28-31. 
33. Finney H, Newman DJ, Thakkar H, Fell JME, Price CP. Reference ranges for plasma cystatin $\mathrm{C}$ and creatinine measurements in premature infants, neonates, and older children. Arch Dis Child 2002;82:71-75.

34.Bökenkamp A, Domanetzki M, Zinck R, Schumann G, Brodehl J. Reference values for cystatin C serum concentrations in children. Pediatr Nephrol 1998;12:125-9.

35. Fischbach M, Graff V, Terzic J, Bergère V, Oudet M, Hamel G. Impact of age on reference values for serum concentration of cystatin $C$ in children. Pediatr Nephrol 2002;17:104-6.

36. Hoek FJ, Kemperman FAW, Krediet RT. A comparison between cystatin C, plasma creatinine and the Cockcroft and Gault formula for the estimation of glomerular filtration rate. Nephrol Dial Transplant 2003;18:2024-31.

37. Filler G, Lepage N. Should the Schwartz formula for estimation of GFR be replaced by cystatin C formula? Pediatr Nephrol 2003;18:981-5.

38. Zahran A, El-Husseini A, Shoker A. Can cystatin C replace creatinine to estimate glomerular filtration rate? A literature review. Am J Nephrol 2007;27:197-205.

39. Harmoinen A, Ylinen E, Ala-Houhala M, Janas M, Kaila M, Kouri T. Reference intervals for cystatin $\mathrm{C}$ in pre and full-term infants and children. Pediatr Nephrol 2000;15:105-8. 
40. Bahar A, Yilmaz Y, Unver S, Gocmen I, Karademir F. Reference values of umbilical cord and third-day cystatin $\mathrm{C}$ levels for determining glomerular filtration rates in newborns. J Int Med Res 2003;31:231-5.

41. Treiber M, Balon BP, Gorenjak M. Cystatin C versus creatinine as a marker of glomerular filtration rate in newborns. Wien Klin Wochenschr 2006; 118:66-70.

42. Jedrasiak U, Grygalewicz J. The influence of delivery and perinatal risk factors on the cystatin $\mathrm{C}$ in umbilical cord blood. Pol Merk Lek $2007 ; 134: 110-5$

43. Malamitsi-Puchner A, Briana D, Kontara L, Boutsikou M, Baka S, Hassiakos D, Marmarinos A, Gougiotis D. Serum cystatin C in pregnancies with normal and restricted fetal growth. Reprod Sci 2007; 14:37-42.

44. Cataldi L, Mussap M, Bertelli L, Ruzzante N, Fanos V, Plebani M. Cystatin $\mathrm{C}$ in healthy women at term pregnancy and in their infant newborns: relationship between maternal and neonatal serum levels and reference values. Am J Perinatol 1999;16:287-95.

45. Capurro H, Konichezky S, Fonseca D, Caldeyro-Barcia R. A simplified method for diagnosis of gestational age in the newborn infant. $J$ Pediatr 1978;93:120-2.

46. Ramos JLA, Corradini HB, Vaz FAC, Barros JCR, Novo ACCF. Avaliação da idade gestacional e da adequação do crescimento intrauterino. In: Marcondes E, Vaz FAC, Ramos JLA, Okay Y, editores. Pediatria básica. 9a ed. São Paulo: Sarvier; 2002. p.321-9. 
47. Alexander G, Himes J, Kaufman RB, Mor J, Kogan M. A United States national reference for fetal growth. Obstet Gynecol 1996;87:163-8.

48. Briggs GG, Freeman RK, Yaffe SJ. Drugs in pregnancy and lactation. $7^{\text {th }}$ ed. Philadelphia: Lippincott Williams \& Wilkins; 2005.

49. Zubrow AB, Hulman S, Kushner H, Falkner B. Determinants of blood pressure in infants admitted to neonatal intensive care units: a prospective multicenter study. J Perinatol 1995;15:470-9.

50. Finney H, Newman DJ, Gruber W, Merle P, Price C. Initial evaluation of cystatin C measurement by particle-enhanced immunonephelometry on the Behring nephelometer systems (BNA, BN II). Clin Chem 1997;43:1016-20.

51. McPherson R, Pincus MR. Clinical diagnosis and management by laboratory methods. $21^{\text {st }}$ ed. Philadelphia: Saunders Elsevier; 2007.

52. Andriolo A. Compostos nitrogenados não proteicos. In: Andriolo A, Carraza F, editores. Diagnóstico laboratorial em pediatria. $2^{a}$ ed. São Paulo: Sarvier; 2007. p.109-14.

53. Ogden CL, Kuczmarski RJ, Flegal KM, Mei Z, Guo S, Wei R, Grummer-Strawn LM, Curtin LR, Roche AF, Johnson CL. Centers for disease control and prevention 2000 growth charts for the United States: improvements to the 1997 national center for health statistics version. Pediatrics 2002;109:45-60.

54. Chevalier RL. Developmental renal physiology of the low birth weight pre-term newborn. J Urol 1996;156:714-9. 
55. Rostand SG. Oligonephronia, primary hypertension and renal disease: 'is the child father to the man?' Nephrol Dial Transplant 2003;18:1434-8.

56. American Academy of Pediatrics, Committee on Fetus and Newborn and American College of Obstetricians and Gynecologists, Committee on Obstetric Practice. Use and abuse of the Apgar score. Pediatrics 1996;98:141-2.

57. American Academy of Pediatrics, Committee on Fetus and Newborn and American College of Obstetricians and Gynecologists, Committee on Obstetric Practice. The Apgar score. Pediatrics 2006;117:1444-7.

58. Martin-Ancel A, Garcia-Alix A, Gaya F, Cabanas F, Burgueros M, Quero J. Multiple organ involvement in perinatal asphyxia. J Pediatr 1995;127:786-93.

59. Limwongse C, Cassidy SB. Syndromes and malformations of the urinary tract. In: Avner E D, Harmon WE, Niaudet P, editors. Pediatric Nephrology. $5^{\text {th }}$ ed. Philadelphia: Lippincott Williams \& Wilkins; 2004. p.25-44.

60. Grandjean H, Larroque D, Salvator L. The performance of routine ultrasonographic screening of pregnancies in the Eurofetus Study. Am J Obstet Gynecol 1999;181:446-54.

61. Docimo SG, Silver RL. Renal ultrasonography in newborns with prenatally detected hydronephrosis: why wait? J Urol 1997;157:1387-9. 
62. Landy HJ. The impact of maternal illness on the neonate. In: MacDonald MG, Seshia MMK, Mullett MD, editors. Avery's Neonatology. $6^{\text {th }}$ ed. Philadelphia: Lippincott Williams \& Wilkins; 2005. p.202-23.

63. Beckman DA, Fawcett LB, Brent RL. The effects of maternal drugs on the developing fetus. In: MacDonald MG, Seshia MMK, Mullett MD, editors. Avery's Neonatology. $6^{\text {th }}$ ed. Philadelphia: Lippincott Williams \& Wilkins; 2005. p.225-60.

64. King SM. Evaluation and Treatment of the Human Immunodeficiency Virus-1-Exposed Infant. Pediatrics 2004;114:497-505.

65. Havens PL, Waters D. Management of the infant born to a mother with HIV infection. Pediatr Clin N Am 2004;51:909-37.

66. Amey M, Butchard N, Hanson L, Kinross D,Mannion M, Parsons J, Wright I. Cautionary tales from the neonatal intensive care unit: diapers may mislead urinary output estimation in extremely low birthweight infants. Pediatric Critical Care Medicine 2008;9:76-9.

67. Oddie S, Adappa R, Wyllie J. Measurement of urine output by weighing nappies. Arch Dis Fetal Neonatal Ed 2004;89:180-1.

68. Brace RA. Fluid distribution in the fetus and neonate. In: Polin RA, Fox WW, Abman SH, editors. Fetal and neonatal physiology. $3^{\text {rd }}$ ed. Philadelphia: Elsevier Inc.; 2004. p.1341-50.

69. Powes N. How to assess slow growth in the breastfed infant birth to 3 months. Pediatr Clin N Am 2001;48:345-63. 
70. Macdonald PD, Ross SR, Grant L, Young D. Neonatal weight loss in breast and formula fed infants. Arch Dis Fetal Neonatal Ed 2003;88:472-6.

71. Report of the second task force on blood pressure control in children. Pediatrics 1987;79:1-25.

72. Nafday SM, Brion LP, Benchimol C, Satlin LM, Flynn JT, Edelmann Jr CM. Renal disease. In: MacDonald MG, Seshia MMK, Mullett MD, editors. Avery's Neonatology. $6^{\text {th }}$ ed. Philadelphia: Lippincott Williams \& Wilkins; 2005. p.981-1065.

73. Butani L, Morgenstern BZ. Are pitfalls of oscilometric blood pressure measurement preventable in children? Pediatr Nephrol 2003;18:3138.

74. Maayan-Metzger A, Hadad E, Sirota L. Transepidermal water loss and skin hydration in preterm infants during phototherapy. Am J Perinatol 2001;18:393-6.

75. Maisels MJ. Jaundice. In: MacDonald MG, Seshia MMK, Mullett MD, editors. Avery's Neonatology. $6^{\text {th }}$ ed. Philadelphia: Lippincott Williams \& Wilkins; 2005. p.202-23.

76. Chenadec J, Mayauxa M, Blanchec S. Perinatal antiretroviral treatment and hematopoiesis in HIV-uninfected infants. AIDS 2003;17:2053-61.

77. Rose SR, Brown RS, Wilkins L. Update of newborn screening and therapy for congenital hypothyroidism. Pediatrics 2006;117:2290-303. 
78. Rudd PT, Hughes EA, Placzek MM, Hodes DT. Reference ranges for plasma creatinine during the first month of life. Arch Dis Child $1983 ; 58: 212-5$

79. Brion LP, Fleischman AR, McCarton C, Schwartz GJ. A simple estimate of glomerular filtration rate in low birth weight infants during the first year of life: noninvasive assessment of body composition and growth. J Pediatr 1986;109:698-707.

80. Bueva A, Guignard JP. Renal function in preterm neonates. Pediatr Res 1994;36:572-7.

81. Awad H, El-Safty I, El-Barbary N, Imam S. Evaluation of renal glomerular and tubular functional and structural integrity in neonates. Am J Med Sci 2002;324:261-6.

82. Babay Z, Wakeel J, Addar M, Mittwalli A, Tarif N, Hammad D. Serum cystatin $\mathrm{C}$ in pregnant women: reference values, reliable and superior diagnostic accuracy. Clin Exp Obstet Gynecol 2005;32:175-9.

83. Lain KY, Markovic N, Ness PB, Roberts JM. Effect of smoking on uric acid and other metabolic markers throughout normal pregnancy. $J$ Clin Endocrinol Metab 2005;90:5743-6.

84. Sanders CL, Lucas MJ. Renal disease in pregnancy. Obstet Gynecol Clin North Am 2001;28:593-600.

85. Jones EE, DeCherney AH. Fertilization, pregnancy and lactation. In: Boron WF, Boulpaep E, editors. Medical physiology - updated edition. Philadelphia: Elsevier Saunders; 2005. p.1167-89. 
86. Janson T, Powell T, Illsley N. Non-electrolyte solute permeabilities of human placental microvillous and basal membranes. J Physiol 1993;468:261-74.

87. Guignard JP, Torrado A, Da Cunha O, Gautier E. Glomerular filtration rate in the first three weeks of life. J Pediatr 1975;87:268-72.

88. Fawer CL, Torrado A, Guignard JP. Maturation of renal function in fullterm and premature neonates. Helv Pediatr Acta 1979;34:11-21.

89. Coulthard MG, Hey EN, Ruddock V. Creatinine and urea clearances compared to inulin clearance in preterm and mature babies. Early Hum Dev 1985;11:11-9. 